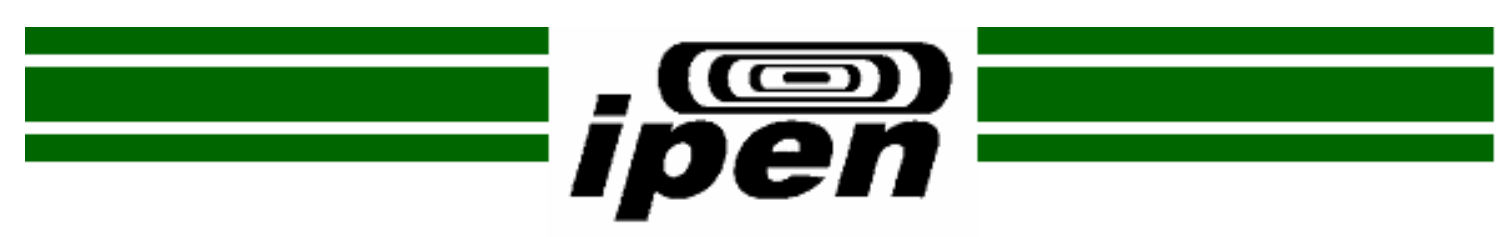

Autarquia associada à Universidade de São Paulo

\title{
ESTUDO COMPARATIVO ENTRE MÉTODOS DE CALIBRAÇÃO DE APLICADORES CLÍNICOS DE RADIAÇÃO BETA
}

\author{
PATRÍCIA DE LARA ANTONIO
}

Dissertação apresentada como parte dos requisitos para obtenção do Grau de Mestre em Ciências na Área de Tecnologia Nuclear - Aplicações.

Orientadora:

Dr ${ }^{\mathrm{a}}$. Linda V. E. Caldas

SÃO PAULO

2009 
INSTITUTO DE PESQUISAS ENERGÉTICAS E NUCLEARES

Autarquia associada à Universidade de São Paulo

\section{ESTUDO COMPARATIVO ENTRE MÉTODOS DE CALIBRAÇÃO DE APLICADORES CLÍNICOS DE RADIAÇÃO BETA}

PATRÍCIA DE LARA ANTONIO

Dissertação apresentada como parte dos requisitos para obtenção do Grau de Mestre em Ciências na Área de Tecnologia Nuclear - Aplicações.

Orientadora:

Dra ${ }^{\text {a }}$ Linda V. E. Caldas

SÃO PAULO 
Aos meus pais e ao meu irmão, meus tesouros, e ao meu tio Osmil (in memorian), que estarão eternamente em meu coração, com carinho. 


\section{AGRADECIMENTOS}

Agradeço à minha orientadora Dra. Linda V. E. Caldas, por um dia apresentar-me o tema do meu Mestrado e pela oportunidade de concretização deste trabalho, pela orientação dedicada e atenciosa, pela paciência, compreensão, confiança, incentivo, pelos valiosos ensinamentos, por tantos momentos agradáveis e pela disposição sempre presente para ouvir e atender às minhas dúvidas. Sou grata, de forma especial, pela preocupação e por todo o carinho, amizade e apoio constantes, não somente nos momentos de orientação referentes ao trabalho, mas também à vida, para a qual se estendem a sabedoria e os ensinamentos transmitidos. Sinto-me grandemente honrada em tê-la como orientadora!

Meus agradecimentos se estendem:

À Dra. Maria da Penha Albuquerque Potiens, por autorizar o uso do Laboratório de Calibração de Instrumentos (LCI) para a realização dos experimentos com radiação beta e pela amizade.

Ao Dr. Vitor Vivolo, pela disposição constante no auxílio da utilização das câmaras de extrapolação, eletrômetros e outros equipamentos do LCI, pelo esclarecimento de dúvidas e pela amizade.

À Dra. Letícia Lucente Campos Rodrigues, pelo esclarecimento de dúvidas relacionadas à utilização e caracterização de dosímetros termoluminescentes, e pelo fornecimento das amostras de sulfato de cálcio; ao MSc. David Tadashi Fukumori, também pelo fornecimento das pastilhas termoluminescentes.

À Dra. Mércia Liane de Oliveira, pela disposição e pelos ensinamentos sobre a utilização da mini-câmara de extrapolação de janela plana, dosímetros termoluminescentes e calibração de aplicadores.

Aos técnicos do LCI, pela ajuda no desenvolvimento deste trabalho, pelas instruções e pela manutenção de equipamentos, em especial ao Sr. Marcos Xavier e Sr. Claudinei Cescon; ao Sr. Valdir Souza Carvalho e Sr. Rafael Elias Diniz, por permitirem a utilização do Laboratório de Calibração Beta e pelo auxílio nas irradiações feitas neste laboratório; à Sra. Linda Therese Mor e ao Sr. Antônio Cornélio de Souza, do Laboratório de Materiais Dosimétricos (LMD), pelas instruções de uso das pastilhas termoluminescentes e do 
sistema leitor TL, e pela pesagem de pastilhas e ensinamentos de confecção de amostras de sulfato de cálcio, respectivamente.

À Sra. Donata Celicea de Oliveira Zanin que, de forma muito carinhosa, amiga e atenciosa, sempre se dispôs a me atender e auxiliar em tudo o que eu precisasse. Muito obrigada pela amizade, carinho, cuidado, preocupação, pelos grandes momentos de conversa, conselhos, descontração e alegria e pela paciência com todos os alunos. Agradeço também pelo grande auxílio na impressão deste trabalho.

Ao Dr. Marco Antônio Rodrigues Fernandes, da Faculdade de Medicina Veterinária, da Universidade Estadual Júlio de Mesquita Filho, e à Sra. Virgínia Maria Totti Pedroso de Lima, do Instituto de Radioterapia do $\mathrm{ABC}$, pelo empréstimo dos aplicadores clínicos de ${ }^{90} \mathrm{Sr}+{ }^{90} \mathrm{Y}$ utilizados para o desenvolvimento deste trabalho.

Aos meus queridos e amados pais, amigos e conselheiros, Omar e Marisa. Muito obrigada por tanto amor sem fim, pelo companheirismo, fidelidade e união, por me apoiarem e incentivarem em tudo o que eu sempre desejei e sonhei fazer na minha vida, com orientação, pelas orações que me abençoam dia após dia, por cada lágrima derramada e cada sorriso e brado de vitória dados comigo, pelos ensinamentos de como ser quem eu sou e por me ajudarem a concluir esta etapa tão importante e sonhada da minha vida. Ao meu querido irmão Thiago, por todo amor e apoio, por saber demonstrar preocupação nas horas que eu mais preciso, de forma tão carinhosa e pelas fundamentais ajudas com relação ao computador.

A todos os meus tios e primos, que também são um pedacinho deste trabalho, pelas mais variadas demonstrações de amor, pela união, carinho, preocupação e cuidado, e por todo o apoio nas mais diversas maneiras. Eu os amo imensamente!

A todos os irmãos da Igreja Apostólica Plenitude da Graça, minha outra família, por todo apoio e incentivo, por orarem por mim, pela força e preocupação, mas principalmente, por todo amor e carinho.

Ao Prof. MSc. Ricardo Coura Oliveira, pelo incentivo constante, pelas doces palavras de amizade e carinho e por um dia ir comigo ao IPEN e me apresentar à Dra. Linda Caldas.

Às minhas grandes e queridas amigas: Christianne Cobello Cavinato, Maíra Tiemi Yoshizumi e Priscilla Roberta T. L. Camargo, pelo companheirismo, amizade, apoio, incentivo, paciência, carinho e preocupação, por todos os momentos de alegria e diversão, 
pelas agradáveis e alegres conversas, pelos conselhos, pelos ensinamentos e valiosas sugestões no trabalho. Agradeço também à Maíra pelos importantes ensinamentos sobre incertezas. Aos meus queridos companheiros de sala e mais novos amigos, Fernanda Beatrice Conceição Nonato e Jonas Oliveira da Silva, também meu companheiro de oração, por todo carinho, apoio, incentivo, companheirismo, paciência e por tantos momentos de alegria e descontração. Às amigas Marcela Costa Alcântara, Margareth Lika Onishi Tongu e Lúcia Helena da Silva Santos, por serem amigas tão especiais e divertidas, carinhosas e atenciosas. Aos meus queridos amigos Eric Alexandre Brito da Silva, Cléber Feijó e Gustavo Villa Barreto, pela amizade, companheirismo, por todo auxílio nos laboratórios e suporte computacional e pelos grandes momentos de alegria que vocês proporcionam. A todos vocês, muito obrigada pela amizade sincera.

À MSc. Cláudia Gronchi e à MSc. Tereza Nathan Outeiro, pela amizade, incentivo, apoio e por todo ensinamento sobre avaliação de pastilhas termoluminescentes.

À minha amiga tão especial Isis Sabrina Scarso, pela amizade fiel e inestimável desde os nossos dez anos de idade, por todo carinho, preocupação, compreensão e paciência, e principalmente, por se fazer sempre presente na minha vida.

A todos os funcionários da Gerência de Ensino (GE) do IPEN, na pessoa do Presidente da Comissão de Pós-Graduação (CPG), Dr. José Carlos Bressiani, por todos os serviços prestados.

Aos funcionários da Biblioteca do IPEN, “Terezine Arantes Ferraz”, pela gentileza e auxílio.

Ao Instituto de Pesquisas Energéticas e Nucleares, Comissão Nacional de Energia Nuclear (IPEN-CNEN/SP), na pessoa do Superintendente Dr. Nilson Dias Vieira Júnior, pela rica oportunidade de realizar e concluir este trabalho de Mestrado em Tecnologia Nuclear.

À Comissão Nacional de Energia Nuclear (CNEN), pelo suporte financeiro.

E a todos aqueles que, de uma forma ou de outra, contribuíram para que este trabalho fosse desenvolvido e concluído. Muito obrigada!

Agradeço, de forma especial, a Deus, meu Senhor e Rei, a quem eu não poderia deixar de agradecer. Se não fosse pela vontade d'Ele, eu não teria chegado até aqui. Muito obrigada pelo dom da vida, por todas as coisas que o Senhor já me deu, por colocar em 
meu caminho pessoas tão especiais e queridas, com as quais tenho aprendido muito, a começar pela minha orientadora. Muito obrigada por me dar direção para cada decisão, por iluminar meu caminho em cada estrada que eu percorro e por me dar sabedoria e força para que eu chegasse até aqui. E principalmente pela conclusão deste trabalho, no qual eu tive tanto prazer. Tu és a razão da minha vida e por isso eu Te louvarei para sempre, eternamente. Muito obrigada pelo seu amor incondicional, irresistível, incomparável! 
"Tu és digno, Senhor e Deus nosso, de receber a glória, a honra e o poder, porque todas as coisas Tu criaste, sim, por causa da Tua vontade vieram a existir e foram criadas."

(Ap. 4:11) 


\title{
ESTUDO COMPARATIVO ENTRE MÉTODOS DE CALIBRAÇÃO DE APLICADORES CLÍNICOS DE RADIAÇÃO BETA
}

\author{
Patrícia de Lara Antonio
}

\begin{abstract}
RESUMO
Os aplicadores clínicos de ${ }^{90} \mathrm{Sr}+{ }^{90} \mathrm{Y}$ são instrumentos utilizados em procedimentos de braquiterapia e devem ser calibrados periodicamente, de acordo com normas e recomendações internacionais. Neste trabalho, foram estudados quatro métodos de calibração de aplicadores dermatológicos e oftálmicos, comparando-se os resultados com os fornecidos pelos certificados de calibração dos fabricantes dos aplicadores. Os métodos envolveram o aplicador clínico padrão do Laboratório de Calibração de Instrumentos (LCI), calibrado pelo laboratório padrão primário americano do National Institute of Standards and Technology, como referência; um aplicador da Amersham, também pertencente ao LCI, como referência; uma mini-câmara de extrapolação desenvolvida no IPEN como padrão absoluto; e dosimetria termoluminescente. A mini-câmara de extrapolação e uma câmara de extrapolação comercial PTW foram estudadas com relação ao seu desempenho por meio de testes de controle de qualidade, como corrente de fuga, repetitividade e reprodutibilidade. A distribuição de dose em profundidade na água, estudo de grande importância na dosimetria de aplicadores clínicos, foi determinada utilizando-se a mini-câmara de extrapolação e dosímetros termoluminescentes. Os resultados obtidos foram considerados satisfatórios para os dois casos, quando comparados com os dados fornecidos pela norma IAEA (2002). Além disso, foi desenvolvido um sistema postal dosimétrico para a calibração de aplicadores clínicos por meio da técnica da termoluminescência, para ser enviado para clínicas e hospitais, sem a necessidade do transporte das fontes ao LCI do IPEN para calibração.
\end{abstract}




\title{
COMPARATIVE STUDY AMONG CALIBRATION METHODS OF CLINICAL APPLICATORS OF BETA RADIATION
}

\author{
Patrícia de Lara Antonio
}

\begin{abstract}
${ }^{90} \mathrm{Sr}+{ }^{90} \mathrm{Y}$ clinical applicators are instruments used in brachytherapy procedures and they have to be periodically calibrated, according to international standards and recommendations. In this work, four calibration methods of dermatological and ophthalmic applicators were studied, comparing the results with those given by the calibration certificates of the manufacturers. The methods included the use of the standard applicator of the Calibration Laboratory (LCI), calibrated by the National Institute of Standards and Technology; an Amersham applicator (LCI) as reference; a mini-extrapolation chamber developed at LCI as an absolute standard; and thermoluminescent dosimetry. The mini-extrapolation chamber and a PTW commercial extrapolation chamber were studied in relation to their performance through quality control tests of their response, as leakage current, repetibility and reproducibility. The distribution of the depth dose in water, that presents high importance in dosimetry of clinical applicators, was determined using the miniextrapolation chamber and the thermoluminescent dosimeters. The results obtained were considered satisfactory for the both cases, and comparable to the data of the IAEA (2002) standard. Furthermore, a dosimetry postal kit was developed for the calibration of clinical applicators using the thermoluminescent technique, to be sent to clinics and hospitals, without the need of the transport of the sources to IPEN for calibration.
\end{abstract}




\section{SUMÁRIO}

1 Introdução

2 Fundamentos Teóricos.

2.1 Conceitos sobre Física das Radiações.................................................................... 23

2.1.1 Processos de Interação da Radiação com a Matéria............................................. 25

2.1.1.1 Interações de Elétrons com a Matéria..................................................................... 25

2.1.1.2 Interações de Fótons com a Matéria..................................................................... 25

2.1.2 Grandezas e Unidades de Radiação......................................................................... 26

2.2 Fundamentos sobre Calibração e Dosimetria de Instrumentos

Metrológicos e Fontes de Radiação Beta.................................................................. 31

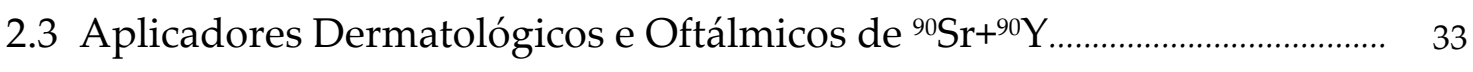

2.4 Câmaras de Ionização.............................................................................................. 35

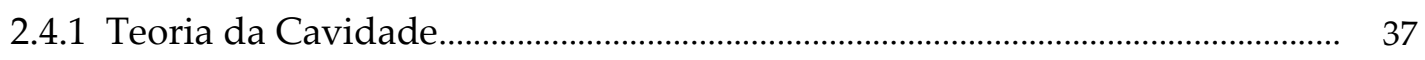

2.4.2 Câmaras de Extrapolação........................................................................................ 39

2.4.3 Determinação da Taxa de Dose Absorvida na Água....................................... 42

2.5 Materiais Dosimétricos Termoluminescentes.................................................... 44

2.5.1 Teoria de Bandas.............................................................................................. 45

2.5.2 Curva de Emissão TL....................................................................................... 47

2.5.3 Dosimetria Termoluminescente.......................................................................... 49

2.5.3.1 Caracterização Dosimétrica................................................................................. $\quad 50$

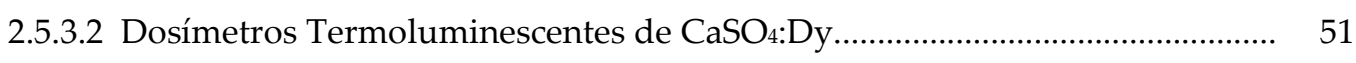

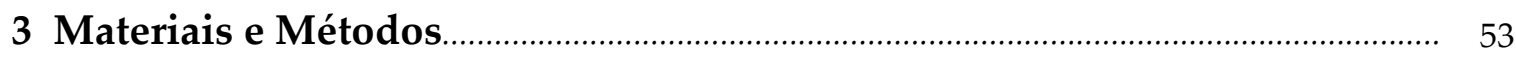

3.1 Sistemas de Medição................................................................................................ 53

3.1.1 Câmaras de Extrapolação.......................................................................................... 53

3.1.2 Dosimetria Termoluminescente............................................................................ 55

3.2 Fontes de Radiação Beta.................................................................................... 56

3.3 Sistemas Auxiliares e Acessórios Diversos............................................................ 59 
4.1 Utilização de Câmaras de Extrapolação na Calibração e Dosimetria de Aplicadores Clínicos de ${ }^{90} \mathrm{Sr}+{ }^{90} \mathrm{Y}$. 60

4.1.1 Câmara de Extrapolação PTW. 60

4.1.1.1 Corrente de Fuga Pré-Irradiação. 60

4.1.1.2 Testes de Repetitividade e Reprodutibilidade.. 61

4.1.1.3 Curvas de Extrapolação com Fontes de ${ }^{90} \mathrm{Sr}+{ }^{90} \mathrm{Y}$. 62

4.1.1.4 Profundidade Nula Real 66

4.1.1.5 Calibração da Câmara de Extrapolação PTW utilizando os Sistemas BSS1 e BSS2. 67

4.1.2 Mini-Câmara de Extrapolação de Janela Plana. 69

4.1.2.1 Corrente de Fuga Pré-Irradiação. 69

4.1.2.2 Testes de Repetitividade e Reprodutibilidade. 70

4.1.2.3 Curvas de Extrapolação com Aplicadores Dermatológicos e Oftálmicos. 71

4.1.3 Calibração e Dosimetria dos Aplicadores Clínicos utilizando diferentes Métodos. 76

4.1.3.1 Calibração dos Aplicadores utilizando o Aplicador NIST como Referência (Método 1) 76

4.1.3.2 Calibração dos Aplicadores utilizando o Aplicador A como Referência (Método 2)

4.1.3.3 Calibração dos Aplicadores utilizando a Mini-Câmara de Extrapolação como Sistema de Referência Absoluta (Método 3)

4.1.3.4 Curvas de Dose $x$ Profundidade para os Aplicadores..

4.2 Utilização da Dosimetria Termoluminescente para a Calibração dos Aplicadores de ${ }^{90} \mathrm{Sr}+{ }^{90} \mathrm{Y}$

4.2.1 Caracterização Dosimétrica das Pastilhas Finas de CaSO4:Dy.. 88

4.2.1.1 Reprodutibilidade das Pastilhas de CaSO4:Dy. 88

4.2.1.2 Linearidade da Resposta TL x Tempo de Irradiação (para Aplicadores A e B) 90

4.2.1.3 Limite Inferior de Detecção.. 90

4.2.2 Calibração dos Aplicadores com Dosímetros Termoluminescentes (Método 4)

4.2.3 Curvas de Dose x Profundidade para os Aplicadores Clínicos de ${ }^{90} \mathrm{Sr}+{ }^{90} \mathrm{Y} . . \quad 93$ 
4.3 Comparação entre os Resultados das Curvas de Dose x Profundidade, obtidos com a Mini-Câmara de Extrapolação e os Dosímetros

Termoluminescentes.

4.4 Comparação entre os 4 Métodos de Calibração de Aplicadores Clínicos. 100

4.5 Elaboração de um Sistema Postal Dosimétrico

5 Conclusões.

Referências Bibliográficas. 108

Apêndice A - Procedimento para a Irradiação de Dosímetros

Termoluminescentes com Aplicadores Clínicos de ${ }^{90} \mathrm{Sr}+{ }^{90}$. 114

A.1 - Objetivo. 114

A.2 - Campo de Aplicação 114

A.3 - Procedimento. 114

A.3.1 - Condições e Recursos Necessários. 114

A.3.2 - Cuidados Especiais.. 115

A.3.3 - Descrição das Atividades. 115

Apêndice B - Modelo de Certificado de Calibração a ser emitido pelo IPEN. 


\section{LISTA DE TABELAS}

TABELA 3.1 - Características das fontes de ${ }^{90} \mathrm{Sr}+{ }^{90} \mathrm{Y}$ à distância fonte-detector de $30 \mathrm{~cm}$.

TABELA 3.2 - Características dos aplicadores clínicos de ${ }^{90} \mathrm{Sr}+{ }^{90} \mathrm{Y}$.

TABELA 4.1 - Fatores de calibração da câmara de extrapolação PTW, para as fontes de ${ }^{90} \mathrm{Sr}+{ }^{90} \mathrm{Y}$, obtidos à distância de $30 \mathrm{~cm}$.................................. 68

TABELA 4.2 - Taxas de dose absorvida às distâncias de 0 e 1,0 $\mathrm{mm}$ dos aplicadores, utilizando o Método 1.

TABELA 4.3 - Taxas de dose absorvida às distâncias de 0 e 1,0 mm dos

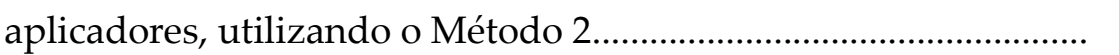

TABELA 4.4 - Valores das constantes utilizadas na determinação da taxa de dose absorvida, utilizando-se a mini-câmara de extrapolação como sistema de referência absoluto.

TABELA 4.5 - Taxas de dose absorvida às distâncias de 0 e 1,0 mm dos aplicadores, Utilizando o Método 3.

TABELA 4.6 - Estudo de dose x profundidade para os aplicadores clínicos e em relação aos valores da norma IAEA (2002), variando-se as profundidades em água e normalizando-se os valores para $1,0 \mathrm{~mm}$ de profundidade.

TABELA 4.7 - Taxas de dose absorvida (às distâncias nulas), dos aplicadores, utilizando o Método 4.

TABELA 4.8 - Dose $\mathrm{x}$ profundidade para os aplicadores clínicos de ${ }^{90} \mathrm{Sr}+{ }^{90} \mathrm{Y}$, com dosímetros termoluminescentes e em relação aos valores da norma IAEA (2002), variando-se as profundidades em água e normalizando-se os valores para $1,0 \mathrm{~mm}$ de profundidade............

TABELA 4.9 - Diferença percentual na comparação entre os valores de dose $x$ profundidade obtidos com a mini-câmara de extrapolação e dosímetros termoluminescentes.

TABELA 4.10 - Calibração dos aplicadores NIST, A, B, C, D, E e F por meio de 4 métodos diferentes. 


\section{LISTA DE FIGURAS}

FIGURA 2.1 - Esquemas de aplicadores clínicos de ${ }^{90} \mathrm{Sr}+{ }^{90} \mathrm{Y}$ : (a) plano e (b) curvo...

FIGURA 2.2 - Representação esquemática de uma câmara de extrapolação..... 41

FIGURA 2.3 - Estágios do fenômeno da termoluminescência.............................. 45

FIGURA 2.4 - Esquema dos níveis de energia e transições eletrônicas: (a) processo de ionização, (b) e (f) armadilhamento de elétron e lacuna, respectivamente, (c) e (g) liberação de elétron e lacuna, respectivamente, (d) e (h) recombinação indireta, e (e) recombinação direta.

FIGURA 2.5 - Curva de emissão TL típica de uma amostra de CaSO4:Dy, irradiada com 10 mGy $\left({ }^{60} \mathrm{Co}\right)$

FIGURA 3.1 - Câmaras de extrapolação utilizadas no trabalho: (a) câmara de extrapolação, modelo 23391, PTW e (b) mini-câmara de extrapolação de janela plana, desenvolvida no LCI

FIGURA 3.2 - Pastilhas de CaSO4:Dy com e sem 10\% de grafite, num suporte de alumínio para o tratamento térmico das amostras...

FIGURA 3.3 - Aplicadores dermatológicos de ${ }^{90} \mathrm{Sr}+{ }^{90} \mathrm{Y}:$ (a) A, (b) B e (c) NIST.

FIGURA 3.4 - Placas de acrílico confeccionadas para as medições de dose em profundidade na água: (a) de diferentes espessuras e (b) para o posicionamento das pastilhas.

FIGURA 4.1 - Estabilidade a médio prazo da resposta da câmara de extrapolação PTW, com eletrodo coletor de grafite, para a fonte de ${ }^{90} \mathrm{Sr}+{ }^{90} \mathrm{Y}$ de $74 \mathrm{MBq}$.

FIGURA 4.2 - Arranjo experimental utilizado durante as medições para as curvas de extrapolação, com o sistema beta BSS1.

FIGURA 4.3 - Curvas de extrapolação obtidas com a câmara de extrapolação PTW com eletrodo coletor de alumínio para as fontes de ${ }^{90} \mathrm{Sr}+{ }^{90} \mathrm{Y}$ de (a) $74 \mathrm{MBq}$ com filtro, (b) $1850 \mathrm{MBq}$ sem filtro,

(c) $460 \mathrm{MBq}$ sem filtro e (d) $460 \mathrm{MBq}$ com filtro.

FIGURA 4.4 - Curvas de extrapolação obtidas com a câmara de extrapolação com eletrodo coletor de grafite para as fontes de ${ }^{90} \mathrm{Sr}+{ }^{90} \mathrm{Y}$ de (a) $74 \mathrm{MBq}$ com filtro, (b) $1850 \mathrm{MBq}$ sem filtro, (c) $460 \mathrm{MBq}$ sem filtro, e (d) $460 \mathrm{MBq}$ com filtro..

FIGURA 4.5 - Determinação da profundidade nula real da câmara de extrapolação PTW (eletrodo coletor de grafite) 
FIGURA 4.6 - Arranjo utilizado durante o teste de estabilidade a curto prazo com a mini-câmara de extrapolação de janela plana, o suporte de acrílico e a fonte de controle.

FIGURA 4.7 - Teste de reprodutibilidade da resposta da mini-câmara de extrapolação desenvolvida no LCI, para uma fonte de controle de ${ }^{90} \mathrm{Sr}+{ }^{90} \mathrm{Y}$

FIGURA 4.8 - Arranjo utilizado durante as medições de curvas de extrapolação, onde se pode observar o aplicador posicionado à frente da mini-câmara de extrapolação de janela plana.

FIGURA 4.9 - Curvas de extrapolação obtidas com a mini-câmara para as fontes de ${ }^{90} \mathrm{Sr}+{ }^{90} \mathrm{Y}:$ (a) aplicador NIST, (b) aplicador A e (c) aplicador B

FIGURA 4.10 - Curvas de extrapolação obtidas com a mini-câmara para o aplicador $\mathrm{C}$ de ${ }^{90} \mathrm{Sr}+{ }^{90} \mathrm{Y}$ : (a) aplicador $\mathrm{C}$ a $0 \mathrm{~mm}$ e com capa protetora, (b) aplicador $\mathrm{C}$ a $0 \mathrm{~mm}$ e com capa com orifício, (c) aplicador $\mathrm{C}$ a $0 \mathrm{~mm}$ e sem capa protetora e (d) aplicador $\mathrm{C}$ a $1,0 \mathrm{~mm}$ e sem capa protetora.

FIGURA 4.11 - Curvas de extrapolação obtidas com a mini-câmara para as fontes de ${ }^{90} \mathrm{Sr}+{ }^{90} \mathrm{Y}:$ (a) aplicador $\mathrm{D}$, (b) aplicador $\mathrm{E} e$ (c) aplicador F.

FIGURA 4.12 - Arranjo experimental utilizado no Método 2.

FIGURA 4.13 - Arranjo experimental para o estudo de distribuição de dose em profundidade na água, com a mini-câmara de extrapolação, a placa de acrílico e o aplicador clínico.

FIGURA 4.14 - Curvas de distribuição de dose em profundidade na água realizadas com a mini-câmara de extrapolação e os aplicadores: (a) aplicador NIST, (b) aplicador A, (c) aplicador B e (d) aplicador C, variando-se a espessura das placas de acrílico entre a mini-câmara e cada aplicador.

FIGURA 4.15 - Curvas de distribuição de dose em profundidade na água realizadas com a mini-câmara de extrapolação e os aplicadores: (a) aplicador D, (b) aplicador E e (c) aplicador F, variando-se a espessura das placas de acrílico entre a minicâmara e cada aplicador.

FIGURA 4.16 - Curvas de distribuição de dose em profundidade para os aplicadores de ${ }^{90} \mathrm{Sr}+{ }^{90} \mathrm{Y}$, normalizados para $1,0 \mathrm{~mm}$ e em meio equivalente à água.

FIGURA 4.17 - Histogramas elaborados para a primeira seleção de pastilhas de (a) CaSO4:Dy e (b) CaSO4:Dy + 10\% C 
FIGURA 4.18 - Resposta TL das pastilhas finas de CaSO4:Dy, em função do tempo de irradiação, para os aplicadores A e B de ${ }^{90} \mathrm{Sr}+{ }^{90} \mathrm{Y} \ldots . . . . . . . \quad 90$

FIGURA 4.19 - Curva de dose-resposta obtida das pastilhas finas de CaSO4:Dy, para o aplicador NIST $\left({ }^{90} \mathrm{Sr}+{ }^{90} \mathrm{Y}\right)$....................................

FIGURA 4.20 - Arranjo experimental utilizado durante a irradiação das pastilhas para a determinação da distribuição da dose $x$ profundidade na água........................................................................

FIGURA 4.21 - Curvas de dose x profundidade obtidas com (a) dosímetros termoluminescentes, e (b) comparando-se estes resultados com os obtidos com a mini-câmara de extrapolação, para o aplicador A, variando-se a espessura de acrílico entre fonte e dosímetro

FIGURA 4.22 - Curvas de dose $x$ profundidade obtidas utilizando-se dosímetros termoluminescentes de $\mathrm{CaSO} 4: \mathrm{Dy}$, para: (a) aplicador NIST, (b) aplicador B e (c) aplicador C

FIGURA 4.23 - Curvas de dose x profundidade obtidas com amostras de CaSO4:Dy, para: (a) aplicador D, (b) aplicador E e (c) aplicador F.

FIGURA 4.24 - Curvas de dose $\mathrm{x}$ profundidade obtidas para os aplicadores clínicos de ${ }^{90} \mathrm{Sr}+{ }^{90} \mathrm{Y}$ NIST, A, B, C, D, E, e F, com dosímetros termoluminescentes finos de $\mathrm{CaSO} 4: \mathrm{Dy}$.

FIGURA 4.25 - Porta-dosímetros de acrílico confeccionados para a irradiação das 5 pastilhas a serem enviados para as clínicas 


\section{INTRODUÇÃO}

A pesquisa envolvendo a radiação teve início em 1895, quando o físico, professor e pesquisador $W$. Röentgen descobriu um tipo de radiação de natureza desconhecida e a denominou de radiação X. Quando Henri Becquerel descobriu em 1896 a radioatividade, e em 1898 Pierre e Marie Curie descobriram o rádio, a área de pesquisa se intensificou, uma vez que a radiação $X$ e o rádio se tornaram importantes instrumentos da Medicina.

Após alguns anos utilizando-se a radiação e os elementos radioativos até então descobertos, constatou-se que a exposição à radiação por tempo indeterminado e de forma desnecessária poderia provocar danos biológicos. Sendo assim, tiveram início os conceitos de Proteção Radiológica e algumas organizações foram fundadas. O conhecimento das doses recebidas pelos usuários de fontes de radiação passou a ser de importância fundamental.

A dosimetria, com o passar dos anos, comprovou que não eram apenas as radiações indiretamente ionizantes, como a radiação gama e $X$, que causavam alterações e efeitos biológicos, mas também as radiações diretamente ionizantes, como a radiação $\beta$, pois diversos estudos demonstraram que este tipo de radiação apresenta risco, principalmente para a epiderme e o cristalino. Por isso, o estudo da radiação beta passou a ganhar maior importância, e diversos pesquisadores passaram a desenvolver trabalhos nesta área, envolvendo a dosimetria e a calibração de fontes de radiação beta.

Para se determinar a dose absorvida, é necessário ter um instrumento que possa medir a radiação e ao mesmo tempo fornecer a taxa de dose absorvida. Em 1937, Failla apresentou a câmara de extrapolação, uma câmara de ionização de placas paralelas e volume variável, que passou a ser o instrumento principal para a determinação da taxa de dose absorvida devida à radiação beta e à radiação $X$ de baixas energias. 
O início da utilização de fontes de radiação beta na Medicina ocorreu no começo do século passado. As fontes de ${ }^{90} \mathrm{Sr}+{ }^{90} \mathrm{Y}$ vêm sendo utilizadas desde 1950 em procedimentos de braquiterapia, no tratamento de lesões superficiais nos olhos e na pele. Estas fontes, denominadas aplicadores clínicos, foram desenvolvidas em 1950 por Friedell e colaboradores (FRIEDELL e col., 1950). Conforme Soares (1995) descreve em seu trabalho, estima-se que na década de 90 aproximadamente 10 fabricantes diferentes produziram centenas de aplicadores; assim, estas fontes passaram a ser utilizadas em todo o mundo.

Os aplicadores oftálmicos podem ser utilizados no tratamento pós-operatório de pterígio, resultando numa diminuição significativa de recidiva. O pterígio é um tipo de tecido fibrovascular da conjuntiva; cresce do lado interno do olho em direção à córnea, chegando a cobri-la se não for tratado, causando cegueira. Os aplicadores dermatológicos são utilizados no tratamento de quelóide, uma cicatriz endurecida e irregular, que se eleva acima do nível normal da pele, podendo ser resultado de um corte, incisão cirúrgica ou queimadura, quando há predisposição genética, causando dor e/ou prurido. Embora os aplicadores clínicos não sejam mais fabricados e comercializados há vários anos, os anteriormente adquiridos ainda são muito utilizados em clínicas brasileiras de radioterapia, devido à longa meia-vida do ${ }^{90} \mathrm{Sr}+{ }^{90} \mathrm{Y}(28,8$ anos).

Estas fontes diferem quanto à sua geometria, sendo os aplicadores oftálmicos geralmente côncavos e os dermatológicos, planos. Além disso, estas fontes possuem certificados de calibração dos fabricantes, mas poucas foram calibradas por laboratórios padrões. Apenas quatro laboratórios oferecem este tipo de serviço: três dos Estados Unidos e um da Alemanha. No Brasil não há normas que estabeleçam a necessidade da dosimetria periódica destas fontes, uma vez que os órgãos reguladores exigem apenas o certificado de calibração do fabricante, que pode ser antigo.

Alguns estudos, referentes à calibração de aplicadores oftálmicos, revelaram uma diferença existente entre a calibração feita pelo fabricante e a de um laboratório padrão (SOARES, 1995; HOLMES e col., 2009). Este fato torna clara a importância da necessidade da calibração e dosimetria periódicas dos aplicadores ainda existentes e em uso em hospitais, clínicas e laboratórios, de acordo com 
recomendações internacionais (De ALMEIDA e col., 2000; IAEA, 2002; ISO, 2004). Uma vez que o envio das fontes das clínicas de radioterapia e hospitais para um laboratório de calibração é difícil por acarretar uma interrupção dos tratamentos em progresso de pacientes, a necessidade de se fazer a calibração dos aplicadores no próprio ambiente onde são utilizados torna-se ainda mais real.

A dosimetria de ambos os tipos de aplicadores é um procedimento difícil devido ao curto alcance das partículas beta, às curtas distâncias utilizadas no tratamento, aos altos gradientes de dose e à rápida variação da taxa de dose absorvida com a distância. No caso dos aplicadores oftálmicos, este procedimento torna-se ainda mais complexo devido à sua curvatura. A grandeza dosimétrica recomendada para a especificação destas fontes, é a taxa de dose absorvida na água, determinada em seu ponto de referência, a 1,0 mm da superfície da fonte em relação ao seu centro (IAEA, 2002).

Dois métodos podem ser utilizados para a calibração e dosimetria de aplicadores de ${ }^{90} \mathrm{Sr}+{ }^{90} \mathrm{Y}$ : uso de câmaras de extrapolação e uso da técnica da termoluminescência (TL). A câmara de extrapolação é uma câmara de ionização especial, com a possibilidade de variação do seu volume sensível, quando a distância entre seus eletrodos pode ser variada por meio de um parafuso micrométrico existente no próprio instrumento. As câmaras de extrapolação são instrumentos metrológicos muito empregados na detecção de radiação beta e raios-X de baixa energia (BÖHM e SCHNEIDER, 1986), pois possibilitam a determinação da taxa de dose superficial de uma fonte por meio da extrapolação da corrente de ionização medida para uma distância inter-eletródica nula (IAEA, 2002). As câmaras de extrapolação são empregadas na calibração de aplicadores planos.

Para a calibração de aplicadores curvos, pode-se utilizar, além das câmaras de extrapolação, os dosímetros termoluminescentes. Os dosímetros TL são recomendados, neste caso, devido à geometria da fonte, pois o contato com a fonte pode ser feito de maneira melhor e mais fácil, por serem materiais menores e finos. Outros métodos ainda podem ser utilizados, e consistem no uso de filmes radiocrômicos, diodos, detectores de diamante, entre outros (De ALMEIDA e col., 2000; IAEA, 2002). 
No Laboratório de Calibração de Instrumentos (LCI) do IPEN foi desenvolvida uma câmara de extrapolação para radiação beta e $X$ de baixas energias (DIAS, 1996; DIAS e CALDAS, 1998). Também foram desenvolvidas duas mini-câmaras de extrapolação, ambas com geometria adequada para a calibração e dosimetria de aplicadores dermatológicos e oftálmicos (OLIVEIRA, 2005; OLIVEIRA e CALDAS, 2005a; OLIVEIRA e CALDAS, 2007a); elas podem ser utilizadas como sistemas de referência, pois permitem a determinação de taxas de dose absorvida superficiais de forma absoluta, sem a necessidade de calibrações prévias contra um instrumento ou uma fonte padrão.

Alguns autores (REFT e col., 1990) demonstraram a utilidade dos dosímetros TL na calibração de aplicadores planos e curvos. Estes dosímetros apresentam as vantagens de: pequenas dimensões, fácil manuseio e baixo custo. Estudos anteriores, desenvolvidos no LCI, demonstraram o desempenho de vários tipos de materiais termoluminescentes em campos de radiação beta (OLIVEIRA e CALDAS, 2004). Além disso, também foi demonstrado que, devido ao baixo poder de penetração das partículas beta na matéria, os dosímetros mais apropriados para esta finalidade são os finos (OLIVEIRA e CALDAS, 2004). Para a calibração de aplicadores oftálmicos foi demonstrada a utilidade de pastilhas finas de CaSO4:Dy (OLIVEIRA e CALDAS, 2007b), que apresentaram a melhor resposta à radiação beta entre vários materiais estudados.

O objetivo principal deste trabalho consiste na comparação entre quatro técnicas de calibração e dosimetria de aplicadores clínicos de ${ }^{90} \mathrm{Sr}+{ }^{90} \mathrm{Y}$, utilizando dois aplicadores como referência, uma mini-câmara de extrapolação de janela plana como sistema absoluto e a dosimetria termoluminescente.

Os objetivos específicos deste trabalho são:

- Estudar a resposta de uma câmara de extrapolação comercial PTW, modelo 23391, em campos de radiação beta de ${ }^{90} \mathrm{Sr}+{ }^{90} \mathrm{Y}$ dos sistemas padrões secundários beta BSS1 e BSS2, utilizando eletrodos coletores de alumínio e grafite; 
- Realizar testes de controle de qualidade de uma mini-câmara de extrapolação de janela plana, com radiação beta, a ser utilizada como sistema de referência na calibração de aplicadores clínicos;

- Realizar a caracterização dosimétrica de pastilhas termoluminescentes de CaSO4:Dy;

- Calibrar diversos aplicadores clínicos dermatológicos e oftálmicos;

- Determinar a distribuição de dose em profundidade na água para os aplicadores clínicos utilizando uma mini-câmara de extrapolação e a dosimetria termoluminescente;

- Desenvolver um sistema postal dosimétrico utilizando a técnica da TL, para envio aos usuários de aplicadores dermatológicos. Elaborar o seu procedimento de utilização. 


\section{FUNDAMENTOS TEÓRICOS}

Neste capítulo serão abordados os principais conceitos necessários para a compreensão da teoria e prática adotadas neste trabalho, referentes aos processos de dosimetria e calibração de câmaras de extrapolação e fontes de radiação beta de ${ }^{90} \mathrm{Sr}+{ }^{90} \mathrm{Y}$ por meio de duas técnicas: ionometria e termoluminescência.

\subsection{Conceitos sobre Física das Radiações}

A definição mais comumente empregada para se descrever a radiação é a propagação de energia por meio de formas diferentes. Esta propagação ocorre através do tempo e do espaço. Os principais tipos de radiações são: alfa, beta, gama, $X$ e de nêutrons.

As radiações alfa e beta são corpusculares e originadas no núcleo atômico, mas diferem quanto ao seu alcance. As partículas alfa possuem pouco poder de penetração, sendo barradas por uma simples folha de papel e não possuindo capacidade de penetração na pele. As partículas beta podem se apresentar sob a forma de feixe de pósitrons, $\beta^{+}$, ou feixe de elétrons, $\beta$, apresentam alcance maior que as partículas alfa, podendo ser barradas por 1,0 $\mathrm{mm}$ de acrílico, uma folha de plástico ou de alumínio e penetrar alguns milímetros na pele.

As radiações gama e $X$ constituem-se de ondas eletromagnéticas, sendo que as primeiras são formadas no núcleo do átomo e as segundas, na eletrosfera. Ambas as radiações gama e $X$ não apresentam massa e, por este motivo, possuem um alto poder de penetração.

A radiação é classificada em duas categorias: ionizante e não ionizante, dependendo de sua capacidade de ionizar a matéria. A radiação não ionizante não tem o poder de ionizar o meio com a qual ela interage, enquanto que a radiação 
ionizante pode ser caracterizada por sua habilidade de excitar e ionizar os átomos da matéria com a qual ela interage (ATTIX, 1986; PODGORSAK, 2005).

A radiação diretamente ionizante consiste de partículas que possuem carga: elétrons, prótons, radiação alfa e íons pesados. Este tipo de radiação deposita energia na matéria por meio de interações coulombianas diretas entre as partículas carregadas e elétrons orbitais dos átomos no meio. A radiação indiretamente ionizante é formada por fótons (raios X e gama) e os nêutrons, que transferem sua energia para partículas carregadas da matéria com as quais se recombinam em interações de curto alcance (ATTIX, 1986). Esta perda de energia na matéria pode ocorrer por meio de dois processos (PODGORSAK, 2005):

1) A partícula carregada é liberada no meio, onde fótons liberam elétrons ou pósitrons e nêutrons liberam prótons ou íons pesados;

2) As partículas carregadas e liberadas depositam energia no meio por intermédio de interações coulombianas diretas com elétrons orbitais dos átomos do meio.

As radiações direta e indiretamente ionizantes são utilizadas no tratamento de doenças, mas não necessariamente em doenças malignas. O ramo da Medicina que aplica a radiação no tratamento de doenças é denominado radioterapia, radiologia terapêutica ou oncologia da radiação. A braquiterapia é uma modalidade da radioterapia na qual a fonte de radiação é colocada diretamente ou próxima à região a ser tratada.

Neste tipo de tratamento, a dose é depositada continuamente, ou durante um curto período de tempo (implante temporário) ou durante a vida do radioisótopo, para um completo decaimento radioativo (implante permanente) (PODGORSAK, 2005). Fontes de radiação beta, como o ${ }^{90} \mathrm{Sr}+{ }^{90} \mathrm{Y}$, são muito utilizadas em braquiterapia, mas há tratamentos também realizados com fótons e nêutrons.

Os principais tipos de braquiterapia são:

1) Intracavitário - as fontes são colocadas em cavidades corporais perto do tumor;

2) Intersticial - as fontes são implantadas dentro do tumor. 


\subsubsection{Processos de Interação da Radiação com a Matéria}

\subsubsection{Interações de Elétrons com a Matéria}

Quando elétrons atravessam a matéria, ocorre interação destas partículas carregadas com o meio por processos coulombianos com elétrons orbitais e o núcleo do átomo. Por este motivo, os elétrons podem perder sua energia cinética ou podem mudar de direção, uma vez que são relativamente leves e, por isso, apresentam trajetória irregular nos materiais absorvedores (KNOLL, 2000; TAUHATA e col., 2003;). As colisões que ocorrem entre um elétron incidente no meio e um elétron orbital ou um núcleo atômico podem ser elásticas ou inelásticas.

Na colisão elástica, o elétron é deslocado de seu caminho original, mas sem perder energia. Numa colisão inelástica, o elétron muda de direção e perde parte de sua energia cinética, que é transferida para um elétron orbital ou é emitida sob a forma de radiação de freamento, ou Bremsstrahlung (TAUHATA e col., 2003; PODGORSAK, 2005).

\subsubsection{Interações de Fótons com a Matéria}

Dependendo de sua origem, os fótons podem ser de quatro tipos:

1) Bremsstrahlung ou raios $X$ de freamento, emitidos por meio de interações elétron-núcleo;

2) Raios $X$ característicos (discretos) emitidos em transições de elétrons orbitais de uma órbita para uma vacância em outra órbita;

3) Raios gama (discretos), emitidos por meio de transições nucleares e decaimento gama;

4) Radiação de aniquilação (discreta, normalmente 0,511 MeV), emitida por meio de aniquilação pósitron-elétron (PODGORSAK, 2005). 
Os fótons podem sofrer diversas interações com os átomos de um atenuador. A probabilidade de cada interação ocorrer depende da energia $h v$ do fóton e do número atômico $\mathrm{Z}$ do atenuador. Durante a interação, o fóton pode desaparecer completamente (efeito fotoelétrico e produção de pares) ou pode ser espalhado de forma coerente (espalhamento coerente) ou incoerente (efeito Compton). Os principais processos de interação são (TAUHATA e col., 2003; PODGORSAK, 2005):

a) Efeito fotoelétrico - ocorre interação do fóton com um elétron orbital firmemente ligado de um atenuador e, então, o fóton desaparece e o átomo é ionizado, pois ele transfere toda a sua energia para o elétron. Enquanto isso, o elétron orbital é ejetado do átomo como um fotoelétron. Este efeito tem maior probabilidade de ocorrer quando a energia do fóton é menor que $100 \mathrm{keV}$.

b) Espalhamento coerente (Rayleigh) - o fóton interage com um elétron orbital ligado. Esta interação é elástica, porque o fóton não perde essencialmente energia e, por isso, este espalhamento não desempenha nenhum papel no coeficiente de transferência de energia, mas apenas contribui no coeficiente de atenuação.

c) Efeito Compton (Espalhamento incoerente) - o fóton é espalhado por um elétron de baixa energia de ligação (denominado também de elétron recuado ou Compton), que recebe parte de sua energia. Este efeito ocorre com maior frequência quando a energia do fóton é maior que $100 \mathrm{keV}$.

d) Produção de pares - um fóton de alta energia desaparece ao se aproximar do núcleo atômico, e um par elétron-pósitron é produzido. Já que a massa é produzida totalmente da energia do fóton na forma de um elétron-pósitron, a produção de par tem uma energia limiar (energia mínima necessária do fóton para o efeito acontecer).

\subsubsection{Grandezas e Unidades de Radiação}

A dosimetria está relacionada a métodos de determinação da quantidade de dose que é depositada em um meio, pelas radiações direta e indiretamente ionizantes. Sendo assim, a dose de radiação que um indivíduo recebe determina os 
efeitos biológicos que podem ocorrer sobre ele. Por este motivo, as grandezas e as unidades específicas são definidas e aplicadas à dosimetria das radiações, bem como à calibração de fontes de radiação e instrumentos metrológicos.

Serão apresentadas neste item as principais grandezas envolvidas na dosimetria das radiações: kerma, exposição, dose absorvida e dose equivalente, bem como os conceitos de meia vida e atividade de uma fonte radioativa (ATTIX, 1986; ICRU, 1998; PODGORSAK, 2005). Além disso, também será definida a taxa de dose absorvida, grandeza diretamente relacionada com a calibração e a dosimetria de instrumentos metrológicos e fontes de radiação.

\section{\& Meia vida, $T_{1 / 2}$}

A meia vida é o intervalo de tempo durante o qual o número de átomos radioativos decai para metade do seu valor inicial, ou seja, é o tempo necessário para que metade dos átomos sofram decaimento.

$\mathrm{O}$ número de átomos radioativos inicial, $\mathrm{N}(\mathrm{t})$, presente em $\mathrm{t}=0$, diminui de acordo com a seguinte fórmula do decaimento radioativo:

$$
N(t)=N_{0} \cdot e^{-\lambda \cdot t}
$$

onde: $N_{0}$ é o número inicial de átomos radioativos no instante $\mathrm{t}=0$ e $\lambda=$ constante do decaimento radioativo $\left[\mathrm{s}^{-1}\right]$.

Aplicando-se a constante de decaimento à meia-vida, tem-se a seguinte relação:

$$
T_{1 / 2}=\frac{\ln 2}{\lambda}
$$

¿ Atividade, $A$

Define-se atividade de uma amostra como sendo a sua velocidade de desintegração, pois se trata do número de desintegrações dos núcleos atômicos 
que constituem uma amostra durante um determinado intervalo de tempo. A atividade pode ser obtida por meio da seguinte relação:

$$
A(t)=A_{0} \cdot e^{-\lambda \cdot t}
$$

onde: $A_{0}$ é a atividade inicial de uma amostra no instante $\mathrm{t}=0$.

A atividade também pode ser diretamente relacionada com o número de átomos $N$ de uma amostra utilizando-se a seguinte relação:

$$
A=\lambda \cdot N
$$

A unidade atual da atividade, utilizada no Sistema Internacional de Unidades (SI), recomendada em 1975 pela Comissão Internacional de Medidas e Unidades Radiológicas (ICRU), é o becquerel (Bq), que corresponde a uma desintegração por segundo (dps). Contudo, a unidade antiga, curie (Ci), ainda vem sendo utilizada nas clínicas de radiodiagnóstico, e a relação existente entre as duas unidades é:

$$
1 \mathrm{Ci}=3,7 \cdot 10^{10} \mathrm{~Bq}
$$

\section{d Kerma, $K$}

O kerma é aplicável a radiações indiretamente ionizantes como fótons e nêutrons. Esta grandeza mede a energia transferida da radiação indiretamente ionizante para partículas carregadas, como os elétrons, e é representada pela expressão (ICRU, 1998):

$$
K=\frac{d E}{d m}
$$

onde: $d E$ é a energia transferida [J] e $d m=$ massa de ar [kg].

A unidade do kerma é joule por kilograma $(\mathrm{J} / \mathrm{kg})$. O nome dado a esta unidade é gray (Gy). 


\section{¿ Exposição, $X$}

O conceito de exposição relaciona-se à quantidade total de cargas elétricas de mesmo sinal produzidas no ar quando elétrons e pósitrons liberados ou criados por fótons, em uma quantidade de massa, são completamente freados no ar. A exposição é expressa pela seguinte relação (ICRU, 1998):

$$
X=\frac{d Q}{d m}
$$

onde: $d Q$ é a quantidade total de cargas elétricas [C] e $d m=$ massa de ar [kg].

A unidade atual da grandeza exposição é o coulomb por kilograma $(\mathrm{C} / \mathrm{kg})$. A unidade antiga era o roentgen $(\mathrm{R})$, e a relação entre as duas unidades pode ser expressa como:

$$
1 \mathrm{R}=2,58 \cdot 10^{-4} \mathrm{C} / \mathrm{kg}
$$

\section{¿ Dose absorvida, $D$}

A dose absorvida é uma grandeza que pode ser aplicada a ambas as radiações diretamente e indiretamente ionizantes e para qualquer tipo de material, e representa a quantidade de energia absorvida pelo material exposto à radiação. A dose absorvida pode ser expressa pela seguinte relação (ICRU, 1998):

$$
D=\frac{d \bar{\varepsilon}}{d m}
$$

onde: $d \bar{\varepsilon}$ é a energia absorvida de radiação [J] e $d m$ massa do material absorvedor $[\mathrm{kg}]$.

A unidade atual e utilizada da dose absorvida é o gray (Gy), também recomendada em 1975 pelo ICRU, e passou a ser adotada pelo SI. A unidade antiga era o rad (radiation absorbed dose). A relação entre as unidades Gy e rad é:

$$
1 \mathrm{~Gy}=100 \mathrm{rad}
$$


A taxa de dose absorvida, $\dot{D}$, é a quantidade de dose absorvida por um material em um dado intervalo de tempo $(\Delta t)$ :

$$
\dot{D}=\frac{D}{\Delta t}
$$

Levando-se em conta o fato da taxa de dose absorvida estar relacionada com o tempo, esta grandeza também pode ser expressa pela relação:

$$
\dot{D}(t)=\dot{D}_{0} \cdot e^{\frac{\ln 2 \cdot \Delta t}{T_{1 / 2}}}
$$

onde: $\Delta t$ corresponde ao intervalo de tempo entre a data da taxa de dose absorvida inicial, $\dot{D}_{0}$, e a data com relação à qual se deseja determinar a nova taxa de dose absorvida, $\dot{D}(t)$.

A unidade de taxa de dose absorvida é Gy/s.

\section{$\bigotimes$ Dose equivalente, $H$}

A grandeza dose equivalente mostra a relação existente entre doses de radiação e efeitos biológicos. Esta grandeza física pode ser definida como (ICRU, 1998):

$$
H=Q \cdot D
$$

onde: $Q$ é o fator de qualidade da radiação e $D$ é a dose absorvida.

O fator de qualidade (Q) é uma variável aplicada à dose absorvida para fornecer uma estimativa do dano biológico causado por diferentes tipos e energias de radiações ionizantes (ATTIX, 1986).

Sendo a unidade de dose absorvida o Gy, pode-se considerar a unidade da dose equivalente também como Gy $(\mathrm{J} / \mathrm{kg})$, uma vez que as outras unidades são adimensionais. Entretanto, a unidade $\mathrm{J} / \mathrm{kg}$ recebe o nome de Gy em termos de dose 
absorvida; em se tratando de dose equivalente, $\mathrm{J} / \mathrm{kg}$ recebe o nome de sievert (Sv) (ATTIX, 1986).

A unidade antiga para dose equivalente era o rem (röentgen equivalent man). Entretanto, em 1975, a unidade Sv foi estabelecida pelo ICRU e, assim, passou a ser a unidade adotada no SI. Como 1 Sv equivale a $1 \mathrm{~Gy}$, a relação entre as duas unidades de dose equivalente é:

$$
1 \mathrm{~Sv}=100 \mathrm{rem}
$$

\subsection{Fundamentos sobre Calibração e Dosimetria de Instrumentos Metrológicos e Fontes de Radiação Beta}

A calibração de um instrumento metrológico consiste numa comparação entre os valores obtidos pelo instrumento sob calibração e os valores determinados por um sistema de referência. Desta forma, ajusta-se a resposta do instrumento submetido a um campo de radiação de intensidade conhecida e, por isso, é necessário que haja a presença de um instrumento denominado sistema padrão, e que todos os instrumentos utilizados sejam calibrados.

A dosimetria trata da medição de dose absorvida ou taxa de dose absorvida resultante da interação da radiação ionizante com a matéria (ATTIX, 1986).

Um instrumento padrão é um sistema de medição destinado a definir, realizar, conservar ou reproduzir a unidade ou um ou mais valores de uma grandeza, com o objetivo de atuar como referência. Podem ser classificados como: primário, secundário, terciário e nacional.

Padrão primário é o instrumento designado ou amplamente reconhecido como por ter as mais altas qualidades metrológicas e cujo valor fornecido nos certificados de calibração é obtido sem nenhuma referência a outros padrões de mesma grandeza. Um instrumento padrão secundário é aquele calibrado em comparação com um padrão primário de mesma grandeza, sendo utilizados por laboratórios de padronização secundária para serviços de calibração de instrumentos. O instrumento padrão terciário é calibrado por comparação com um 
padrão secundário e é utilizado para medições rotineiras. Padrão nacional é aquele reconhecido por uma decisão nacional para atuar como base, em um país, atribuindo valores a outros padrões de grandeza a que se refere (VIM, 2007).

Em metrologia das radiações, é de fundamental importância a rastreabilidade (IAEA, 2002; ICRU, 2004), definida como “a propriedade de um resultado de uma medição por meio da qual ele pode ser relacionado às referências estabelecidas, geralmente padrões nacionais ou internacionais, por intermédio de uma cadeia de comparações, todas tendo incertezas bem estabelecidas" (ISO, 1984). Portanto, é imprescindível conhecer a rastreabilidade nas medições.

Os laboratórios de padronização primária calibram detectores de radiação e fontes radioativas, que passam a ser classificados como sistemas padrões secundários. Estes laboratórios consistem em ambientes de padronização nacional, designado pelo governo, cujos objetivos são desenvolver, realizar a manutenção e aperfeiçoar padrões primários em dosimetria das radiações. Existem alguns laboratórios padrões primários que realizam a calibração de fontes radioativas beta em termos de taxa de dose absorvida no ar ou na água, que são: o National Institute of Standards and Technology (NIST), nos Estados Unidos, o PhysikalischTechnische Bundesanstalt (PTB), na Alemanha, e o National Physical Laboratory (NPL), na Inglaterra.

Os laboratórios de padronização também podem ser classificados como secundários. São laboratórios regionais, designados por autoridades competentes para o serviço de calibração de instrumentos; para tal, devem possuir ao menos um padrão secundário calibrado em relação a um padrão primário, para cada tipo de radiação. O Accredited Dosimetry Calibration Laboratory (ADCL) da Universidade de Wisconsin, nos Estados Unidos, é um laboratório padrão secundário que calibra fontes de radiação beta.

A calibração de instrumentos metrológicos com radiação beta é um procedimento complexo, pois esta radiação possui baixo poder de penetração e alto gradiente de dose, o que faz com que seja necessário um campo de radiação minuciosamente definido de modo a permitir a sua reprodutibilidade pelos 
laboratórios. Por este motivo, a dosimetria de fontes de radiação beta também se torna complexa.

As fontes de radiação beta, assim como de outros tipos de radiações, necessitam ser calibradas. As publicações da Agência Internacional de Energia Atômica (IAEA) mostram recomendações que envolvem a calibração de feixes de radiação utilizados em radioterapia (IAEA, 1987; 1994). Este procedimento faz parte de programas de controle de qualidade que devem ser adotados durante o uso e o manuseio destas fontes. A grandeza recomendada para a especificação de fontes de radiação beta é a taxa de dose absorvida na água a uma distância de referência da fonte, que difere de uma fonte a outra (IAEA, 2002; ICRU, 2004). Para fontes planas, por exemplo, esta distância de referência é 1,0 $\mathrm{mm}$ do centro da fonte, quando para sementes é de 2,0 $\mathrm{mm}$ na direção transversal do eixo longitudinal da fonte (IAEA, 2002).

\subsection{Aplicadores Dermatológicos e Oftálmicos de ${ }^{90} \mathrm{Sr}+{ }^{90} \mathrm{Y}$}

Os aplicadores clínicos de ${ }^{90} \mathrm{Sr}+{ }^{90} \mathrm{Y}$, embora atualmente não sejam mais fabricados e nem comercializados, ainda são utilizados, principalmente em clínicas brasileiras de radioterapia. Por este motivo, juntamente com o fato de sua utilização ter sido crescente desde que estas fontes de radiação beta foram desenvolvidas, sua dosimetria tornou-se alvo de estudo e interesse clínico.

Os aplicadores de ${ }^{90} \mathrm{Sr}+{ }^{90} \mathrm{Y}$ foram desenvolvidos e propostos em 1950 por Friedell e colaboradores, com o objetivo de substituir os aplicadores de ${ }^{226} \mathrm{Ra}$, utilizados na época (FRIEDELL e col., 1950). Após o início de sua utilização, pôdese constatar que as fontes de ${ }^{90} \mathrm{Sr}^{+90} \mathrm{Y}$ apresentaram vantagens em relação às de ${ }^{226} \mathrm{Ra}$, que são: curto alcance das partículas beta emitidas e ausência de produtos de decaimento gasosos (SINCLAIR e TROTT, 1956; REFT e col., 1990). O esquema do decaimento do isótopo é relativamente simples, uma vez que o isótopo do ${ }^{90} \mathrm{Sr}$ decai com uma meia vida de 28,8 anos, quando em equilíbrio com o isótopo de ${ }^{90} \mathrm{Y}$, emitindo partículas beta com energias máximas de 0,546 e 2,283 $\mathrm{MeV}$, respectivamente. 
Embora estas fontes de radiação beta tenham sido propostas em 1950, a sua utilização na Medicina teve início no século XX. Pelo fato da radiação beta apresentar baixo poder de penetração na matéria, os aplicadores de ${ }^{90} \mathrm{Sr}+{ }^{90} \mathrm{Y}$ passaram a ser utilizados no tratamento de lesões superficiais. Este tipo de tratamento é denominado betaterapia, e consiste em uma modalidade da braquiterapia na qual fontes de radiação beta são posicionadas em contato com a superfície lesionada. Em muitos casos, a betaterapia é profilática e os tratamentos são realizados logo após intervenção cirúrgica.

$\mathrm{O}$ formato da fonte radioativa pode variar, dependendo da finalidade a que o aplicador se destina: dermatológica ou oftálmica. Um esquema de cada tipo de aplicador por ser observado na Figura 2.1, na qual se pode observar a haste metálica, para o operador segurar durante o tratamento, e um protetor de acrílico, que permite a proteção das mãos do operador. As fontes de ${ }^{90} \mathrm{Sr}+{ }^{90} \mathrm{Y}$ são revestidas por uma camada fina de prata, que serve como proteção da fonte e para absorver as partículas beta de energias mais baixas do ${ }^{90} \mathrm{Sr}$, uma vez que as partículas beta emitidas pelo ${ }^{90} \mathrm{Y}$ são usadas terapeuticamente.

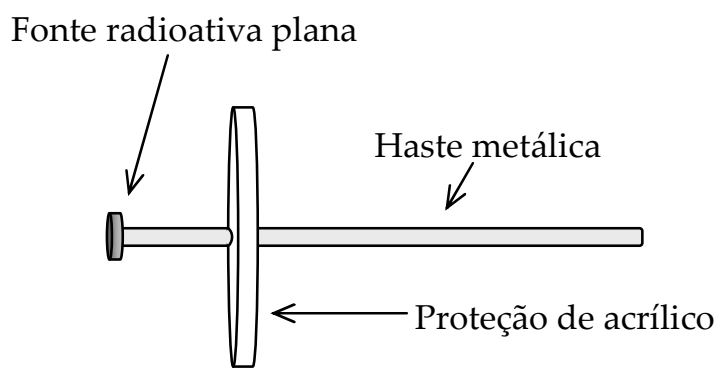

(a)

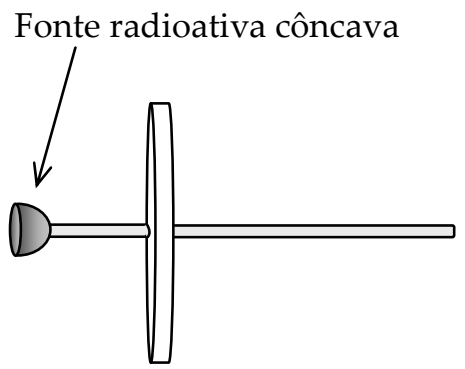

(b)

Figura 2.1: Esquemas de aplicadores clínicos de ${ }^{90} \mathrm{Sr}+{ }^{90} \mathrm{Y}:(\mathrm{a})$ plano e (b) curvo.

Os aplicadores dermatológicos são utilizados no tratamento de câncer de pele e de quelóides e cicatrizes hipertróficas, enquanto que os aplicadores oftálmicos são utilizados no tratamento pós-operatório de pterígio. $\mathrm{O}$ êxito do tratamento depende dos parâmetros físicos a serem adotados, como a qualidade da radiação, o tamanho do campo, a distância entre a fonte e o tumor e a dose correta a ser administrada. 
Nos Estados Unidos, a maioria dos aplicadores oftálmicos consiste de fontes de ${ }^{90} \mathrm{Sr}^{+90} \mathrm{Y}$ (energia máxima de $1,8 \mathrm{MeV}$ e energia média de 0,8 MeV), e sua principal utilização é no tratamento de pterígio (REFT, 1990). Adotando-se o tratamento com aplicadores e o complementar, o índice de recidiva desta doença cai de 30-68\% para 0,5-33\% (GLECKLER e col., 1998).

Na Europa, os aplicadores oftálmicos são, em sua grande maioria, fontes de ${ }^{106} \mathrm{Ru}+{ }^{106} \mathrm{Rh}$ (energia máxima de 3,5 MeV e energia média de 1,5 MeV); estes aplicadores com energias mais altas são mais adequados para tratamentos de lesões mais profundas (SOARES, 1992).

Conforme estes aplicadores foram sendo utilizados, pôde-se verificar que um método de calibração para estas fontes é imprescindível, pois para se assegurar que o tratamento será realizado com êxito e que o paciente receberá a dose correta de radiação, apenas uma correção da atividade das fontes de radiação beta ao decaimento radioativo é insuficiente.

Estudos prévios revelam que as câmaras de extrapolação são os instrumentos adequados para a calibração destes aplicadores (SOARES, 1991; 1995; DIAS, 1996; DIAS e CALDAS, 1998; 1999; OLIVEIRA, 2005; OLIVEIRA e CALDAS, 2005a; 2005b). Além disso, também foram desenvolvidos trabalhos que mostram que outra técnica que pode ser utilizada na calibração de aplicadores clínicos de ${ }^{90} \mathrm{Sr}+{ }^{90} \mathrm{Y}$ é a dosimetria termoluminescente (SOARES e col., 2001; OLIVEIRA e CALDAS, 2004; 2007b).

\subsection{Câmaras de Ionização}

Para a determinação precisa da dose absorvida em um meio exposto às radiações ionizantes, que é de fundamental importância na dosimetria beta, são utilizados instrumentos adequados a esta finalidade, denominados dosímetros (ATTIX, 1986).

Um dosímetro pode ser definido como um dispositivo que fornece uma informação referente à dose absorvida depositada em seu volume sensível (ATTIX, 1986; BOAG, 1987). Este instrumento ou sistema mede ou avalia, 
diretamente ou indiretamente, as grandezas exposição, kerma, dose absorvida ou dose equivalente, ou as suas derivadas do tempo (taxas) e ainda outras grandezas relacionadas à radiação ionizante (PODGORSAK, 2005).

Os dosímetros podem ser físicos ou químicos, sendo os últimos sólidos, líquidos ou gasosos (ATTIX, 1986; PODGORSAK, 2005). Os dosímetros utilizados são vários: os calorímetros, as câmaras de ionização, os dosímetros termoluminescentes ou TLDs (conhecidos como dosímetros de estado sólido), o dosímetro Fricke, os filmes radiocrômicos, os semicondutores, o óxido de nitrogênio (NO) e dióxido de carbono $\left(\mathrm{CO}_{2}\right)$.

Neste item serão discutidos os conceitos acerca das câmaras de ionização, e em um próximo item, definições sobre a dosimetria termoluminescente, que consistem nos dois tipos de dosimetria estudadas e utilizadas durante este trabalho.

Os instrumentos metrológicos mais antigos baseiam-se no princípio da medição por meio da ionização de um gás: são as câmaras de ionização (ATTIX, 1986). Apesar do surgimento de outros sistemas de medição, estes detectores de radiação consistem em instrumentos simples, práticos e precisos para medições de exposição e dose absorvida; por estes motivos, são também os instrumentos mais utilizados.

Estas câmaras são empregadas principalmente na detecção de radiações alfa, beta, $X$, gama e fragmentos de fissão. Há diversos modelos e dimensões, podendo as câmaras de ionização ser cilíndricas, esféricas ou de placas paralelas, dependendo de sua finalidade quanto à medição de exposição ou dose absorvida, tipo de radiação a ser medida e sua intensidade. $O$ material da parede também pode variar; no caso da câmara de ionização ser utilizada com a finalidade de se medir exposição, suas paredes devem ser compostas por um material equivalente ao ar, enquanto que se a câmara for destinada para medições de dose absorvida em um determinado meio, as paredes e o gás devem ser equivalentes ao meio em questão.

As câmaras de ionização mais simples consistem de um fio central, denominado eletrodo coletor, envolto por uma parede que delimita uma cavidade 
preenchida por um gás. No instante em que as partículas carregadas atravessam o gás, são produzidas ionizações e excitações em suas moléculas. Se a molécula neutra é ionizada, origina-se um elétron livre e um íon positivo. Ao se aplicar uma diferença de potencial entre o eletrodo coletor e a parede da câmara, os elétrons livres migram em direção a outro eletrodo, chamado eletrodo central, onde são coletados. Neste instante, os íons positivos migram em direção à parede, resultando na formação de um pulso elétrico. Neste caso, uma vez que a intensidade do sinal de saída é dependente da carga coletada, a intensidade dependerá do número de pares de íons produzidos no gás (ATTIX, 1986; BOAG, 1987).

A aplicação das câmaras de ionização em dosimetria das radiações baseia-se no princípio de relação entre a dose absorvida na parede da câmara e a dose absorvida na cavidade preenchida por um gás. Esta relação recebe o nome de "Teoria da Cavidade", e será apresentada a seguir (SPENCER e ATTIX, 1955; ATTIX, 1986).

\subsubsection{Teoria da Cavidade}

Um detector de radiação na maioria das vezes difere em densidade e número atômico do meio no qual ele é introduzido. Por este motivo, a presença deste instrumento causa uma perturbação no meio. Este problema é solucionado com a aplicação da teoria da cavidade.

O primeiro modelo cavitário foi proposto por Bragg em 1912, e desenvolvido para fótons. Esta teoria propõe que a cavidade deve ser pequena em relação ao alcance das partículas carregadas produzidas pela radiação ionizante. Isto é necessário para que a introdução desta cavidade em um meio não perturbe o fluxo ou a distribuição de partículas secundárias carregadas (ATTIX, 1986; BOAG, 1987; SHANI, 1991).

Em 1928, Gray formulou outro princípio cavitário, que recebeu o nome de "Princípio da Equivalência". Esta teoria foi apresentada, em 1936, como "Relação de Bragg-Gray", e determina que "a energia perdida pelos elétrons na cavidade, por unidade de volume, é $1 / m S_{\text {meio }}^{\text {cav }}$ vezes a energia perdida pela radiação gama, 
por unidade de volume, no meio adjacente". Esta relação é expressa na forma (BOAG, 1987; SHANI, 1991):

$$
D_{\text {meio }}=\frac{1}{m S_{\text {meio }}^{\text {cav }}} D_{\text {cav }}
$$

onde: $D_{\text {meio }}$ é a dose absorvida no meio de interesse, $D_{c a v}$ é a dose na cavidade e $1 / m S_{\text {meio }}^{\text {cav }}$ é o inverso da razão dos poderes de freamento dos elétrons na cavidade e no meio.

Como a teoria de Bragg-Gray nem sempre é atendida na prática, vários estudos foram realizados posteriormente a fim de aprimorar o conceito de teoria da cavidade.

Em 1937, Laurence modificou a relação de Bragg-Gray, considerando que os elétrons não possuem uma única energia inicial, mas que estas energias são distribuídas em um espectro de energias iniciais. Desta maneira, a razão entre os poderes de freamento para uma única energia foi substituída pela média destes espectros iniciais, a uma distância da parede igual ao alcance máximo dos elétrons mais energéticos.

Entretanto, ainda assim as teorias de Bragg-Gray e de Laurence falharam, pois não consideraram o fato de muitas colisões de elétrons primários produzirem elétrons de alta energia, os raios delta $(\delta)$, que são resultantes das colisões entre as partículas carregadas que atravessam a cavidade, e que depositam sua energia fora do volume de interesse. (BOAG, 1987; SHANI, 1991).

Em 1955, Spencer e Attix refizeram a teoria de Laurence, agora englobando as perdas de energia devido aos raios $\delta$. A este novo modelo, foi introduzida uma energia de corte $\Delta$, definida como a energia cinética necessária para um elétron possuir alcance igual ao tamanho médio da cavidade, podendo, assim, atravessá-la. Entretanto, este modelo se limita a cavidades pequenas, assim como a teoria de Bragg-Gray.

Atualmente, a teoria mais utilizada é a proposta por Burlin: a Teoria da Cavidade Geral ou Teoria da Cavidade de Burlin. Esta teoria, que pode ser 
aplicada tanto a cavidades pequenas quanto a cavidades maiores leva em conta a atenuação dos elétrons gerados no meio e o aumento de elétrons gerados na cavidade. A teoria de Burlin é dada pela Equação 2.12 (ATTIX, 1986; SHANI, 1991):

$$
D_{\text {meio }}=\left[d_{m} S_{\text {meio }}^{c a v}+(1-d) \frac{\left(\mu_{e n} / \rho\right)_{\text {cav }}}{\left(\mu_{e n} / \rho\right)_{\text {meio }}}\right]^{-1} D_{\text {cav }}
$$

onde: $m S_{\text {meio }}^{c a v}$ é a razão entre os poderes de freamento de elétrons na cavidade e no meio; $\left(\mu_{e n} / \rho\right)_{c a v}$ e $\left(\mu_{e n} / \rho\right)_{\text {meio }}$ são os coeficientes de absorção de energia de massa para a cavidade e o meio, respectivamente; $D_{c a v}$ e $D_{\text {meio }}$ são as doses absorvidas na cavidade e no meio, respectivamente; e $d$ é um fator, que representa o quanto ocorre de atenuação, na cavidade, do fluxo de elétrons gerados no meio (este fator depende do tamanho da cavidade, sendo igual a zero para cavidades grandes e igual a 1 para cavidades maiores), e é dado pela Equação 2.13:

$$
d=\frac{1-e^{-\beta g}}{\beta g}
$$

onde: $\beta$ é o coeficiente de atenuação de massa efetivo para elétrons e $g$ é o livre caminho médio para os elétrons que atravessam a cavidade.

A teoria de Burlin foi desenvolvida para fótons, mas foi estendida para elétrons em 1969, onde se considerou que nenhum elétron seria gerado na cavidade por meio da interação direta entre o feixe primário de radiação e o material da cavidade (OGUNLEYE e PALIWAL, 1985).

\subsubsection{Câmaras de Extrapolação}

As câmaras de ionização de placas paralelas, também denominadas câmaras superficiais, são utilizadas geralmente em dosimetria de radiação $X$ de energias baixas. Estas câmaras são empregadas na determinação de taxas de exposição e 
podem ser utilizadas como um instrumento padrão secundário e ainda em medições rotineiras (IAEA, 1987; ALBUQUERQUE e CALDAS, 1989). Além disso, as câmaras de placas paralelas podem ser utilizadas na detecção de elétrons com energias menores que $10 \mathrm{MeV}$.

Quando a distância entre a fonte e a câmara de placas paralelas não for pequena, as medições tornam-se semelhantes às de uma câmara de extrapolação, que consiste basicamente de uma câmara de ionização de placas paralelas, diferindo no fato de apresentar volume sensível variável. Esta variação ocorre por meio de um parafuso micrométrico que permanece acoplado à câmara e que permite a variação entre o eletrodo coletor e a janela de entrada.

Em 1937, Failla apresentou uma câmara de extrapolação com o objetivo de medir a dose superficial em um material sob irradiação, com alta precisão, de fontes de radiação beta e raios X de energias baixas (FAILLA, 1937). Esta medição é possível utilizando-se o coeficiente angular (obtido por meio da corrente de ionização em função da distância entre os eletrodos), que é proporcional à taxa de dose absorvida no ar.

Uma câmara de extrapolação é composta basicamente, além do parafuso micrométrico, por dois eletrodos paralelos: o eletrodo coletor e o eletrodo de alta tensão (ou janela de entrada). Esta câmara também apresenta um anel de guarda, que circunda o eletrodo coletor com a finalidade principal de evitar a existência de corrente de fuga. Entre o anel de guarda e o eletrodo coletor há um material isolante. Um esquema de uma câmara de extrapolação pode ser observado na Figura 2.2. 


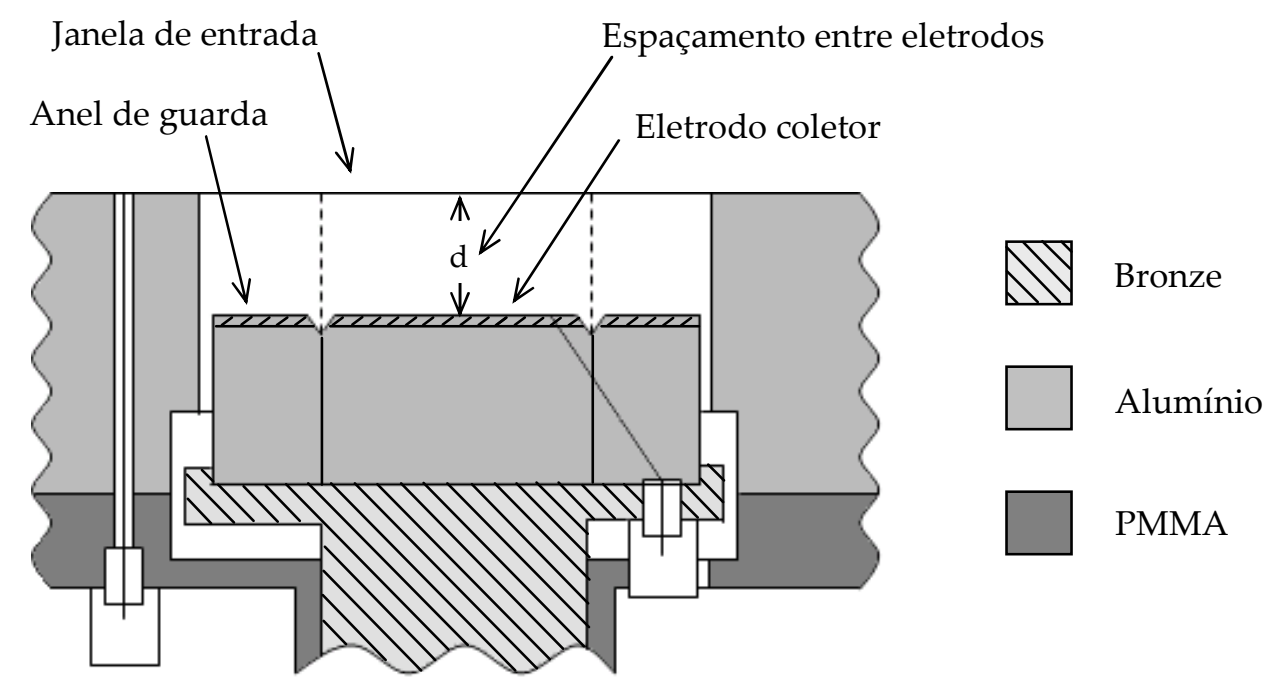

Figura 2.2: Representação esquemática de uma câmara de extrapolação (PRUITT e col., 1988).

Na construção de uma câmara de extrapolação, deve-se formar o conjunto janela de entrada, eletrodo coletor e anel de guarda com um material equivalente ao meio de interesse. É importante ressaltar que a janela de entrada deve possuir boa consistência mecânica para resistir à atração eletrostática, e sua espessura deve ser fina de maneira a não perturbar os elétrons que a atravessa.

Ao longo dos anos, a câmara de extrapolação de Failla foi sendo aprimorada desde que foi desenvolvida e estudada com relação à sua aplicação em diferentes campos de radiação (PAYNE e WAGGNER, 1974; BÖHM e SCHNEIDER, 1986; OLIVEIRA, 2005; OLIVEIRA e CALDAS, 2007a; DIAS e CALDAS, 1998; 1999; 2001). Estes trabalhos mostram que as câmaras de extrapolação têm se tornado instrumentos de extrema importância na caracterização de campos padrões, principalmente de radiação beta.

Algumas câmaras de extrapolação já foram desenvolvidas no Brasil (SILVA, 1985); no IPEN, foram desenvolvidas três câmaras de extrapolação: uma com o objetivo de atuar como instrumento de referência na dosimetria da radiação beta (DIAS, 1996), e outras duas mini-câmaras de extrapolação, uma de janela plana e outra de janela curva, também para servirem de sistemas de referência, para a calibração de aplicadores clínicos utilizados em braquiterapia (OLIVEIRA, 2005a; 2005b). 


\subsubsection{Determinação da Taxa de Dose Absorvida na Água}

A dose absorvida é a grandeza mais utilizada em dosimetria beta, e o meio com o qual a radiação ionizante interage deve ser especificado: dose absorvida no ar ou no tecido (água).

$\mathrm{Na}$ especificação das fontes de radiação beta, a grandeza recomendada é a taxa de dose absorvida na água à distância de referência da fonte: $1,0 \mathrm{~mm}$ a partir de seu centro, em seu eixo de simetria, para fontes planas e curvas (De ALMEIDA e col., 2000; IAEA, 2002; ICRU, 2004).

A determinação da taxa de dose absorvida pode ser realizada de maneira absoluta, ou seja, utilizando-se uma câmara de extrapolação como instrumento de referência.

A taxa de dose absorvida na água relaciona-se com a taxa de dose absorvida no ar, e o valor médio da razão entre os poderes de freamento da água e do ar, por meio da expressão:

$$
\dot{D}_{\text {água }}=S_{a r}^{\text {água }} \cdot \dot{D}_{a r}
$$

onde: $\dot{D}_{\text {agua }}$ e $\dot{D}_{a r}$ são as taxas de dose absorvida na água e no ar, respectivamente; e $S_{a r}^{\text {água }}$ é a razão entre os poderes de freamento da água e do ar. Por meio da definição de dose absorvida, esta expressão pode ser reescrita como:

$$
\dot{D}_{\text {água }}=S_{a r}^{\text {agua }} \cdot(W / e) \cdot\left(\frac{\Delta I}{\Delta m_{a r}}\right)
$$

onde: ( $W / e$ ) é a energia média, em joules, necessária para produzir $1 \mathrm{C}$ de carga de mesmo sinal no ar $\left[(33,97 \pm 0,05) \mathrm{J} . \mathrm{C}^{-1}\right]$; e $\Delta I / \Delta m_{a r}$ é a razão entre a corrente de ionização, $\Delta I$, e a massa de ar, $\Delta m_{a r}$, na qual a corrente é produzida. 
O volume de ar presente no interior da câmara é delimitado pelo espaçamento entre os eletrodos da câmara, $d$, e a área de seu eletrodo coletor, $a$, e é expresso pela seguinte relação:

$$
\begin{gathered}
V_{a r}=d \cdot a \\
\mathrm{e} \\
V_{a r}=\frac{m_{a r}}{\rho_{0}}
\end{gathered}
$$

onde: $\rho_{0}$ é a densidade do ar à temperatura e à pressão de referência.

A taxa de dose absorvida no ar, obtida por meio da inclinação da curva de extrapolação, que se obtém da corrente de ionização em função da distância entre os eletrodos (ou profundidade da câmara), é dada pela Equação 2.17, que se trata da Equação 2.14 reescrita de uma outra forma:

$$
\dot{D}_{\text {água }}=\frac{(W / e) \cdot S_{a r}^{\text {água }}}{\rho_{0} \cdot a} \cdot(\Delta I / \Delta d)_{d \rightarrow 0} \cdot k_{\text {retro }}
$$

onde: $(\Delta I / \Delta d)_{d \rightarrow 0}$ é a inclinação da curva de extrapolação quando o espaçamento entre os eletrodos da câmara tende à zero; e $k_{\text {retro }}$ é o fator de correção que leva em conta a diferença do retroespalhamento no eletrodo coletor quando comparado à água (1,01006) (SOARES, 1991; De ALMEIDA e col., 2000; IAEA, 2002).

É necessário que a corrente de ionização, medida com a câmara de extrapolação, seja corrigida levando-se em conta três fatores: o fator de correção para as condições ambientais de referência, o fator de recombinação e o fator de divergência (OLIVEIRA, 2005). Sendo assim, a taxa de dose absorvida na água, ou no tecido, pode ser determinada aplicando-se estes fatores de correção.

O fator de correção para as condições normais de temperatura e pressão, $k_{T, p}$, é expresso pela seguinte relação:

$$
k_{T, p}=\frac{273,15+T}{293,15} \cdot \frac{101,325}{p}
$$

onde: $T$ é o valor da temperatura e $p$ é o valor da pressão medidos. 
O fator de recombinação, $k_{\text {recom }}$, relaciona-se às perdas de íons que se recombinam antes de serem coletados, e é dado por:

$$
k_{\text {recom }}=\left(1-\frac{0,04554}{\sqrt{E \cdot d^{2}}}\right)^{-1}
$$

onde: $E$ é o campo elétrico aplicado $(\mathrm{V} / \mathrm{mm})$; $d$ é a distância entre os eletrodos da câmara; e 0,04554 é um valor constante que torna o fator $k_{\text {recom }}$ adimensional (LOEVINGER e TROTT, 1966).

Por fim, o fator de divergência, $k_{d i v}$, considera a divergência do feixe de radiação beta emitido pela fonte; no caso de distâncias grandes entre a fonte e a janela de entrada da câmara, este fator é expresso por (OLIVEIRA, 2005):

$$
k_{d i v}=1+\frac{d}{y_{0}}
$$

onde: $y_{0}$ é a distância entre a fonte e a janela de entrada da câmara ( $\left.\mathrm{mm}\right)$. Este fator é mais evidenciado quando os espaçamentos entre os eletrodos da câmara são grandes e as fontes e os eletrodos coletores são pequenos (SOARES e col., 1991). Quando os espaçamentos entre os eletrodos são pequenos, este fator é ignorado e então, $k_{d i v}$ passa a ser igual a 1 (SOARES e col., 1991).

\subsection{Materiais Dosimétricos Termoluminescentes}

Devido à fácil absorção de radiação beta e à alta dependência da taxa de dose absorvida para esta radiação com a distância, a utilização de dosímetros pequenos e finos torna-se uma grande alternativa para a obtenção de medições precisas. Exemplos de dosímetros deste tipo são os termoluminescentes.

O fenômeno da termoluminescência (TL) é um processo físico caracterizado por uma emissão termicamente estimulada, sob a forma de luz, da energia armazenada nos materiais TL quando são irradiados, após serem aquecidos. 
Possui aplicação nas mais variadas áreas: dosimetria pessoal, ambiental, clínica e de altas doses (McKEEVER, 1985; FURETTA e WENG, 1998).

A TL pode ser descrita por dois estágios principais: o primeiro, no qual ocorre uma perturbação no processo levando-o de um estado de equilíbrio a um estado metaestável, e o segundo, no qual ocorre o retorno do processo do estado termicamente estimulado ao de equilíbrio. Inicialmente, a radiação ionizante causa a alteração no processo e, então, há a emissão de luz, como consequência do relaxamento do sistema durante o retorno à estabilidade. A TL emitida durante esta técnica depende da dose de radiação. Os estágios do fenômeno da TL podem ser observados na Figura 2.3.

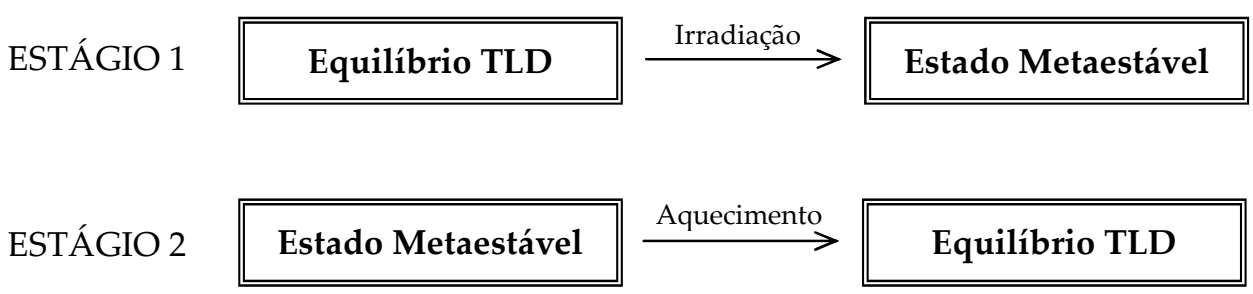

Figura 2.3: Estágios do fenômeno da termoluminescência (McKEEVER e col., 1995).

\subsubsection{Teoria de Bandas}

Os materiais termoluminescentes são, em geral, cristais iônicos. Estes cristais apresentam bandas denominadas banda de valência, banda proibida e banda de condução. A banda de valência, na qual os elétrons ficam presos a sítios na estrutura cristalina, permanece repleta e a de condução, onde os elétrons ficam livres para se moverem no cristal, permanece vazia; estas duas bandas são separadas pela banda proibida, uma faixa larga de estados energéticos não permitidos aos elétrons. A largura da banda proibida determina se o material é um isolante ou um semicondutor (McKEEVER, 1985; SCHARMANN e BÖHM, 1993).

Quando o intervalo de tempo entre a irradiação e emissão de luz for inferior a $10^{-8} \mathrm{~s}$, os cristais são fluorescentes; caso este intervalo seja superior a $10^{-8} \mathrm{~s}$, os 
cristais são chamados fósforos luminescentes ou fosforescentes. Quando o processo de aquecimento do cristal induz a emissão de luz, ocorre o chamado efeito termoluminescente (McKEEVER e col., 1995; FURETTA e WENG, 1998).

Existem níveis de energia metaestáveis localizados na banda proibida, que ocorrem com a incorporação de impurezas ou a formação de defeitos na estrutura cristalina, denominados armadilhas. Os defeitos mais comuns que podem ocorrer nos cristais são a vacância de um átomo ou íon (defeito Schottky), ou a existência de um átomo numa posição intersticial (defeito Frenkel). Também existem defeitos que são responsáveis por conferirem coloração ao cristal, são os chamados centros de cor, como por exemplo os centros $\mathrm{F}$ (centros de elétrons) e os centros $\mathrm{V}_{\mathrm{k}}$ e $\mathrm{H}$ (centros de buracos) (McKEEVER, 1985).

Durante o processo de irradiação (com partículas $\alpha$ e $\beta$, radiação $X$ e $\gamma$ etc) são produzidos no cristal pares elétrons-lacunas, que migram através dele até se recombinarem e serem capturados em armadilhas (McKEEVER, 1985; SCHARMANN e BÖHM, 1993), conforme pode ser observado na Figura 2.4.

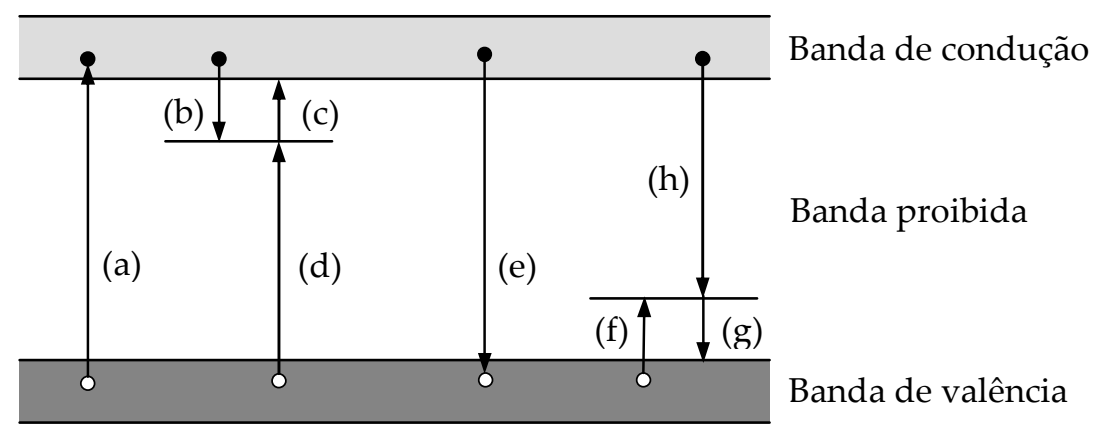

Figura 2.4: Esquema dos níveis de energia e transições eletrônicas: (a) processo de ionização, (b) e (f) armadilhamento de elétron e lacuna, respectivamente, (c) e (g) liberação de elétron e lacuna, respectivamente, $(\mathrm{d})$ e $(\mathrm{h})$ recombinação indireta, e (e) recombinação direta (McKEEVER, 1985).

Quando a amostra é aquecida, os elétrons absorvem energia térmica e escapam das armadilhas, migrando para a banda de condução, onde podem se 
movimentar livremente até se recombinarem com uma lacuna armadilhada, nos chamados centros de recombinação. Após a recombinação, ocorre o processo de aniquilação e, então, a emissão de sua energia na forma de luz.

Após o aquecimento do cristal, embora os elétrons absorvam energia, a maioria deles retorna para a banda de valência após um curto período de tempo, originando a luminescência. Entretanto, alguns elétrons são aprisionados nas chamadas imperfeições da estrutura cristalina dentro da banda proibida. Assim, cada elétron deixa uma lacuna na banda de valência, que rapidamente se recombina com um elétron ou é armadilhada. Estas recombinações originam a termoluminescência, onde parte da energia é liberada sob a forma de luz visível ou ultravioleta (McKEEVER, 1985).

Após uma irradiação, o cristal também pode retornar ao seu estado inicial se for submetido a um tratamento térmico (especial, dependendo do material), para que os elétrons armadilhados sejam liberados.

Durante os processos envolvidos no fenômeno da termoluminescência, tem papel fundamental o leitor termoluminescente. É por meio deste aparelho que ocorre o aquecimento da amostra, o controle da temperatura e a detecção da luz emitida. Estes são os três sistemas principais do leitor termoluminescente.

\subsubsection{Curva de Emissão TL}

A luz emitida por um cristal em função da temperatura ou do tempo de aquecimento pode ser representada por um gráfico denominado curva de emissão termoluminescente. Esta curva é a melhor característica de um fósforo termoluminescente, ou material TL, e pode apresentar vários picos. Cada um desses picos é associado a uma armadilha de certa profundidade, que pode ser de elétrons ou de buracos, e é caracterizado pela temperatura em que ocorre o máximo de emissão (McKEEVER, 1985; FURETTA e WENG, 1998; ROSA, 2000).

A forma da curva de emissão varia de um material para outro e depende de fatores como a taxa de aquecimento, dose de radiação e concentração de armadilhas. Sendo assim, depende dos tipos de armadilhas e, também, do leitor 
termoluminescente utilizado. A presença de dois ou mais picos numa mesma curva de emissão revela a existência de mais de um tipo de armadilha TL (FURETTA e WENG, 1998; ROSA, 2000). Uma curva de emissão típica pode ser observada na Figura 2.5.

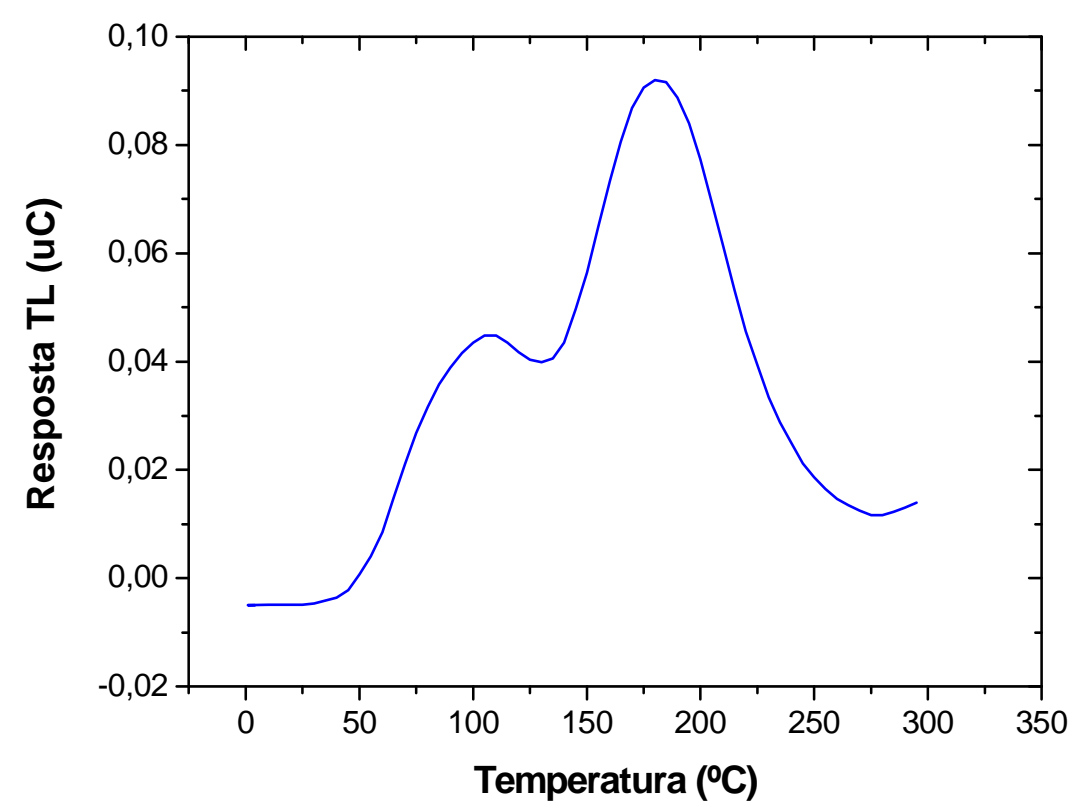

Figura 2.5: Curva de emissão TL típica de uma amostra de CaSO4:Dy, irradiada com 10 mGy ( $\left.{ }^{60} \mathrm{Co}\right)$.

A formação de um pico de emissão TL é determinada pela probabilidade de escape do elétron da armadilha correspondente; quando a temperatura do material TL é menor que a do pico considerado, poucos elétrons são liberados e, então, a luz emitida é fraca. Quando o cristal é aquecido, a probabilidade de escape dos elétrons aumenta e, com isso, ocorre um aumento da emissão, que é máxima justamente na altura do pico. Em seguida, a intensidade decresce devido à redução do número de elétrons (ROSA, 2000).

De maneira geral, a resposta TL exibida por um cristal aumenta quando este é exposto à radiação $X$ ou $\gamma$, atingindo a saturação para exposições elevadas. Em alguns materiais TL a resposta inicial é linear, e em outros observa-se um 
crescimento mais rápido do que o linear, comportamento que recebe o nome de supralinearidade (ROSA, 2000).

\subsubsection{Dosimetria Termoluminescente}

Os materiais que apresentam a propriedade termoluminescente são vários, e a escolha do melhor material a ser utilizado depende de alguns fatores, pois o material deve reunir determinadas características que façam da sua utilização um método prático e eficiente. Estas características são (ROSA, 2000):

- Resposta TL linear para um amplo intervalo de dose;

- Resposta de preferência pouco dependente da energia dos fótons;

- Sensibilidade, mesmo para doses muito baixas (entre 5,0 $\mu$ Sv e 0,2 mSv);

- Resposta TL estável, mesmo em condições ambientais inadequadas;

- Resposta reprodutível, inclusive para doses baixas (próximas ao limite de detecção do material TL); e

- Curva de emissão TL simples, de preferência com um único pico de emissão ou com picos de emissão bem resolvidos.

É importante ressaltar que não há um material que agregue todas estas características. No entanto, é necessário que o material escolhido apresente o maior número destes requisitos.

Os dosímetros TL podem ser fabricados nas mais diversas formas e dimensões, o que torna seu uso vantajoso. Além disso, outra vantagem é a possibilidade de reutilização destes materiais, após seu uso, por meio de tratamentos térmicos bem definidos. 


\subsubsection{Caracterização Dosimétrica}

No início de qualquer estudo empregando amostras TL, elas devem ser caracterizadas em relação aos seus requisitos dosimétricos.

O material TL deve apresentar, preferencialmente, linearidade entre a dose absorvida e a indicação que fornece, e esta resposta deve ser independente da taxa de dose. Entretanto, a maioria dos materiais apresenta um comportamento nãolinear com a dose em alguns intervalos; este problema leva à determinação de um valor sub ou superestimado. Sendo assim, para que esta situação seja resolvida, faz-se necessária a calibração prévia das amostras (McKEEVER, 1985).

A determinação do limite inferior de detecção das amostras também tem sua importância considerável, pois possui relação dependente com a sensibilidade da amostra TL, com o tamanho do dosímetro e com a sensibilidade do leitor TL (McKEEVER, 1985). O limite inferior de detecção é definido como sendo a soma da média das leituras TL, e três vezes o desvio padrão das medições realizadas dos dosímetros não irradiados (que passaram por tratamento térmico), multiplicada por um fator de calibração referente a cada tipo de amostra.

Este limite inferior também depende das características do cristal. Sua determinação é importante, pois quanto menor for este limite, maior utilidade esta amostra terá para fins dosimétricos.

Outro fator importante é a determinação da variação da resposta TL em função da energia da radiação incidente. A dependência energética é definida como sendo a comparação entre a energia absorvida pela amostra em estudo com a energia absorvida por um material de referência, quando submetidos às mesmas condições de irradiação; geralmente, o ar é utilizado como meio de referência.

A sensibilidade da resposta TL de uma amostra depende da energia da radiação incidente, que interage com o cristal de várias formas quando sua energia é variada. É importante salientar que esta sensibilidade depende, de certa forma, dos tratamentos térmicos aos quais as amostras são submetidas, pois pode ocorrer variação da sensibilidade dependendo da duração e da temperatura envolvidas no tratamento. 
Uma amostra TL apresenta boa estabilidade quando a resposta TL devida à exposição do dosímetro a uma irradiação não apresenta variação, durante o seu armazenamento à temperatura ambiente. A estabilidade de um dosímetro é influenciada pelo decaimento do sinal armazenado, entre os instantes da irradiação e da medição. Este decaimento ocorre quando a profundidade da armadilha é pequena, de modo que a energia doada pela radiação solar, por lâmpadas fluorescentes e altas temperaturas, são suficientes para desarmadilhar alguns elétrons (McKEEVER, 1985).

O tratamento térmico a que as amostras são submetidas após irradiação, ou leitura da resposta TL, tem por objetivo esvaziar as armadilhas correspondentes aos picos cujas temperaturas são iguais ou inferiores à temperatura de tratamento. Quando o tratamento é realizado antes da irradiação, recebe o nome de prérecozimento ou tratamento pré-irradiação, e se realizado após a irradiação, é chamado de pós-recozimento ou tratamento pós-irradiação.

\subsubsection{Dosímetros Termoluminescentes de CaSO4:Dy}

Os materiais utilizados na dosimetria termoluminescente são vários, como por exemplo: fluoreto de lítio ativado com magnésio e titânio ( $\mathrm{LiF}: \mathrm{Mg}, \mathrm{Ti}$ ), o material mais utilizado; fluoreto de lítio ativado com magnésio, cobre e fósforo ( $\mathrm{LiF}: \mathrm{Mg}, \mathrm{Cu}, \mathrm{P})$; borato de lítio ativado com manganês ( $\mathrm{Li}_{2} \mathrm{~B} 4 \mathrm{O} 7: \mathrm{Mn}$ ); fluoreto de cálcio ativado com disprósio ( $\mathrm{CaF} 2 \mathrm{Dy})$; e sulfato de cálcio ativado com disprósio (CaSO4:Dy). Neste trabalho, foram utilizadas pastilhas de CaSO4:Dy e, por este motivo, as características deste material serão apresentadas.

O CaSO4:Dy apresenta uma curva de emissão TL relativamente simples, apresentando um pico principal próximo a $220^{\circ} \mathrm{C}$, dois outros, não utilizados em dosimetria, situados em 80 e $120^{\circ} \mathrm{C}$, e um quarto pico, situado a $250^{\circ} \mathrm{C}$. Uma curva de emissão típica do CaSO4:Dy pôde ser observada na Figura 2.5. Este material deve ser tratado a $300^{\circ} \mathrm{C}$ durante 3 horas, para que o pico principal seja eliminado. As principais vantagens deste material são: não apresenta decaimento térmico acentuado e sua resposta não é afetada de modo significativo por condições 
ambientais. Entretanto, o CaSO4:Dy é bastante sensível à luz, sendo necessário, portanto, protegê-lo da luz.

O Laboratório de Materiais Dosimétricos (LMD) do IPEN produz pastilhas de CaSO4:Dy com e sem 10\% de grafite e de diferentes dimensões; as pastilhas finas de CaSO4:Dy, com e sem grafite, apresentam dimensões de 6,0 mm de diâmetro e 0,2 $\mathrm{mm}$ de espessura, e as convencionais sem grafite apresentam 6,0 $\mathrm{mm}$ de diâmetro e $0,8 \mathrm{~mm}$ de espessura. O LMD comercializa estas pastilhas para todo o Brasil. 


\section{MATERIAIS E MÉTODOS}

Neste capítulo, serão descritos os sistemas de medição, as fontes de radiação beta $\mathrm{e}$ os sistemas $\mathrm{e}$ instrumentos auxiliares utilizados durante todo $\mathrm{o}$ desenvolvimento do projeto. Toda a infra-estrutura necessária para o trabalho encontra-se disponível no Laboratório de Calibração de Instrumentos (LCI).

A análise e a expressão das incertezas relativas a todas as medições, ao longo deste trabalho, foram obtidas de acordo com as recomendações da Associação Brasileira de Normas Técnicas (ABNT, 1998). Os valores obtidos correspondem às incertezas expandidas utilizando-se fator de abrangência igual a 2, o que se refere a um nível de confiança de aproximadamente $95 \%$.

\subsection{Sistemas de Medição}

Os sistemas de medição envolvidos neste trabalho foram: câmaras de extrapolação e dosímetros termoluminescentes.

\subsubsection{Câmaras de Extrapolação}

Dois tipos de câmaras de extrapolação foram utilizados para a calibração e a dosimetria de aplicadores: uma câmara de extrapolação da marca PTW, modelo 23391, Alemanha, e uma mini-câmara de extrapolação de janela plana, desenvolvida no LCI (OLIVEIRA, 2005; OLIVEIRA e CALDAS, 2005a; 2005b). Estas câmaras podem ser observadas na Figura 3.1. Todos os valores de corrente de ionização obtidos com as câmaras de extrapolação foram corrigidos para as condições normais de temperatura e pressão.

A câmara de extrapolação comercial PTW utilizada neste trabalho apresenta dois eletrodos coletores: de alumínio e de grafite, com diâmetros variando de 
$10 \mathrm{~mm}$ a $40 \mathrm{~mm}$. Os eletrodos utilizados neste trabalho foram os de $40 \mathrm{~mm}$. A janela de entrada é de Mylar e possui 0,025 mm de espessura. Esta câmara permite uma variação na distância inter-eletródica de 0,5 a 25,0 mm. A mini-câmara de extrapolação apresenta janela de entrada de poliéster aluminizado; o eletrodo coletor é feito de acrílico coberto com grafite e o isolante é de Teflon (PTFE). A área efetiva do eletrodo coletor desta mini-câmara possui 1,68 mm².

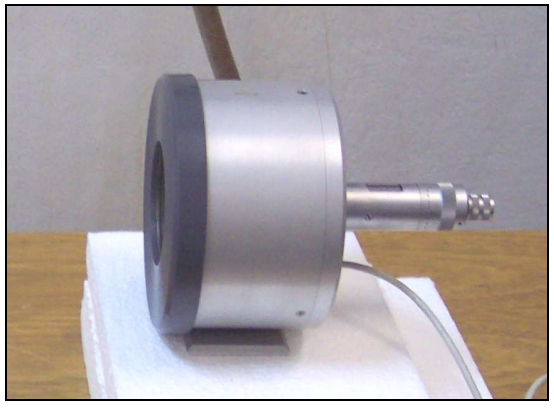

(a)

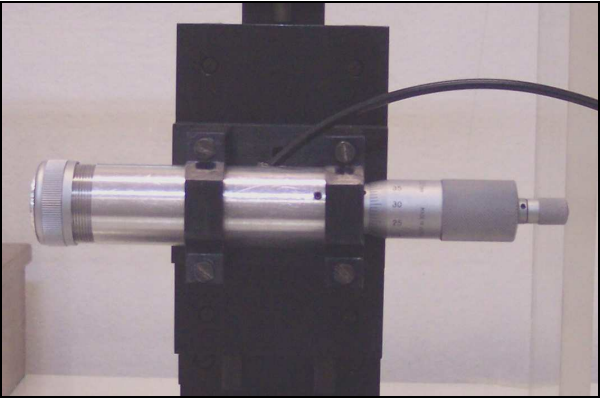

(b)

Figura 3.1: Câmaras de extrapolação utilizadas no trabalho: (a) câmara de extrapolação, modelo 23391, PTW e (b) mini-câmara de extrapolação de janela plana, desenvolvida no LCI (OLIVEIRA, 2005; OLIVEIRA e CALDAS, 2005a; 2005b).

A câmara PTW foi utilizada acoplada a um eletrômetro Keithley, modelo 617. Este eletrômetro foi escolhido por permitir uma variação de $0,5 \mathrm{~V}$ na tensão aplicada à câmara de extrapolação.

Em todas as medições com a câmara PTW, ela foi exposta à radiação beta à distância de calibração de $30 \mathrm{~cm}$, reproduzindo as condições do certificado de calibração das fontes de ${ }^{90} \mathrm{Sr}+{ }^{90} \mathrm{Y}$.

As câmaras foram posicionadas sobre um suporte de acrílico, fixado ao sistema de posicionamento das fontes, de maneira a permitir que o feixe de radiação incidisse no centro da janela de entrada de cada câmara de extrapolação.

A mini-câmara de extrapolação foi acoplada a um eletrômetro PTW, modelo Unidos, número de série 10475. Os valores de carga foram coletados para, então, serem convertidos em corrente de ionização. Em todos os procedimentos, a mini- 
câmara foi fixada a um suporte que foi desenvolvido para seu próprio posicionamento (OLIVEIRA, 2005).

\subsubsection{Dosimetria Termoluminescente}

Os dosímetros utilizados neste trabalho foram as pastilhas finas de CaSO4:Dy e de CaSO4:Dy + 10\% de grafite, com dimensões de 6,0 mm de diâmetro e 0,2 mm de espessura. Estes dosímetros podem ser observados na Figura 3.2. Estas amostras foram escolhidas a partir de um estudo prévio sobre o desempenho de diversos materiais termoluminescentes (OLIVEIRA e CALDAS, 2004), que comprovou que estes materiais apresentam uma resposta adequada em campos de radiação de ${ }^{90} \mathrm{Sr}+{ }^{90} \mathrm{Y}$. As pastilhas utilizadas durante o trabalho foram produzidas e fornecidas pelo Laboratório de Materiais Dosimétricos do IPEN.

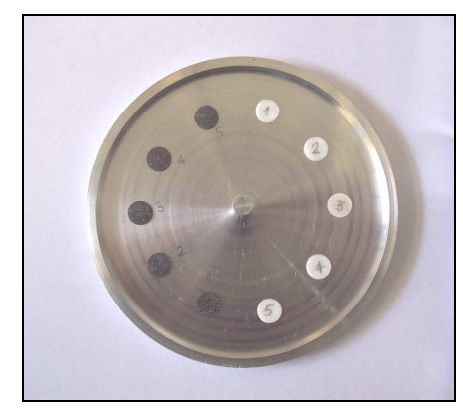

Figura 3.2: Pastilhas de CaSO4:Dy com e sem 10\% de grafite, num suporte de alumínio para o tratamento térmico das amostras.

As amostras de $\mathrm{CaSO} 4: \mathrm{Dy}$ com e sem grafite foram tratadas termicamente $\left(300{ }^{\circ} \mathrm{C} / 3\right.$ horas) e resfriadas rapidamente (sobre uma placa retangular de alumínio de $\left.23 \times 19 \times 2,5 \mathrm{~cm}^{3}\right)$, para reutilização.

As medições TL foram obtidas com um sistema leitor TL, Harshaw Nuclear Systems, modelo 2000A/B, com uma taxa de aquecimento de $10{ }^{\circ} \mathrm{C} / \mathrm{s}$ e fluxo constante de $\mathrm{N}_{2}$ de $5,01 / \mathrm{min}$. 


\subsection{Fontes de Radiação Beta}

Diferentes tipos de fontes de ${ }^{90} \mathrm{Sr}+{ }^{90} \mathrm{Y}$ foram utilizados: três fontes de sistemas padrões secundários e de sete aplicadores clínicos (sendo cinco dermatológicos, um oftálmico e um usado para ambas as finalidades).

O LCI possui dois sistemas padrões secundários de radiação beta: 1) o modelo BSS1, Buchler GmbH \& Co., Alemanha, e 2) o modelo BSS2, Isotrak, Alemanha. O primeiro sistema, BSS1, possui duas fontes de ${ }^{90} \mathrm{Sr}+{ }^{90} \mathrm{Y}$, enquanto o BSS2 possui apenas uma fonte de ${ }^{90} \mathrm{Sr}+{ }^{90} \mathrm{Y}$. Estas fontes foram calibradas no laboratório padrão primário da Alemanha, Physikalisch - Technische Bundesanstalt (PTB), constituindo assim sistemas padrões secundários. As características destas fontes estão apresentadas na Tabela 3.1.

Tabela 3.1: Características das fontes de ${ }^{90} \mathrm{Sr}+{ }^{90} \mathrm{Y}$ à distância fonte-detector de $30 \mathrm{~cm}$ (PTB, 1981a; 1981b; PTB, 2005).

\begin{tabular}{cccc}
\hline \multirow{2}{*}{$\begin{array}{c}\text { Sistema } \\
\text { padrão }\end{array}$} & Atividade (MBq) & $\begin{array}{c}\text { Taxa de dose absorvida } \\
\dot{\boldsymbol{D}}(\boldsymbol{\mu G} / \mathrm{s})\end{array}$ & $\begin{array}{c}\text { Data de } \\
\text { Calibração }\end{array}$ \\
\hline \multirow{2}{*}{ BSS1 } & 74 (com filtro) & $1,707 \pm 0,017$ & 12.01 .81 \\
\cline { 2 - 4 } & 1850 (sem filtro) & $70,60 \pm 0,71$ & 04.02 .81 \\
\hline \multirow{2}{*}{ BSS2 } & 460 (com filtro) & $10,56 \pm 0,14$ & 08.12 .04 \\
\cline { 2 - 4 } & 460 (sem filtro) & $16,46 \pm 0,22$ & 12.01 .05 \\
\hline
\end{tabular}

Os dois sistemas BSS1 e BSS2 apresentam, dentre outros componentes, filtros uniformizadores de campo, que foram utilizados em conjunto com as fontes nos testes realizados com a câmara de extrapolação PTW, dependendo das especificações do certificado de calibração de cada fonte.

O LCI também possui três aplicadores dermatológicos clínicos: um calibrado no laboratório padrão primário do NIST, Estados Unidos, usado como referência na maior parte do trabalho com aplicadores; o aplicador A, que possui certificado de calibração da Amersham, Inglaterra; e o aplicador B, que não possui certificado. Durante o desenvolvimento do projeto, mais quatro aplicadores foram utilizados: 
C, D, E e F, todos vindos de clínicas e institutos de pesquisa, por empréstimo. As informações referentes aos aplicadores podem ser observadas na Tabela 3.2. Todos os aplicadores especificados são da Amersham, exceto o aplicador NIST, que foi fabricado pela Atlantic Research Corporation, e o aplicador B, que não apresenta certificado. Os aplicadores dermatológicos (NIST, A, B, D e E) são planos, o aplicador oftálmico (F) é curvo e o aplicador dermatológico/oftálmico (C) é levemente curvo. Os aplicadores A, B e NIST podem ser observados na Figura 3.3.

Tabela 3.2: Características dos aplicadores clínicos de ${ }^{90} \mathrm{Sr}+{ }^{90} \mathrm{Y}$ (AMERSHAM, 1968; 1986; 1996; NIST, 2003; UNESP, 2003a; 2003b).

\begin{tabular}{|c|c|c|c|c|c|}
\hline Aplicador & Tipo & $\begin{array}{c}\text { Marca } \\
\text { e } \\
\text { Modelo }\end{array}$ & $\begin{array}{c}\text { Atividade } \\
\text { Nominal } \\
\text { (MBq) }\end{array}$ & $\begin{array}{c}\text { Taxa de Dose } \\
\text { Absorvida } \\
\dot{D}(\mathrm{~Gy} / \mathrm{s})\end{array}$ & $\begin{array}{c}\text { Data de } \\
\text { Calibração }\end{array}$ \\
\hline NIST & Dermatológico & $\begin{array}{c}\text { Atlantic } \\
\text { Research } \\
\text { Corporation/ } \\
\text { B-1 S/N 233 }\end{array}$ & N.I. & 0,40 & 28.01 .2003 \\
\hline$A$ & Dermatológico & $\begin{array}{c}\text { Amersham/ } \\
\text { SIQ } 18 \\
\end{array}$ & 1480 & 0,056 & 08.11 .1968 \\
\hline$B$ & Dermatológico & \multicolumn{4}{|c|}{ Não possui certificado } \\
\hline C & $\begin{array}{c}\text { Dermatológico/ } \\
\text { Oftálmico }\end{array}$ & $\begin{array}{c}\text { Amersham/ } \\
\text { SAI } 20\end{array}$ & 2035 & 0,438 & 31.07.1996 \\
\hline$D$ & Dermatológico & $\begin{array}{l}\text { Amersham/ } \\
\text { SIQ } 21\end{array}$ & 740 & 0,053 & 17.09.1986 \\
\hline$E$ & Dermatológico & $\begin{array}{c}\text { Amersham/ } \\
50722096 \\
\end{array}$ & 1850 & 0,0401 & 14.05 .2003 \\
\hline$F$ & Oftálmico & $\begin{array}{l}\text { Amersham/ } \\
\text { SAI 6/1418 }\end{array}$ & 370 & 0,0296 & 14.05 .2003 \\
\hline
\end{tabular}

N.I.: não informado 


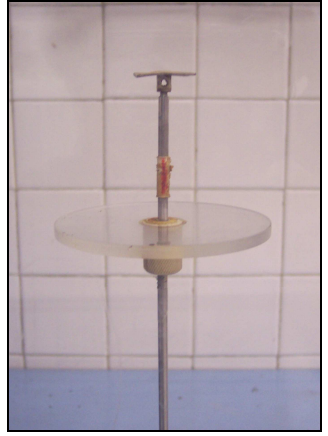

(a)

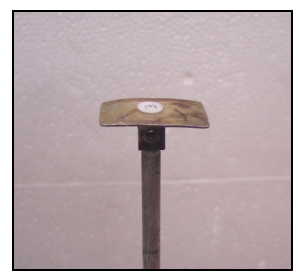

(b)

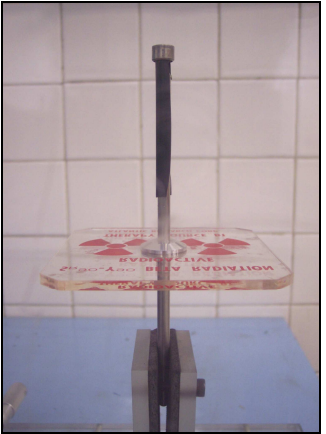

(c)

Figura 3.3: Aplicadores dermatológicos de ${ }^{90} \mathrm{Sr}+{ }^{90} \mathrm{Y}:(\mathrm{a}) \mathrm{A}$, (b) B e (c) NIST.

Além destas fontes, também foi utilizada neste trabalho uma fonte de controle de ${ }^{90} \mathrm{Sr}+{ }^{90} \mathrm{Y}$, de atividade nominal de $33 \mathrm{MBq}$ (1994), da PTW, tipo 8921, durante o teste de estabilidade a médio prazo da resposta da mini-câmara de extrapolação. Esta fonte foi posicionada sobre um suporte de acrílico, confeccionado para o posicionamento reprodutível da fonte em relação à mini-câmara de extrapolação e, além disso, como proteção da janela de entrada da mini-câmara (OLIVEIRA, 2005).

Para as medições de distribuição de dose em profundidade na água, que foram realizadas utilizando-se a mini-câmara de extrapolação e a dosimetria termoluminescente, foram confeccionadas sete placas de acrílico, de 5,4 cm de diâmetro e de espessuras de 1,0, 1,5, 2,0, 2,5, 3,0, 4,0 e 5,0 mm. Estas placas podem ser observadas na Figura 3.4-a.

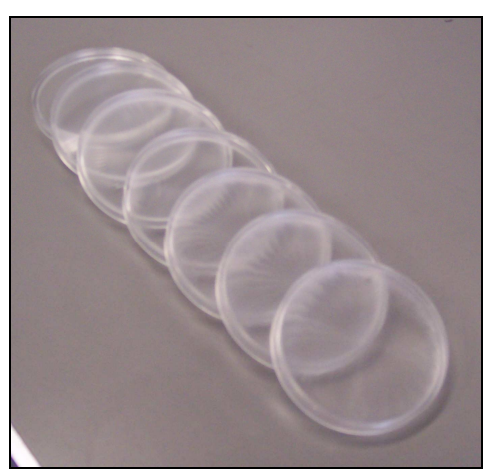

(a)

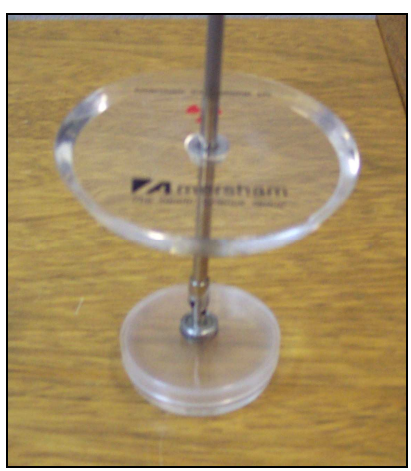

(b)

Figura 3.4: Placas de acrílico confeccionadas para as medições de dose em profundidade na água: (a) de diferentes espessuras e (b) para o posicionamento das pastilhas. 
Além disso, cinco peças de acrílico de $5,0 \mathrm{~cm}$ de diâmetro de $1,0 \mathrm{~cm}$ de espessura, contendo um orifício de mesmo diâmetro e profundidade da espessura das pastilhas, foram confeccionadas para o posicionamento das amostras. Durante o estudo de dose em profundidade de água, as sete placas de diferentes espessuras foram posicionadas sobre as cinco peças de acrílico, contendo as amostras termoluminescentes, conforme mostrado na Figura 3.4-b.

\subsection{Sistemas Auxiliares e Acessórios Diversos}

Foi utilizado um forno, fabricado pelo Instituto de Radioproteção e Dosimetria, CNEN, Rio de Janeiro, que opera até $450{ }^{\circ} \mathrm{C}$, para os tratamentos térmicos dos materiais termoluminescentes. Além disso, foram utilizados: placas circulares de alumínio, de $7 \mathrm{~cm}$, para o tratamento térmico das pastilhas, uma placa retangular de alumínio de $23 \times 19 \times 2,5 \mathrm{~cm}$, para o resfriamento das pastilhas e um cronômetro digital Kenko, modelo KK-1025. Para a verificação e o controle das condições ambientais do laboratório, local de trabalho com as câmaras de extrapolação, foram utilizados um termômetro de mercúrio, um higrômetro Haenni e um transdutor Setra, modelo 270, que é associado a um multímetro digital Keithley, modelo 177, e fornece a pressão atmosférica. 


\section{RESULTADOS}

Os resultados da calibração e dosimetria de fontes e aplicadores clínicos de radiação beta de ${ }^{90} \mathrm{Sr}+{ }^{90} \mathrm{Y}$, obtidos neste trabalho, serão apresentados neste capítulo em duas partes, segundo a técnica de medição: utilizando-se câmaras de extrapolação e dosímetros termoluminescentes.

\subsection{Utilização de Câmaras de Extrapolação na Calibração e Dosimetria de Aplicadores Clínicos de ${ }^{90} \mathrm{Sr}+{ }^{90} \mathrm{Y}$}

Dois tipos de câmaras de extrapolação foram utilizados: uma câmara comercial, para calibração de fontes de radiação beta às distâncias entre 10 a $50 \mathrm{~cm}$, e uma mini-câmara de extrapolação de janela plana desenvolvida no IPEN (OLIVEIRA, 2005) para a calibração de aplicadores dermatológicos.

\subsubsection{Câmara de Extrapolação PTW}

No caso da câmara de extrapolação PTW, as medições foram realizadas com a câmara de extrapolação contendo eletrodo coletor tanto de alumínio como de grafite.

\subsubsection{Corrente de Fuga Pré-Irradiação}

A corrente de fuga pré-irradiação foi estimada antes de cada conjunto de medições, diversas vezes. Para tanto, a carga foi coletada sem a presença de fonte de radiação durante 20 minutos. De acordo com a norma IEC 60731 (1997), o limite recomendável para o teste de corrente de fuga pré-irradiação é de $0,5 \%$ do maior 
valor das medições. Todos os resultados obtidos apresentaram-se dentro deste limite.

\subsubsection{Testes de Repetitividade e Reprodutibilidade}

A câmara de extrapolação PTW com eletrodo coletor de alumínio foi inicialmente estudada em relação à repetitividade, ou teste de estabilidade à curto prazo, de sua resposta. Este teste foi realizado com as três fontes de ${ }^{90} \mathrm{Sr}+{ }^{90} \mathrm{Y}$, com atividades nominais de: $74 \mathrm{MBq}, 460 \mathrm{MBq}$ e $1850 \mathrm{MBq}$.

Durante este teste, as condições experimentais foram mantidas segundo o recomendado pelo certificado de calibração da fonte, com o objetivo de se reproduzir as medições da maneira em que elas foram realizadas por ocasião da calibração das fontes. Estas condições envolvem a utilização de filtro uniformizador de campo e a distância entre a fonte e a câmara de extrapolação, de $30 \mathrm{~cm}$. No caso das fontes de $74 \mathrm{MBq}$ e $1850 \mathrm{MBq}$ (BSS1), as medições foram realizadas com filtro e sem filtro respectivamente, enquanto que para a fonte de $460 \mathrm{MBq}$ (BSS2), as medições foram realizadas com e sem o filtro.

As fontes foram dispostas no sistema de suporte de fontes à frente da câmara de extrapolação que, por sua vez, foi posicionada num suporte de acrílico, formando o arranjo experimental.

Para a realização deste teste, as medições foram tomadas tanto em termos de carga como de corrente. As medições em carga foram tomadas em intervalos de $60 \mathrm{~s}$, e as medições em corrente, em intervalos de $10 \mathrm{~s}$, ambas num total de 10 leituras para cada polaridade. A profundidade da câmara (distância entre o eletrodo coletor e a janela de entrada da câmara) permaneceu constante e igual a 1,82 mm, e a tensão aplicada foi de 18,20 V, ou seja, o campo elétrico foi mantido constante entre os eletrodos em $10 \mathrm{~V} / \mathrm{mm}$.

Este teste foi repetido 10 vezes, constituindo o teste de reprodutibilidade, ou de estabilidade a médio prazo, da resposta da câmara.

Um teste de estabilidade a curto prazo com a fonte de ${ }^{90} \mathrm{Sr}^{+90} \mathrm{Y}$ de $74 \mathrm{MBq}$ também foi realizado quando a câmara de extrapolação teve o seu eletrodo coletor 
de alumínio trocado pelo de grafite. O teste de estabilidade a médio prazo com o novo eletrodo foi realizado sob as mesmas condições que para o eletrodo anterior. Os resultados deste teste de estabilidade, com os valores normalizados para o valor médio, podem ser observados na Figura 4.1.

A variação da resposta da câmara obtida neste teste de repetitividade, foi inferior a $0,88 \%$. No teste de reprodutibilidade, a variação máxima obtida nestas medições foi de 3,2\%. No caso das medições com as fontes de 74, 460 e $1850 \mathrm{MBq}$, e para o eletrodo coletor de alumínio, a resposta da câmara apresentou comportamento semelhante.

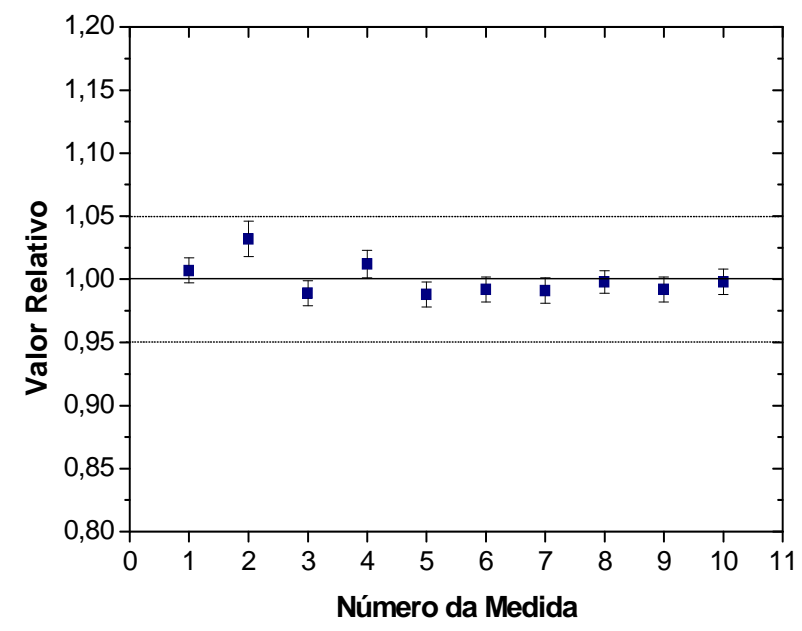

Figura 4.1: Estabilidade a médio prazo da resposta da câmara de extrapolação PTW, com eletrodo coletor de grafite, para a fonte de ${ }^{90} \mathrm{Sr}+{ }^{90} \mathrm{Y}$ de $74 \mathrm{MBq}$.

\subsubsection{Curvas de Extrapolação com Fontes de ${ }^{90} \mathrm{Sr}+{ }^{90} \mathrm{Y}$}

As curvas de extrapolação foram obtidas utilizando-se as fontes de ${ }^{90} \mathrm{Sr}+{ }^{90} \mathrm{Y}$ de $74 \mathrm{MBq}, 1850 \mathrm{MBq}$ e $460 \mathrm{MBq}$, com e sem filtro uniformizador de feixe de radiação, e para os eletrodos coletores tanto de alumínio como de grafite.

Inicialmente, com a câmara de extrapolação com eletrodo coletor de alumínio, adotou-se a profundidade nula real de $0,32 \mathrm{~mm}$, já determinado anteriormente por Caldas (1986), nas medições para as curvas de extrapolação. Após a troca do eletrodo coletor para o de grafite, foi necessário determinar-se novamente a profundidade nula real. 
Para as curvas de extrapolação com eletrodo coletor de alumínio, as medições de carga foram tomadas em intervalos de 60 s. Como a curva de extrapolação é dada em termos de corrente de ionização em função da profundidade da câmara, os valores de carga acumulada foram divididos pelo tempo de medição, obtendo-se assim, os valores da corrente de ionização. A distância entre a janela de entrada da câmara e cada fonte foi de $30 \mathrm{~cm}$. As fontes foram posicionadas no suporte para fontes, do BSS1 e BSS2, e a câmara de extrapolação PTW no suporte de acrílico de cada sistema padrão secundário beta. Este arranjo pode ser observado na Figura 4.2.

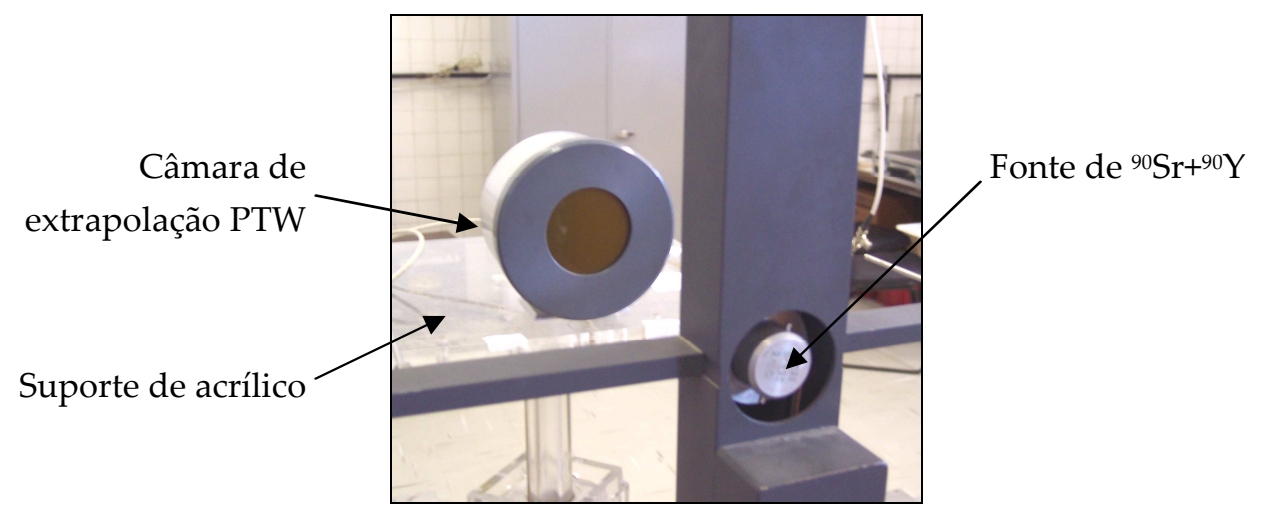

Figura 4.2: Arranjo experimental utilizado durante as medições para as curvas de extrapolação, com o sistema beta BSS1.

Para a obtenção das curvas de extrapolação completas, variou-se a distância inter-eletródica em oito profundidades, entre 1,02 e 5,32 mm, e 10 leituras foram tomadas para cada profundidade e polaridade, com exceção no caso da fonte de $460 \mathrm{MBq}$ (com filtro), cuja distância foi variada em apenas quatro profundidades, de 1,02 $\mathrm{mm}$ a 2,32 $\mathrm{mm}$, pois para a determinação da taxa de dose absorvida final, basta variar-se a profundidade da câmara até cerca de 2,5 mm (CALDAS, 1986). No caso do eletrodo coletor de grafite, esta opção também foi adotada, ou seja, foram feitas curvas de extrapolação com 4 profundidades. O campo elétrico foi sempre mantido constante em $10 \mathrm{~V} / \mathrm{mm}$ em todas as medições.

Os resultados obtidos das curvas de extrapolação para cada fonte, com ou sem a utilização de filtro, podem ser observados na Figura 4.3. Pode-se verificar que a partir de 3,0 $\mathrm{mm}$ de profundidade da câmara ocorre uma falta de linearidade desta curva. Esta deflexão ocorre devido à distorção do campo 
elétrico, e torna-se ainda mais acentuado em casos onde o eletrodo coletor possui dimensão pequena. No caso das Figuras 4.3-b e c, as incertezas calculadas foram pequenas a ponto das barras de erro se tornarem imperceptíveis.

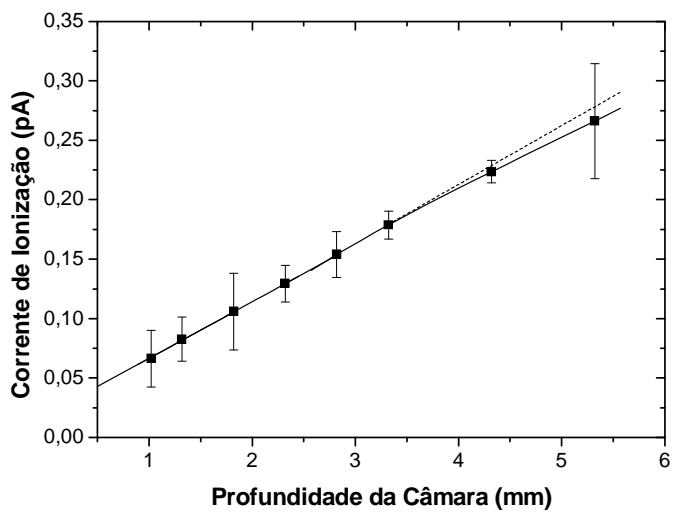

(a)

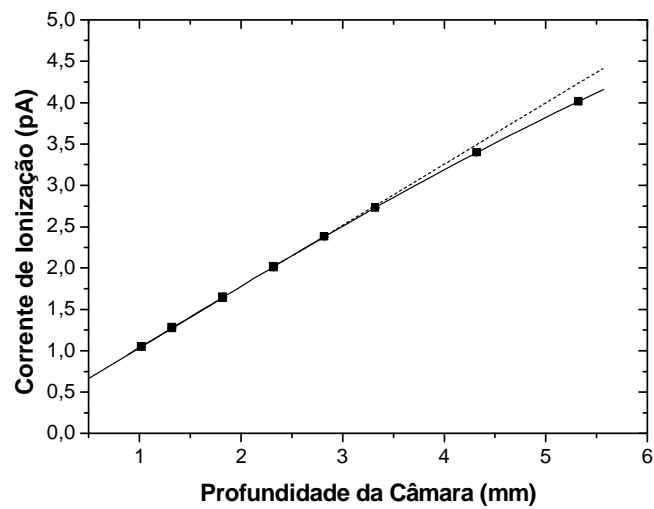

(c)

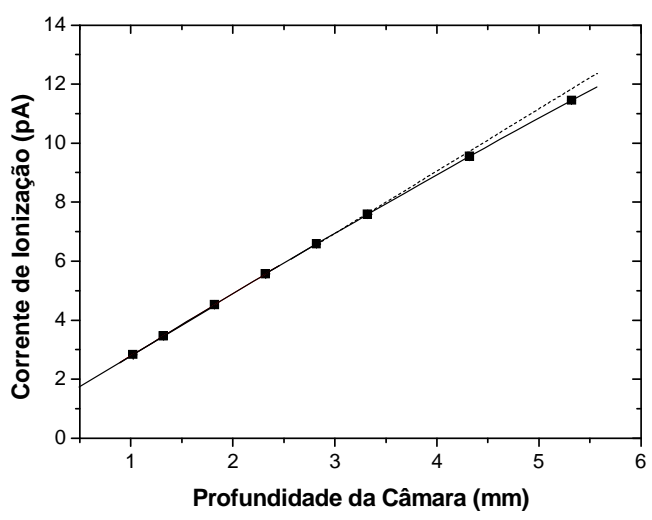

(b)

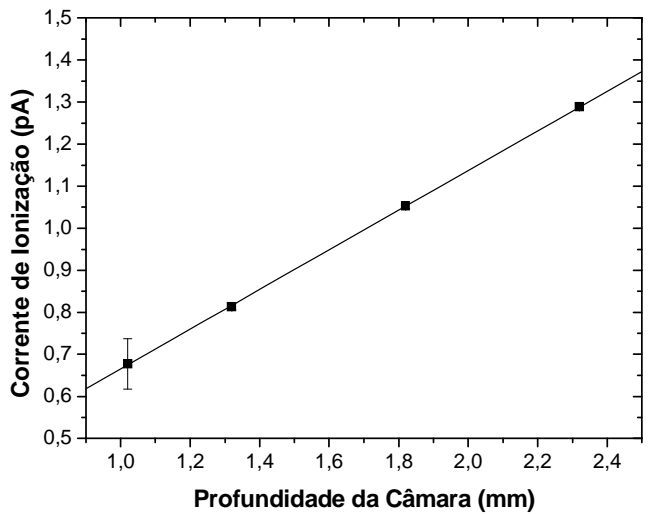

(d)

Figura 4.3: Curvas de extrapolação obtidas com a câmara de extrapolação PTW com eletrodo coletor de alumínio para as fontes de ${ }^{90} \mathrm{Sr}+{ }^{90} \mathrm{Y}$ de (a) $74 \mathrm{MBq}$ com filtro, (b) $1850 \mathrm{MBq}$ sem filtro, (c) $460 \mathrm{MBq}$ sem filtro e (d) $460 \mathrm{MBq}$ com filtro.

Após o eletrodo de alumínio ser substituído pelo de grafite, as curvas de extrapolação foram obtidas novamente. Durante as medições para estas curvas, foram adotados os mesmos procedimentos que foram utilizados para a câmara com eletrodo de alumínio, com relação à tensão aplicada à câmara e o número de 
medições e o método de sua obtenção. As curvas de extrapolação, da câmara com eletrodo de grafite, podem ser observadas na Figura 4.4. No caso das Figuras 4.4-b, c e d, as incertezas calculadas foram pequenas e, sendo assim, as barras de erro se tornaram imperceptíveis.

Para a realização destas curvas, foi levada em consideração a profundidade nula real da câmara com o eletrodo de grafite. A obtenção desta profundidade será apresentada no próximo item.

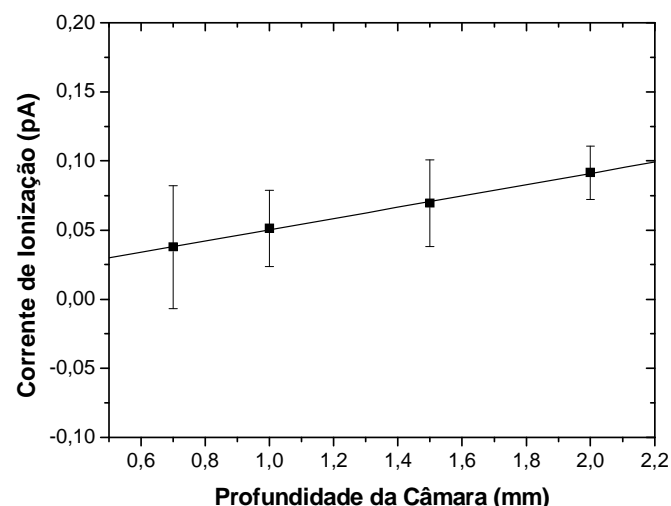

(a)

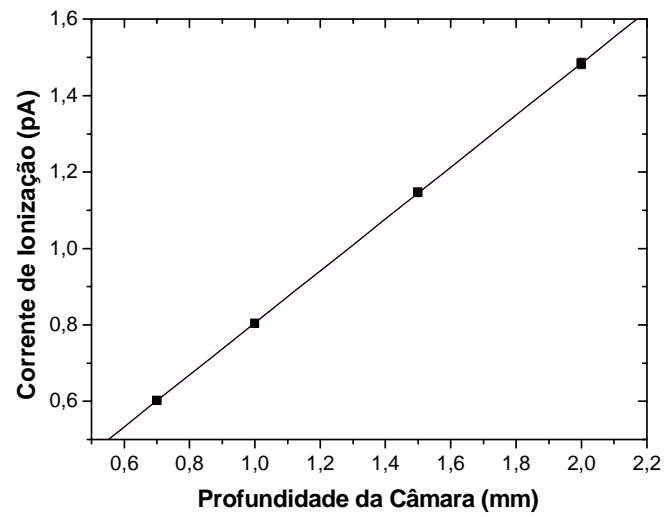

(c)

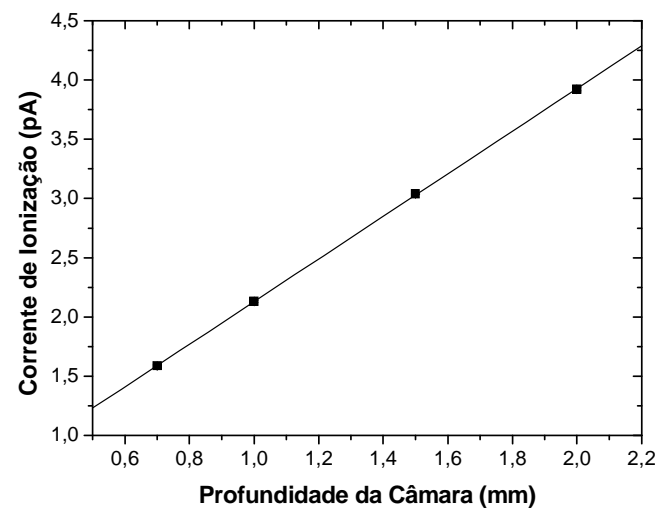

(b)

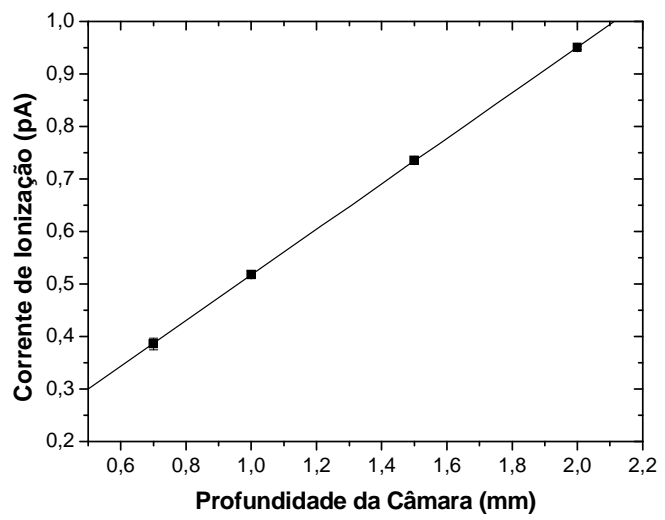

(d)

Figura 4.4: Curvas de extrapolação obtidas com a câmara de extrapolação com eletrodo coletor de grafite para as fontes de ${ }^{90} \mathrm{Sr}+{ }^{90} \mathrm{Y}$ de (a) $74 \mathrm{MBq}$ com filtro, (b) $1850 \mathrm{MBq}$ sem filtro, (c) $460 \mathrm{MBq}$ sem filtro, e (d) $460 \mathrm{MBq}$ com filtro. 
Comparando-se os coeficientes angulares das curvas de extrapolação obtidas com os eletrodos de alumínio e de grafite, para as três fontes, pode-se concluir que todas as curvas até cerca de $2,5 \mathrm{~mm}$ de profundidade da câmara apresentaram comportamentos lineares, e o coeficiente de correlação, $r$, apresentou-se superior a 0,9992 em todos os casos. Pode-se verificar ainda que a câmara com eletrodo coletor de grafite é menos sensível do que a câmara com eletrodo coletor de alumínio, embora o eletrodo coletor de grafite seja o recomendado para deteç̧ão de radiação beta.

\subsubsection{Profundidade Nula Real}

Após a troca do eletrodo coletor de alumínio pelo de grafite, houve a necessidade da determinação da profundidade nula real da câmara de extrapolação PTW. Este valor representa a menor distância possível entre os eletrodos da câmara de extrapolação para que eles não encostem e, sendo assim, sua finalidade é ajustar, com maior precisão, a profundidade da câmara para as curvas de extrapolação.

Para a determinação da profundidade nula real, as medições foram realizadas da mesma forma que para uma curva de extrapolação. Foi obtido um gráfico da corrente medida em função da profundidade da câmara, que variou de $0,7 \mathrm{~mm}$ a $2,0 \mathrm{~mm}$, para as duas polaridades de tensão. Por meio de um ajuste linear para cada uma das retas (de cada polaridade), pôde-se obter a profundidade nula real da câmara, que corresponde ao valor onde as retas obtidas para ambas as polaridades se cruzam. Para a câmara de extrapolação PTW, o valor médio da profundidade nula real obtido foi de - 0,18 mm. Pode-se observar, na Figura 4.5, os resultados obtidos, onde a profundidade nula real é indicada por $\mathrm{d}$. 


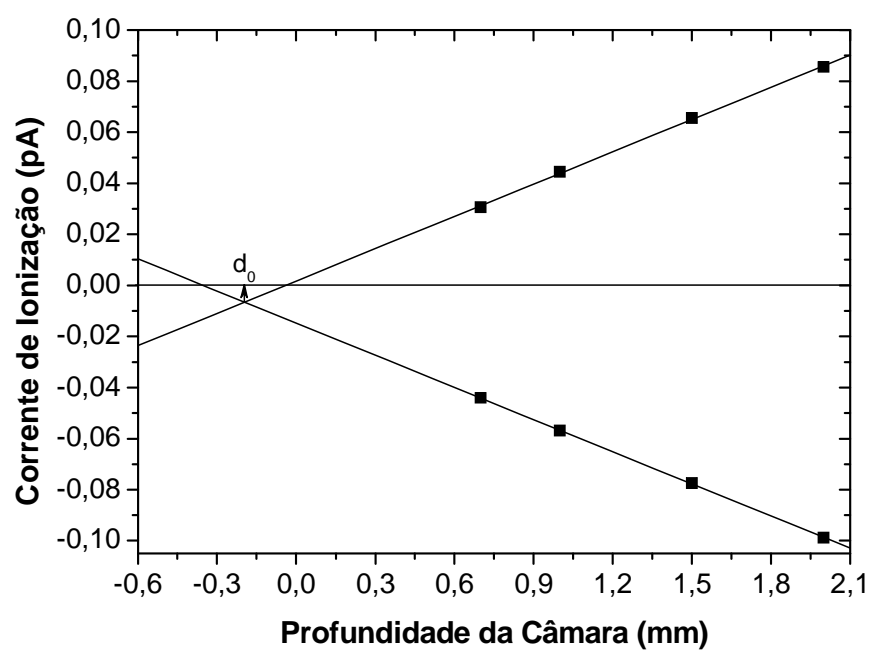

Figura 4.5: Determinação da profundidade nula real da câmara de extrapolação PTW (eletrodo coletor de grafite).

\subsubsection{Calibração da Câmara de Extrapolação PTW utilizando os Sistemas BSS1 e BSS2}

A câmara de extrapolação foi calibrada utilizando os dois sistemas padrões secundários, BSS1 e BSS2, a partir das curvas de extrapolação obtidas anteriormente (Figuras 4.3, 4.4 e 4.5), para cada fonte e tipo de eletrodo coletor.

O fator de calibração da câmara de extrapolação, $F$, para cada fonte, foi obtido pela razão entre a taxa de dose absorvida da fonte, $\dot{D}$ (fornecida no certificado de calibração do PTB) e o coeficiente angular da reta da curva de extrapolação, B , conforme mostra a Equação 3.1 (CALDAS, 1980):

$$
F=\frac{\dot{D}}{B}
$$

Os fatores de calibração para a câmara de extrapolação PTW podem ser observados na Tabela 4.1. 
Tabela 4.1: Fatores de calibração da câmara de extrapolação PTW, para as fontes de ${ }^{90} \mathrm{Sr}+{ }^{90} \mathrm{Y}$, obtidos à distância de $30 \mathrm{~cm}$.

\begin{tabular}{|c|c|c|c|c|}
\hline $\begin{array}{c}\text { Eletrodo } \\
\text { Coletor } \\
\text { da Câmara } \\
\end{array}$ & $\begin{array}{c}\text { Atividade } \\
\text { da Fonte } \\
(\mathrm{MBq})\end{array}$ & Filtro & $\begin{array}{c}\text { Sistema Padrão } \\
\text { Secundário } \\
\text { BSS1/2 }\end{array}$ & $\begin{array}{c}\text { Fator de Calibração } F_{C} \\
(\mu \mathrm{Gy} / \mathrm{s} \cdot \mathrm{mm} / \mathrm{pA})\end{array}$ \\
\hline \multirow{4}{*}{ Alumínio } & $74 \mathrm{MBq}$ & Sim & 1 & $17,95 \pm 0,44$ \\
\hline & $1850 \mathrm{MBq}$ & Não & 1 & $19,90 \pm 0,30$ \\
\hline & $460 \mathrm{MBq}$ & Sim & 2 & $20,05 \pm 0,43$ \\
\hline & $460 \mathrm{MBq}$ & Não & 2 & $16,87 \pm 0,31$ \\
\hline \multirow{4}{*}{ Grafite } & $74 \mathrm{MBq}$ & Sim & 1 & $21,66 \pm 0,53$ \\
\hline & $1850 \mathrm{MBq}$ & Não & 1 & $20,30 \pm 0,25$ \\
\hline & $460 \mathrm{MBq}$ & Sim & 2 & $21,93 \pm 0,48$ \\
\hline & $460 \mathrm{MBq}$ & Não & 2 & $22,33 \pm 0,38$ \\
\hline
\end{tabular}

Os resultados desta tabela mostram que os fatores obtidos para a câmara de extrapolação PTW podem ser analisados de duas formas: com relação ao sistema padrão secundário beta (BSS1 e BSS2) e com ou sem a utilização de filtro, para a câmara tanto com eletrodo coletor de alumínio como para eletrodo coletor de grafite. As incertezas associadas aos fatores de calibração foram obtidas levandose em conta as incertezas do tipo A, ou seja, as relacionadas com a série de medições obtidas durante o experimento (erro estatístico).

Os fatores de calibração obtidos para o sistema padrão secundário BSS1 e a câmara com eletrodo coletor de alumínio apresentaram uma diferença de 10,8\%, enquanto que para o sistema BSS2, com o mesmo eletrodo, a diferença foi de 18,9\%. Com relação aos resultados da câmara com eletrodo coletor de grafite, a diferença entre os fatores de calibração foi de 6,7\% para o sistema BSS1 e de 1,8\% para o sistema BSS2.

Analisando-se os resultados sob o ponto de vista de uso de filtro uniformizador de campo, a diferença obtida entre as fontes de $74 \mathrm{MBq}$ e $460 \mathrm{MBq}$ com filtro, para o eletrodo coletor de alumínio, foi de $11,7 \%$, e para as fontes de $460 \mathrm{MBq}$ sem filtro e $1850 \mathrm{MBq}$, a diferença foi de 18,0\%. Para o eletrodo coletor de grafite, a diferença entre as fontes que utilizaram filtro foi de $1,2 \%$, e para as que não utilizaram filtro, foi de 10,0\%. 
Assim, pode-se observar, também, que os valores obtidos com o eletrodo coletor de alumínio apresentam uma discrepância maior, pois o desvio padrão relativo obtido entre os fatores de calibração para este eletrodo foi de 8,3\%, enquanto que para o eletrodo coletor de grafite, foi de 4,1\%. Isto se deve provavelmente ao fato deste tipo de eletrodo coletor (alumínio) não ser recomendado para detectar radiação beta.

\subsubsection{Mini-Câmara de Extrapolação de Janela Plana}

A mini-câmara de extrapolação foi utilizada no objetivo principal deste trabalho: a comparação de várias técnicas de calibração de aplicadores dermatológicos.

Para a comparação dos métodos, foram obtidas inicialmente curvas de extrapolação para todos os aplicadores.

A mini-câmara de extrapolação também foi utilizada para a obtenção das curvas de distribuição de dose em profundidade na água, para cada um dos aplicadores. Este estudo foi realizado por fazer parte das recomendações internacionais de calibração e dosimetria de fontes radioativas utilizadas em braquiterapia (IAEA, 2002; ICRU, 2004).

\subsubsection{Corrente de Fuga Pré-Irradiação}

Para a mini-câmara de extrapolação de janela plana, a corrente de fuga préirradiação foi avaliada antes de cada conjunto de medições. Assim, a carga foi coletada sem a presença de fonte de radiação durante 20 minutos. Todos os resultados obtidos apresentaram-se inferiores ao limite recomendado pela norma IEC 60731 (1997), de 0,5\% do maior valor das medições. 


\subsubsection{Testes de Repetitividade e Reprodutibilidade}

O teste de repetitividade foi realizado utilizando-se uma fonte de controle de ${ }^{90} \mathrm{Sr}+{ }^{90} \mathrm{Y}$ de atividade nominal de $33 \mathrm{MBq}$ (1994), da PTW, tipo 8921, posicionada sobre a janela de entrada da mini-câmara com o auxílio de um suporte de acrílico especialmente desenvolvida para esta mini-câmara de extrapolação, conforme pode ser observado na Figura 4.6.

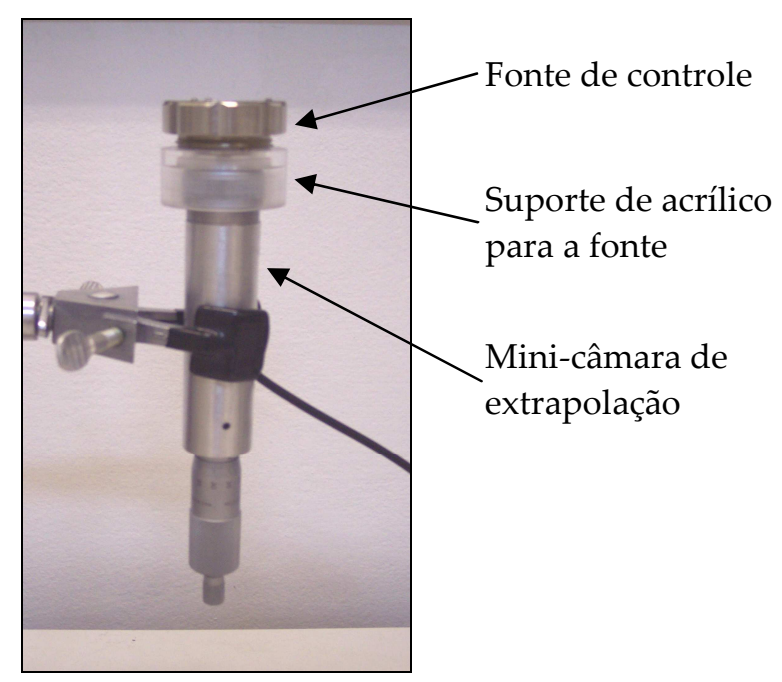

Figura 4.6: Arranjo utilizado durante o teste de estabilidade a curto prazo com a mini-câmara de extrapolação de janela plana, a suporte de acrílico e a fonte de controle.

As medições foram realizadas tomando-se 10 leituras de carga para cada polaridade. A profundidade da mini-câmara foi mantida fixa em 1,0 mm, levando-se em conta a profundidade nula real de 0,39 $\mathrm{mm}$, determinada anteriormente por Oliveira (2005). Cada medição foi realizada durante $120 \mathrm{~s}$ e a tensão aplicada à mini-câmara foi de $\pm 50 \mathrm{~V}$.

A variação máxima da resposta da mini-câmara de extrapolação apresentouse inferior a 0,28\%. De acordo com a norma IEC 60731 (1997), o limite de aceitação para o teste de repetitividade, quando realizado utilizando-se uma fonte de controle, é de $0,3 \%$. 
O teste de reprodutibilidade da resposta da mini-câmara de extrapolação, consistiu em testes periódicos de repetitividade. Para tal, foi utilizada a mesma fonte de controle de ${ }^{90} \mathrm{Sr}+{ }^{90} \mathrm{Y}$.

Para este teste de reprodutibilidade foram realizadas cada vez 10 medições de carga para cada polaridade, sob as mesmas condições que para o teste de repetitividade, com relação à profundidade da mini-câmara, à profundidade nula real, o tempo de coleta da medição e a tensão aplicada à mini-câmara. Os resultados obtidos neste teste podem ser observados na Figura 4.7.

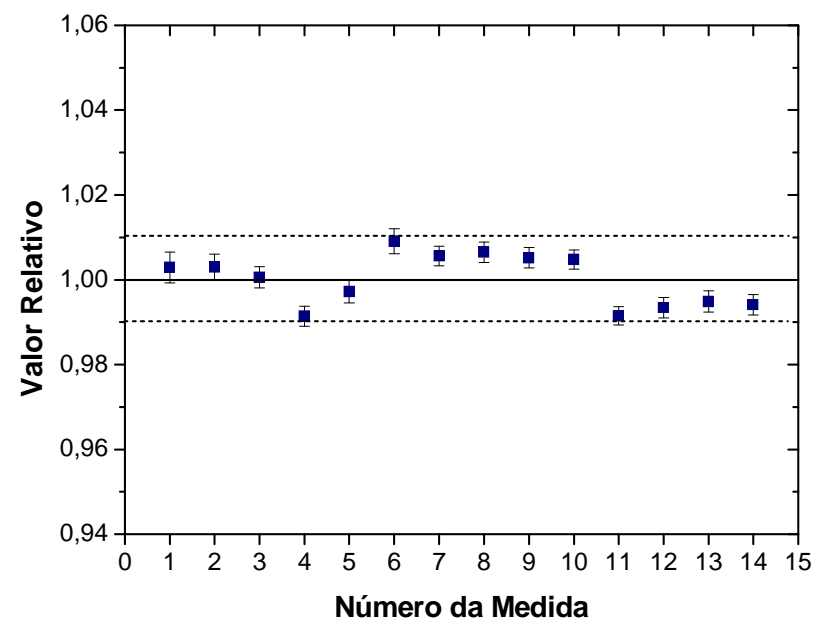

Figura 4.7: Teste de reprodutibilidade da resposta da mini-câmara de extrapolação desenvolvida no LCI, para uma fonte de controle de ${ }^{90} \mathrm{Sr}+{ }^{90} \mathrm{Y}$.

A variação máxima da resposta da mini-câmara obtida nas medições deste teste foi de $0,7 \%$.

\subsubsection{Curvas de Extrapolação com Aplicadores Dermatológicos e Oftálmicos}

As curvas de extrapolação da mini-câmara de extrapolação de janela plana foram obtidas para os aplicadores dermatológicos de ${ }^{90} \mathrm{Sr}+{ }^{90} \mathrm{Y}$ : NIST, A, B, C, D, E e F.

Durante todas as medições para as curvas de extrapolação com a minicâmara de extrapolação, foi levada em consideração a profundidade nula real de 
0,40 mm, determinada em trabalho anterior por Oliveira (2005) e a distância intereletródica foi de $0,7,0,8,0,9$ e 1,0 mm. Todas as curvas de extrapolação dos aplicadores foram obtidas à distância nula entre a mini-câmara e o aplicador, com exceção do aplicador $C$, para o qual (além de distância nula) também foi utilizada a distância de 1,0 mm. Além disso, como o aplicador $C$ possui uma capa protetora e uma outra capa com um orifício central, 3 curvas de extrapolação foram obtidas neste caso: sem capa protetora, com capa protetora e com capa contendo orifício. O arranjo utilizado para a elaboração das curvas de extrapolação pode ser observado na Figura 4.8.

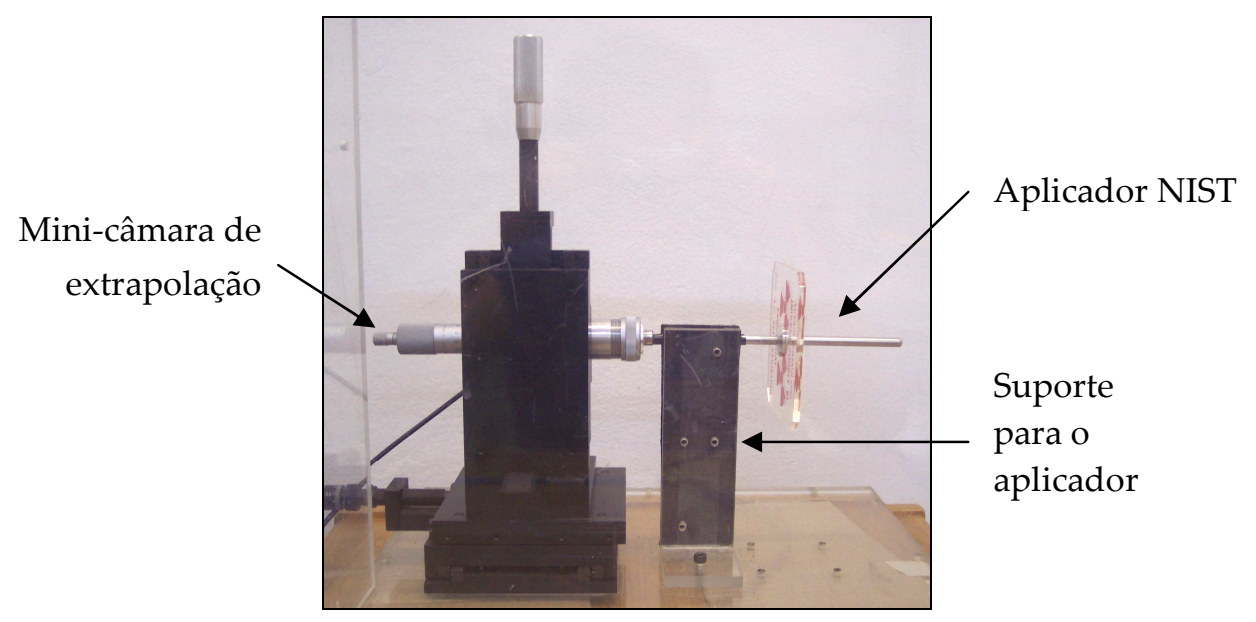

Figura 4.8: Arranjo utilizado durante as medições de curvas de extrapolação, onde se pode observar o aplicador posicionado à frente da minicâmara de extrapolação de janela plana.

Apesar da taxa de dose absorvida na água ter seu ponto de referência a $1,0 \mathrm{~mm}$ da superfície da fonte em relação ao seu centro, a calibração dos aplicadores foi realizada adotando-se a taxa de dose absorvida superficial a $0 \mathrm{~mm}$, segundo recomendações de Soares (2009), pois as medições a 1,0 mm são difíceis de serem realizadas acuradamente. Esta dificuldade existe já que as medições devem ser feitas em meio equivalente à água e o material que mais se assemelha à água é o poliestireno; entretanto, é difícil fabricar uma placa de poliestireno de 1,0 $\mathrm{mm}$, pois este material nesta espessura facilmente se quebra. Infelizmente, nem todos os certificados apresentaram a informação referente à calibração ter sido feita em meio equivalente à água ou no ar, mas apenas os aplicadores NIST, A e D. O aplicador NIST apresenta taxa de dose absorvida na água à distância nula, e os 
aplicadores A e D trazem em seu certificado a especificação da taxa de dose absorvida superficial, o que permite supor que tenha sido determinada no ar.

No procedimento de elaboração das curvas de extrapolação de todos os aplicadores, foram realizadas 5 leituras de carga para cada polaridade, e o tempo de coleta da carga, para cada medição, foi de 60 s. A tensão aplicada à minicâmara durante todas as medições foi de $\pm 50 \mathrm{~V}$, dependendo da polaridade. A mini-câmara foi fixada em um suporte de acrílico, e o aplicador foi, então, posicionado à sua frente, de maneira que o arranjo fosse horizontal. Nas Figuras $4.9,4.10$ e 4.11 podem ser observadas as curvas de extrapolação para os aplicadores.

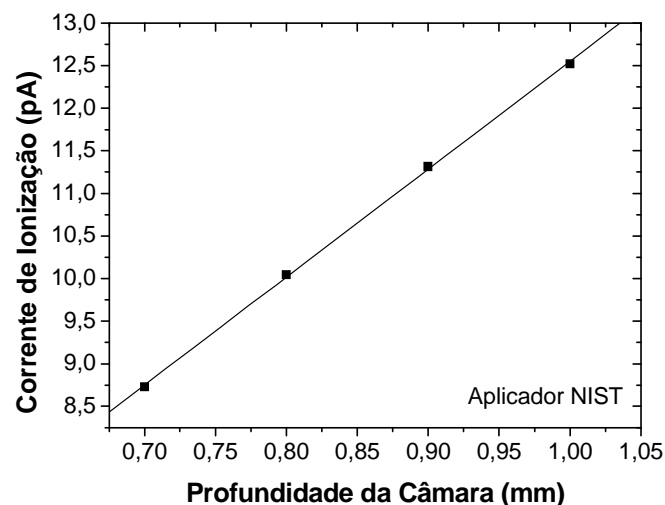

(a)

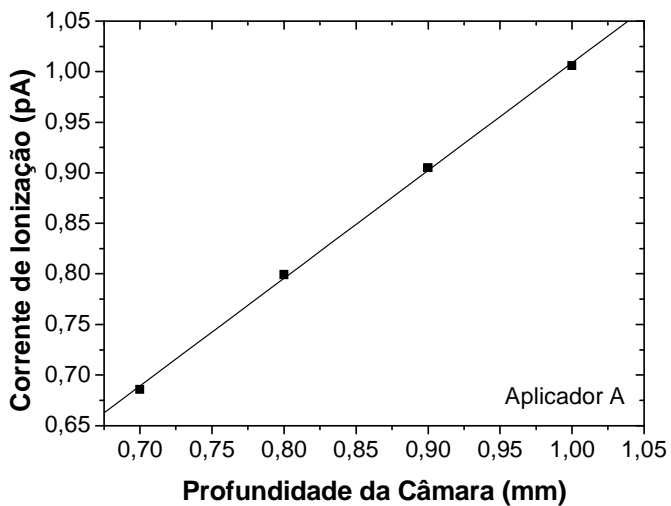

(b)

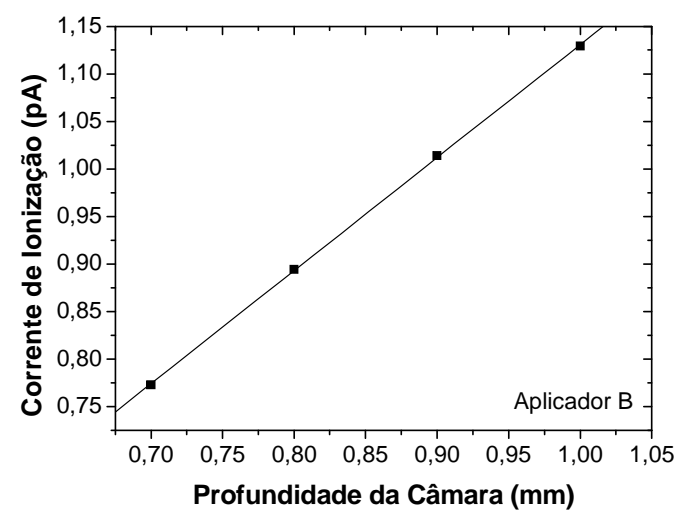

(c)

Figura 4.9: Curvas de extrapolação obtidas com a mini-câmara para as fontes de ${ }^{90} \mathrm{Sr}+{ }^{90} \mathrm{Y}$ : (a) aplicador NIST, (b) aplicador A e (c) aplicador B. 


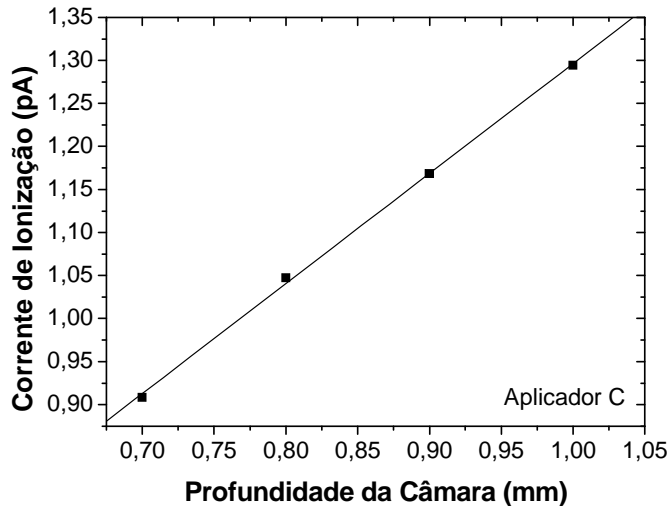

(a)

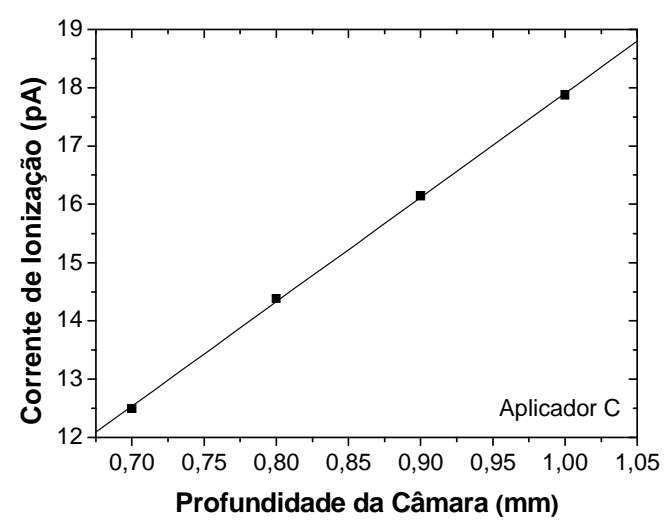

(c)

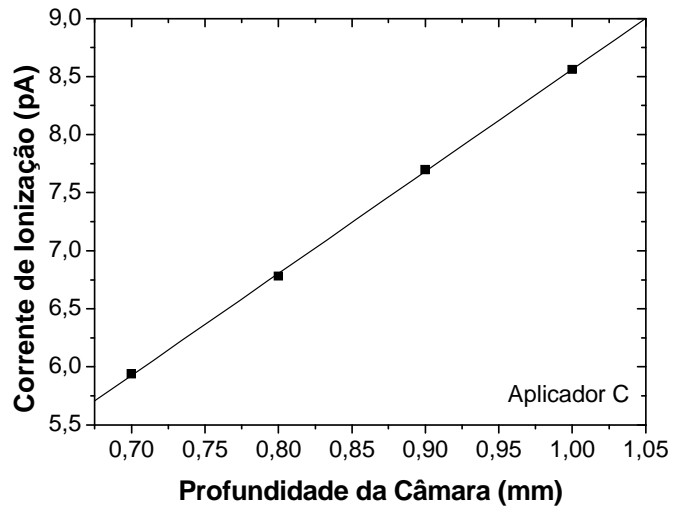

(b)

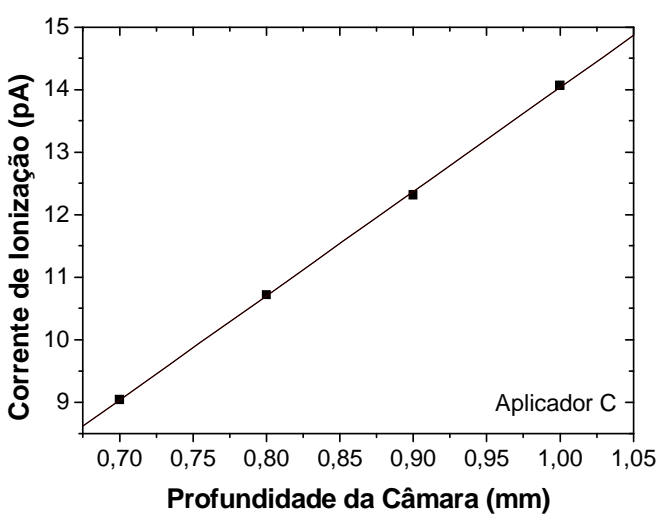

(d)

Figura 4.10: Curvas de extrapolação obtidas com a mini-câmara para o aplicador $\mathrm{C}$ de ${ }^{90} \mathrm{Sr}+{ }^{90} \mathrm{Y}:$ (a) aplicador $\mathrm{C}$ a $0 \mathrm{~mm}$ e com capa protetora, (b) aplicador C a $0 \mathrm{~mm}$ e com capa com orifício, (c) aplicador C a $0 \mathrm{~mm}$ e sem capa protetora e $(\mathrm{d})$ aplicador $\mathrm{C}$ a $1,0 \mathrm{~mm}$ e sem capa protetora. 


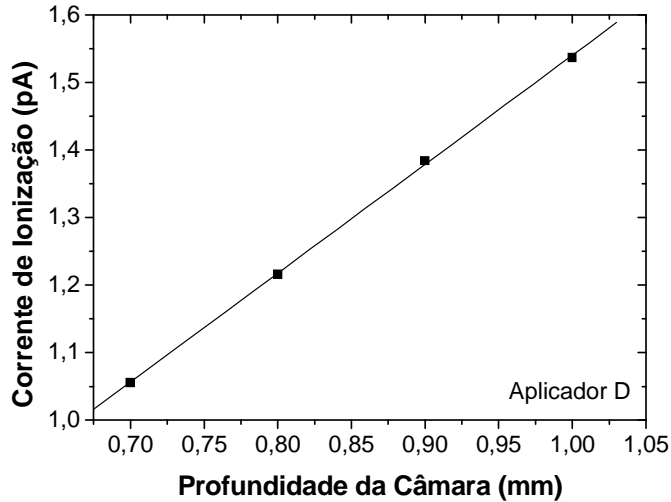

(a)

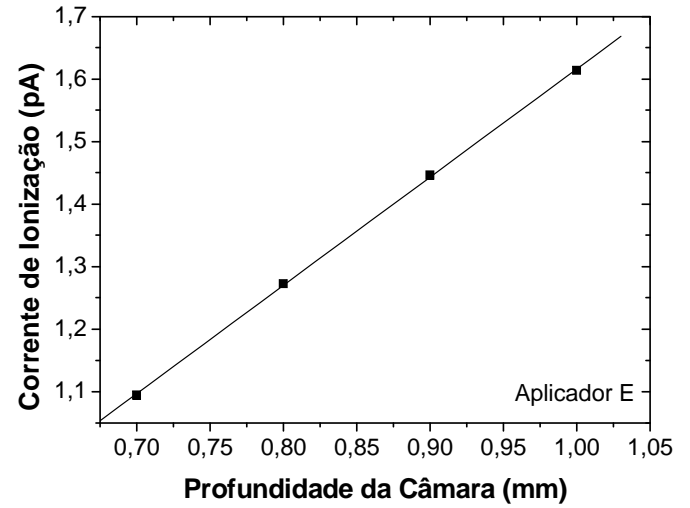

(b)

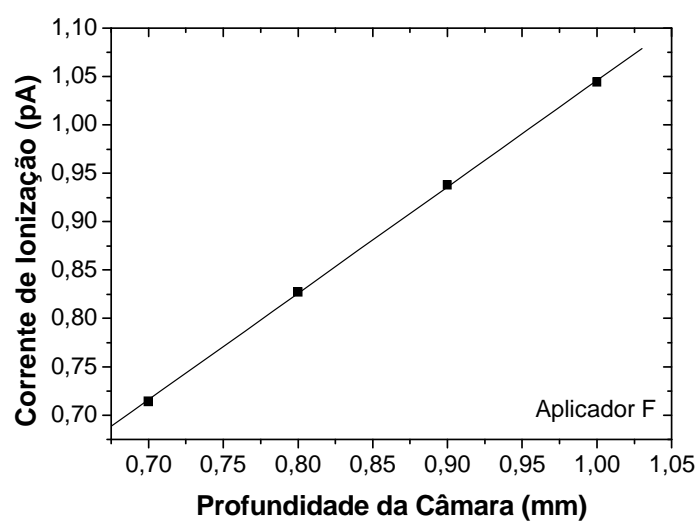

(c)

Figura 4.11: Curvas de extrapolação obtidas com a mini-câmara para as fontes de ${ }^{90} \mathrm{Sr}+{ }^{90} \mathrm{Y}$ : (a) aplicador D, (b) aplicador E e (c) aplicador F.

É possível notar que todas as curvas apresentaram comportamento semelhante e linear, pois o coeficiente de correlação, r, apresentou-se maior que 0,9995 em todos os casos. 


\subsubsection{Calibração e Dosimetria dos Aplicadores Clínicos utilizando diferentes Métodos}

A calibração dos aplicadores clínicos de ${ }^{90} \mathrm{Sr}+{ }^{90} \mathrm{Y}$ foi realizada por meio dos seguintes métodos:

1) Método 1 - utilizando o aplicador calibrado no laboratório padrão primário do National Institute of Standards and Technology, NIST, como referência;

2) Método 2 - utilizando um aplicador fabricado e calibrado pela Amersham, denominado aplicador A, como referência;

3) Método 3 - utilizando a mini-câmara de extrapolação como sistema absoluto e

4) Método 4 - utilizando a técnica de dosimetria termoluminescente.

\subsubsection{Calibração dos Aplicadores utilizando o Aplicador NIST como Referência (Método 1)}

O Método 1 representa a obtenção das curvas de extrapolação dos aplicadores por meio da calibração de cada um dos aplicadores, utilizando o aplicador NIST como padrão. Para isso, utilizando-se a Equação 4.1, ou seja, o coeficiente angular da curva de extrapolação com aplicador NIST e a taxa de dose absorvida fornecida pelo certificado, para este mesmo aplicador, pôde-se obter o fator de calibração da mini-câmara de extrapolação de janela plana.

Utilizando-se a Equação 4.1, o fator de calibração obtido para o aplicador NIST foi aplicado juntamente com o coeficiente angular da curva de extrapolação para cada aplicador fornecendo, então, a taxa de dose absorvida para cada aplicador.

Os resultados obtidos das taxas de dose absorvida dos aplicadores, ou seja, a calibração dos aplicadores em relação ao aplicador NIST, estão apresentados na Tabela 4.2. 
Tabela 4.2: Taxas de dose absorvida às distâncias de 0 e 1,0 mm dos aplicadores, utilizando o Método 1.

\begin{tabular}{ccc}
\hline $\begin{array}{c}\text { Distância } \\
(\mathbf{m m})\end{array}$ & Aplicador & $\begin{array}{c}\text { Taxa de dose } \\
\text { absorvida } \\
\text { (Gy/s) } \\
\text { Método 1 }\end{array}$ \\
\hline 0 & $\mathrm{~A}$ & $0,0295 \pm 0,0036$ \\
\hline 0 & $\mathrm{~B}$ & $0,0329 \pm 0,0040$ \\
\hline 0 & $\mathrm{C}_{1}$ & $0,4953 \pm 0,0587$ \\
\hline 0 & $\mathrm{C}_{1}$ & $0,4773 \pm 0,0587$ \\
\hline 1 & $\mathrm{C}_{1 \mathrm{~A}}$ & $0,3854 \pm 0,0472$ \\
\hline 1 & $\mathrm{C}_{1 \mathrm{~A}}$ & $0,3742 \pm 0,0461$ \\
\hline 0 & $\mathrm{C}_{2}$ & $0,3045 \pm 0,0375$ \\
\hline 0 & $\mathrm{C}_{2}$ & $0,2431 \pm 0,0298$ \\
\hline
\end{tabular}

\begin{tabular}{ccc}
\hline $\begin{array}{c}\text { Distância } \\
(\mathbf{m m})\end{array}$ & Aplicador & $\begin{array}{c}\text { Taxa de dose } \\
\text { absorvida } \\
\text { (Gy/s) } \\
\text { Método 1 }\end{array}$ \\
\hline 0 & $\mathrm{C}_{3}$ & $0,0354 \pm 0,0044$ \\
\hline 0 & $\mathrm{D}$ & $0,0446 \pm 0,0055$ \\
\hline 0 & $\mathrm{D}$ & $0,0471 \pm 0,0059$ \\
\hline 0 & $\mathrm{E}$ & $0,0511 \pm 0,0065$ \\
\hline 0 & $\mathrm{E}$ & $0,0479 \pm 0,0059$ \\
\hline 0 & $\mathrm{~F}$ & $0,0302 \pm 0,0037$ \\
\hline 0 & $\mathrm{~F}$ & $0,0304 \pm 0,0037$ \\
\hline
\end{tabular}

onde:

- $\mathrm{C}_{1}$ - aplicador sem capa e medições a $0 \mathrm{~mm}$;

- $\mathrm{C}_{1 \mathrm{~A}}$ - aplicador sem capa e medições a 1,0 mm;

- $\mathrm{C}_{2}$ - aplicador com a capa com orifício;

- $\mathrm{C}_{3}$ - aplicador com a capa protetora.

O estudo das incertezas de cada uma das taxas de dose absorvida, obtidas por meio do Método 1, levou em conta incertezas relativas, como a do aplicador NIST (incerteza expandida igual a 12,0\%), do fator de calibração obtido com este aplicador e do coeficiente angular de cada curva de extrapolação. Os valores obtidos de incerteza se apresentaram entre $11,8 \%$ e $13,3 \%$, para um fator de abrangência, k, igual a 2 .

No caso dos aplicadores C, D, E e F, as medições foram repetidas em todos os métodos, porque estas fontes provêm de clínicas e, por este motivo, resolveu-se verificar a reprodutibilidade destas medições. 


\subsubsection{Calibração dos Aplicadores utilizando o Aplicador A como Referência} (Método 2)

O Método 2 foi realizado em conformidade com os mesmos procedimentos adotados para o Método 1. A diferença entre os Métodos 1 e 2 baseia-se no fato de que no segundo método foi utilizado o aplicador A como referência, enquanto no primeiro método foi utilizado o aplicador NIST. Na Figura 4.12 pode-se verificar o arranjo utilizado neste método.

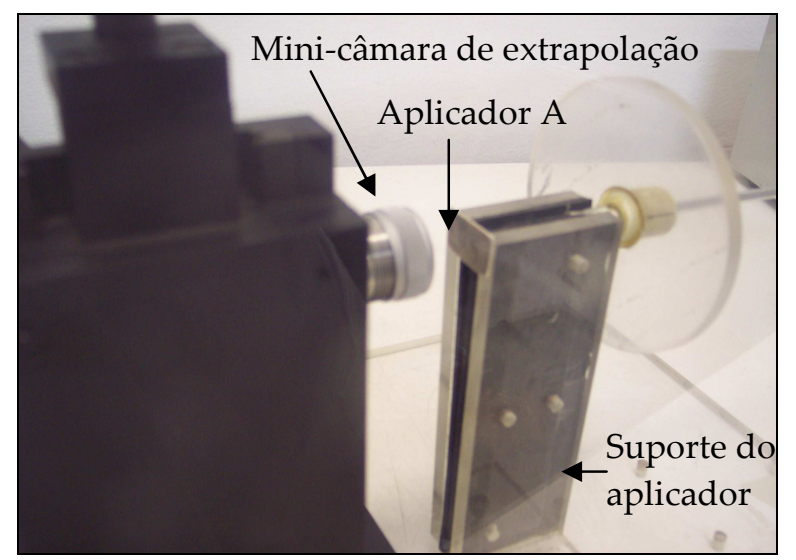

Figura 4.12: Arranjo experimental utilizado no Método 2.

Neste método de calibração, foi determinado um fator de calibração para a mini-câmara de extrapolação para o aplicador A por meio da Equação 4.1, isto é, a razão entre a taxa de dose absorvida deste aplicador dada pelo seu certificado de calibração e corrigida para a data da medição, e o coeficiente angular da curva de extrapolação obtida com o aplicador A. Adotando-se novamente a Equação 4.1 e multiplicando-se o fator de calibração deste aplicador pelo coeficiente angular obtido da curva de extrapolação com cada aplicador, foi obtida a taxa de dose absorvida para cada um dos aplicadores, que mais uma vez foi comparada com a taxa de dose fornecida pelo certificado e corrigida para a data atual.

Os resultados das taxas de dose absorvida obtidas em relação ao aplicador A, podem ser observados na Tabela 4.3. 
Tabela 4.3: Taxas de dose absorvida às distâncias de 0 e 1,0 mm dos aplicadores, utilizando o Método 2.

\begin{tabular}{ccc}
\hline $\begin{array}{c}\text { Distância } \\
(\mathbf{m m})\end{array}$ & Aplicador & $\begin{array}{c}\text { Taxa de dose } \\
\text { absorvida } \\
\text { (Gy/s) } \\
\text { Método 2 }\end{array}$ \\
\hline 0 & NIST & $0,2519 \pm 0,0510$ \\
\hline 0 & $\mathrm{~B}$ & $0,0236 \pm 0,0048$ \\
\hline 0 & $\mathrm{C}_{1}$ & $0,3426 \pm 0,0694$ \\
\hline 0 & $\mathrm{C}_{1}$ & $0,3433 \pm 0,0695$ \\
\hline 1 & $\mathrm{C}_{1 \mathrm{~A}}$ & $0,2772 \pm 0,0560$ \\
\hline 1 & $\mathrm{C}_{1 \mathrm{~A}}$ & $0,2691 \pm 0,0545$ \\
\hline 0 & $\mathrm{C}_{2}$ & $0,2190 \pm 0,0443$ \\
\hline 0 & $\mathrm{C}_{2}$ & $0,1749 \pm 0,0354$ \\
\hline
\end{tabular}

\begin{tabular}{ccc}
\hline $\begin{array}{c}\text { Distância } \\
(\mathbf{m m})\end{array}$ & Aplicador & $\begin{array}{c}\text { Taxa de dose } \\
\text { absorvida } \\
\text { (Gy/s) } \\
\text { Método 2 }\end{array}$ \\
\hline 0 & $\mathrm{C}_{3}$ & $0,0254 \pm 0,0052$ \\
\hline 0 & $\mathrm{D}$ & $0,0321 \pm 0,0065$ \\
\hline 0 & $\mathrm{D}$ & $0,0339 \pm 0,0069$ \\
\hline 0 & $\mathrm{E}$ & $0,0368 \pm 0,0076$ \\
\hline 0 & $\mathrm{E}$ & $0,0345 \pm 0,0070$ \\
\hline 0 & $\mathrm{~F}$ & $0,0217 \pm 0,0044$ \\
\hline 0 & $\mathrm{~F}$ & $0,0219 \pm 0,0044$ \\
\hline
\end{tabular}

O cálculo das incertezas de cada uma das taxas de dose absorvida, obtidas por meio do Método 2, foi realizado da mesma maneira que para o método anterior, ou seja, levou em conta as incertezas relativas do aplicador A (incerteza expandida igual a 20,0\%), do fator de calibração obtido para este aplicador e do coeficiente angular de cada curva de extrapolação. Os valores obtidos de incerteza apresentaram-se entre $20,2 \%$ e $20,9 \%$.

\subsubsection{Calibração dos Aplicadores utilizando a Mini-Câmara de Extrapolação como Sistema de Referência Absoluta (Método 3)}

O Método 3 consistiu na calibração dos aplicadores clínicos sem a utilização de nenhuma outra fonte como referência, mas apenas a mini-câmara de extrapolação de janela plana, de maneira absoluta. Para isso, aplicando-se o coeficiente angular, obtido por meio das curvas de extrapolação apresentadas nas Figuras 4.10, 4.11 e 4.12, diretamente na Equação 2.17 (De ALMEIDA e col., 2000), já apresentada no item 2.4.3, tornou-se possível a determinação das taxas de dose absorvida para cada aplicador. A Tabela 4.4 apresenta todos os valores das constantes utilizados nesta Equação, durante este trabalho. 
Tabela 4.4: Valores das constantes utilizadas na determinação da taxa de dose absorvida, utilizando-se a mini-câmara de extrapolação como sistema de referência absoluto (ISO, 2004).

\begin{tabular}{cc}
\hline Grandezas & Valores \\
\hline$W / e\left(\mathrm{~J} . \mathrm{C}^{-1}\right)$ & $33,830 \pm 0,068$ \\
\hline$S_{a r}^{\text {água }}$ & $1,124 \pm 0,007$ \\
\hline$\rho_{0}\left(\mathrm{~kg} / \mathrm{m}^{3}\right)$ & $1,197 \pm 0,0001$ \\
\hline$a\left(\mathrm{~mm}^{2}\right)$ & 1,68 \\
\hline$k_{\text {retro }}$ & 1,01006 \\
\hline
\end{tabular}

Assim, por meio da Equação 2.17, as taxas de dose absorvida foram obtidas.

Os resultados obtidos por meio deste Método 3 podem ser observados na Tabela 4.5.

Tabela 4.5: Taxas de dose absorvida às distâncias de 0 e 1,0 mm dos aplicadores, utilizando o Método 3.

\begin{tabular}{ccc}
\hline $\begin{array}{c}\text { Distância } \\
(\mathbf{m m})\end{array}$ & Aplicador & $\begin{array}{c}\text { Taxa de dose } \\
\text { absorvida } \\
\text { (Gy/s) } \\
\text { Método 3 }\end{array}$ \\
\hline 0 & NIST & $0,2417 \pm 0,0037$ \\
\hline 0 & $\mathrm{~A}$ & $0,0203 \pm 0,0004$ \\
\hline 0 & $\mathrm{~B}$ & $0,0227 \pm 0,0002$ \\
\hline 0 & $\mathrm{C}_{1}$ & $0,3288 \pm 0,0059$ \\
\hline 0 & $\mathrm{C}_{1}$ & $0,3295 \pm 0,0054$ \\
\hline 1 & $\mathrm{C}_{1 \mathrm{~A}}$ & $0,2660 \pm 0,0034$ \\
\hline 1 & $\mathrm{C}_{1 \mathrm{~A}}$ & $0,2583 \pm 0,0045$ \\
\hline 0 & $\mathrm{C}_{2}$ & $0,2102 \pm 0,0036$ \\
\hline
\end{tabular}

\begin{tabular}{ccc}
\hline $\begin{array}{c}\text { Distância } \\
(\mathbf{m m})\end{array}$ & Aplicador & $\begin{array}{c}\text { Taxa de dose } \\
\text { absorvida } \\
\text { (Gy/s) } \\
\text { Método 3 }\end{array}$ \\
\hline 0 & $\mathrm{C}_{2}$ & $0,1678 \pm 0,0022$ \\
\hline 0 & $\mathrm{C}_{3}$ & $0,0244 \pm 0,0005$ \\
\hline 0 & $\mathrm{D}$ & $0,0308 \pm 0,0004$ \\
\hline 0 & $\mathrm{D}$ & $0,0325 \pm 0,0008$ \\
\hline 0 & $\mathrm{E}$ & $0,0353 \pm 0,0014$ \\
\hline 0 & $\mathrm{E}$ & $0,0331 \pm 0,0004$ \\
\hline 0 & $\mathrm{~F}$ & $0,0208 \pm 0,0003$ \\
\hline 0 & $\mathrm{~F}$ & $0,0210 \pm 0,0003$ \\
\hline
\end{tabular}


A determinação das incertezas de cada uma das taxas de dose absorvida, para os aplicadores clínicos de ${ }^{90} \mathrm{Sr}+{ }^{90} \mathrm{Y}$, obtidas por meio do Método 3, levou em conta as incertezas relativas às medições de corrente de ionização realizadas com a mini-câmara de extrapolação como padrão absoluto, bem como as incertezas associadas às constantes das fórmulas e à determinação dos fatores de correção. As incertezas expandidas $(\mathrm{k}=2)$ obtidas para as taxas de dose absorvida deste método se apresentaram entre $0,7 \%$ e $5,4 \%$.

A comparação entre os diversos métodos será apresentada após os resultados de dosimetria TL.

\subsubsection{Curvas de Dose $x$ Profundidade para os Aplicadores}

De acordo com recomendações (SOARES e col., 2001; IAEA, 2002; ICRU, 2004), as fontes de braquiterapia devem ser especificadas do ponto de vista a se alcançar a rastreabilidade das calibrações. A distribuição de dose em profundidade na água para fontes de radiação beta é definida como uma das grandezas que deve ser levada em conta na calibração e dosimetria de aplicadores clínicos.

A obtenção de curvas de distribuição de dose em profundidade na água (curvas de dose x profundidade) é de importância fundamental em braquiterapia, pois este estudo leva à determinação da dose que o paciente em tratamento deverá receber em determinadas profundidades da pele, no caso, com relação aos aplicadores dermatológicos, ou do olho e órgãos que apresentam a lesão em questão. Além disso, conhecendo-se as curvas de dose x profundidade, é possível determinar também a dose que a região circunvizinha de, por exemplo, a lesão receberá. Com esta informação, o médico saberá como proceder para que doses de radiação desnecessárias não atinjam as regiões sadias ao redor da lesão. Por este motivo, um estudo de dose $x$ profundidade foi realizado para cada aplicador, utilizando-se placas de acrílico de diferentes espessuras entre a mini-câmara de extrapolação e cada aplicador. 
Foram utilizados neste estudo sete placas de acrílico, confeccionadas com espessuras de 1,0 a 5,0 $\mathrm{mm}$; porém, foram oito as profundidades testadas, pois além das sete espessuras também foram feitas medições à distância nula, ou seja, encostando-se o aplicador à janela de entrada da mini-câmara de extrapolação. A Figura 4.13 mostra um arranjo com uma das placas de acrílico entre a mini-câmara e o aplicador.

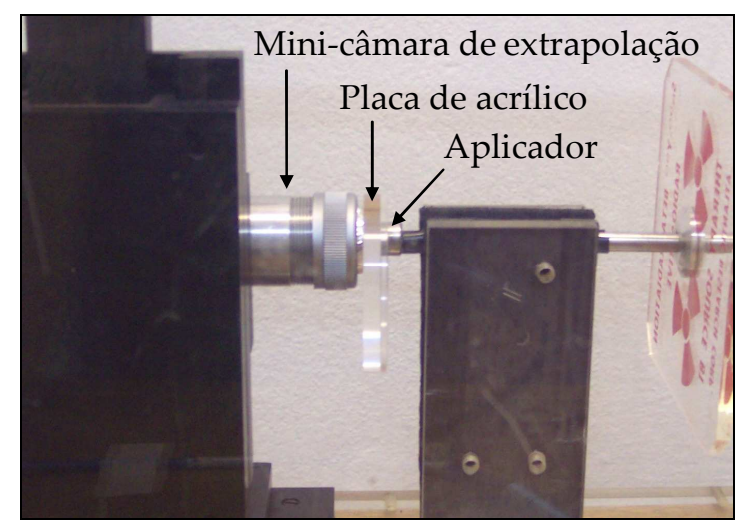

Figura 4.13: Arranjo experimental para o estudo de distribuição de dose em profundidade na água, com a mini-câmara de extrapolação, a placa de acrílico e o aplicador clínico.

Durante estas medições, a profundidade da câmara de extrapolação foi mantida fixa em 1,0 $\mathrm{mm}$. Os resultados obtidos para cada aplicador podem ser observados nas Figuras 4.14 e 4.15. A variação máxima obtida para cada aplicador, nestas medições, foi: 1,2\% (aplicador NIST), 4,6\% (aplicador A), 4,0\% (aplicador B), 0,3\% (aplicador C), 2,7\% (aplicador D), 2,5\% (aplicador E) e 4,4\% (aplicador F). 


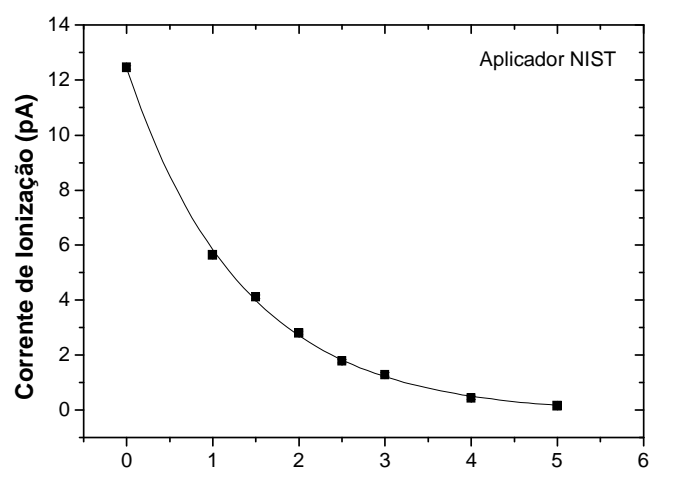

Espessura de Acrílico entre Aplicador e Mini-Câmara (mm)

(a)

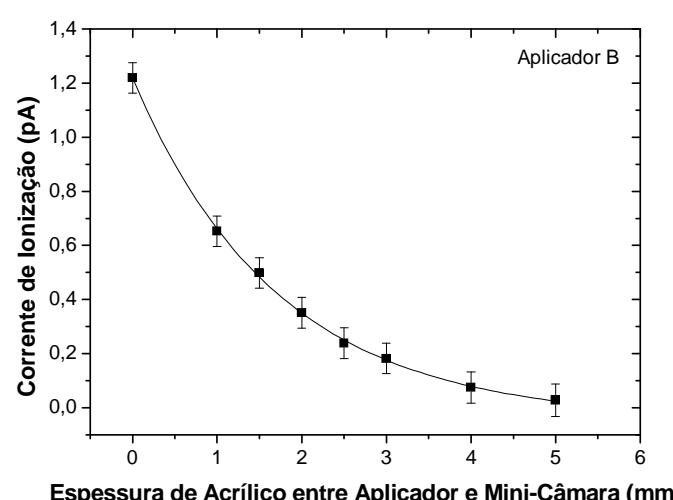

(c)

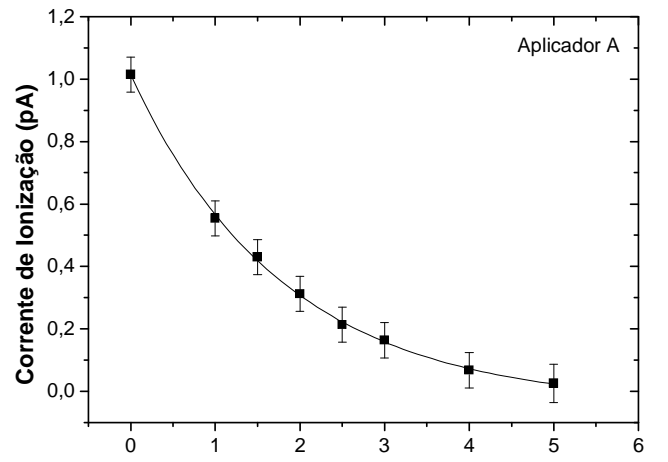

Espessura de Acrílico entre Aplicador e Mini-Câmara (mm)

(b)

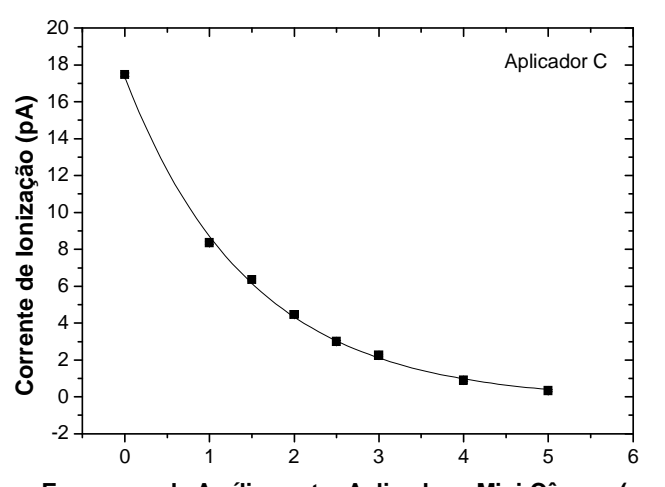

Espessura de Acrílico entre Aplicador e Mini-Câmara (mm)

Figura 4.14: Curvas de distribuição de dose em profundidade na água realizadas com a mini-câmara de extrapolação e os aplicadores: (a) aplicador NIST, (b) aplicador A, (c) aplicador B e (d) aplicador C, variando-se a espessura das placas de acrílico entre a mini-câmara e cada aplicador. 


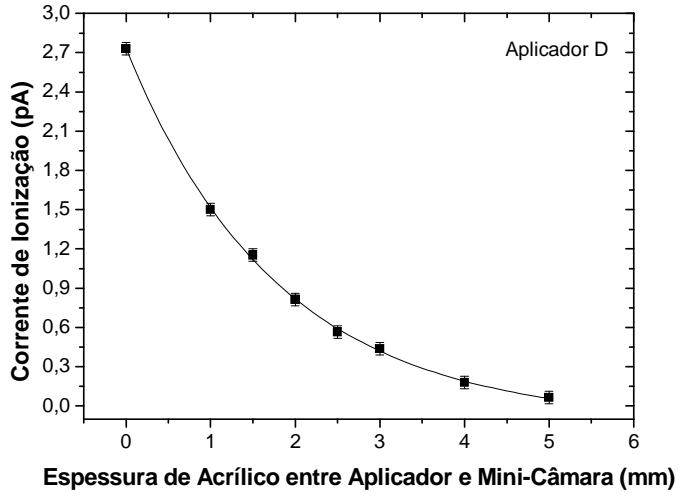

(a)

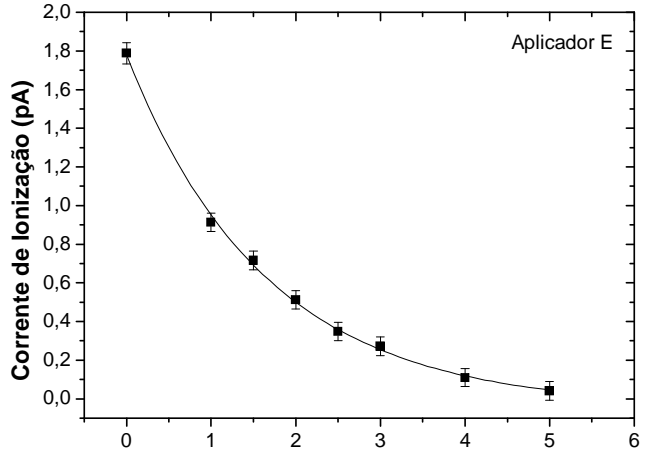

Espessura de Acrílico entre Aplicador e Mini-Câmara (mm)

(b)

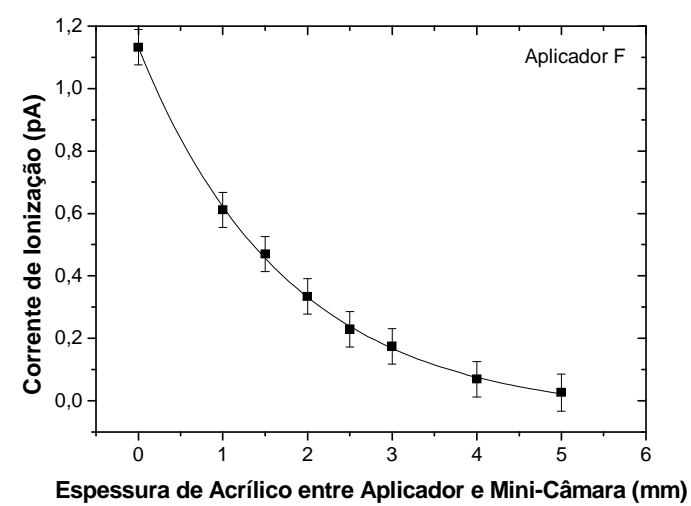

(c)

Figura 4.15: Curvas de distribuição de dose em profundidade na água realizadas com a mini-câmara de extrapolação e os aplicadores: (a) aplicador D, (b) aplicador E e (c) aplicador F, variando-se a espessura das placas de acrílico entre a mini-câmara e cada aplicador.

Estes resultados foram comparados com o resultado padrão para a fonte de ${ }^{90} \mathrm{Sr}+{ }^{90} \mathrm{Y}$ apresentado na norma IAEA (2002). A Figura 4.16 mostra as curvas de dose $\mathrm{x}$ profundidade para todos os aplicadores, com os valores equivalentes à água e normalizados para 1,0 $\mathrm{mm}$. 


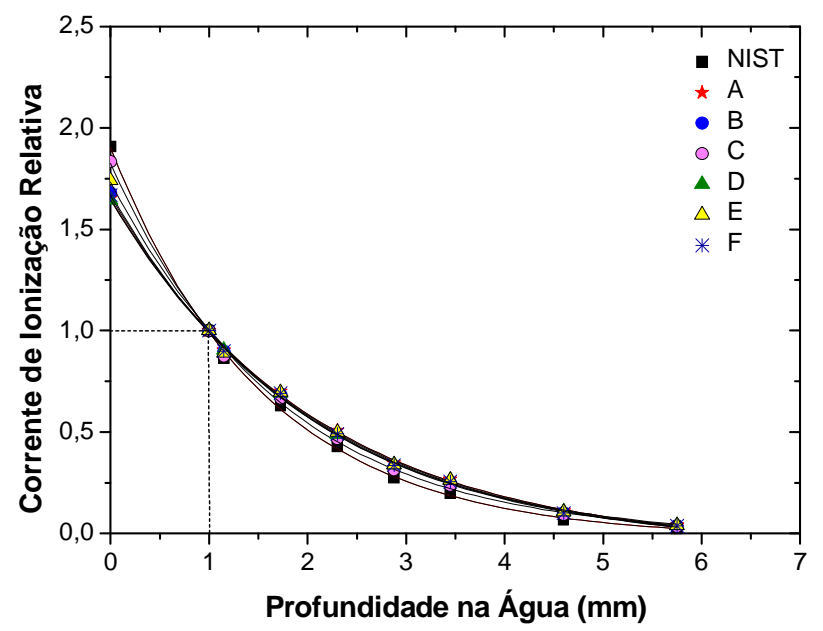

Figura 4.16: Curvas de distribuição de dose em profundidade para os aplicadores de ${ }^{90} \mathrm{Sr}+{ }^{90} \mathrm{Y}$, normalizados para 1,0 $\mathrm{mm}$ e em meio equivalente à água.

Os resultados apresentados foram altamente satisfatórios, pois se assemelham ao resultado obtido com a fonte padrão, apresentado na norma IAEA (2002).

Como a grandeza dosimétrica recomendada para estes aplicadores é a taxa de dose absorvida na água, a conversão faz-se necessária. Assim, as espessuras de acrílico utilizadas durante as medições no ar foram convertidas para espessuras em meio equivalente à água por meio da Equação 3.3:

$$
\rho_{\text {agua }} \cdot d_{\text {agua }}=\rho_{\text {acrílico }} \cdot d_{\text {acrilico }}
$$

onde: -

- $\rho_{\text {agua }}$ é a densidade volumétrica da água $\left(1,0 \mathrm{~g} / \mathrm{cm}^{3}\right)$;

- $d_{\text {agua }}$ é a espessura do material utilizado equivalente à água;

- $\rho_{\text {acrílico }}$ é a densidade volumétrica do acrílico $\left(1,15 \mathrm{c} / \mathrm{cm}^{3}\right)$;

- $d_{\text {acrílico }}$ é a espessura de acrílico utilizada. 
A Tabela 4.6 mostra os resultados obtidos no estudo de dose $\mathrm{x}$ profundidade com cada aplicador, em meio equivalente à água, e com valores normalizados para $1,0 \mathrm{~mm}$.

Pode-se observar que a diferença entre os valores obtidos para cada aplicador e o fornecido pela norma, nas profundidades de 0 a 1,0 mm, foram semelhantes, apresentando uma variação entre 0,1\% (aplicador C) e 8,6\% (aplicador NIST). Esta semelhança é de grande importância no que se refere à dosimetria dos aplicadores, uma vez que este estudo representa um dos parâmetros da calibração de aplicadores clínicos. 
Tabela 4.6: Estudo de dose x profundidade para os aplicadores clínicos e em relação aos valores da norma IAEA (2002), variando-se as profundidades em água e normalizando-se os valores para 1,0 $\mathrm{mm}$ de profundidade.

\begin{tabular}{ccccccccc}
\hline $\begin{array}{c}\text { Profundidade } \\
\text { na água } \\
(\mathbf{m m})\end{array}$ & $\begin{array}{c}\text { Norma } \\
\text { IAEA } \\
\mathbf{( 2 0 0 2 )}\end{array}$ & $\mathbf{N I S T}$ & $\mathbf{A}$ & $\mathbf{B}$ & $\mathbf{C}$ & D & E & F \\
\cline { 5 - 10 } & 1,752 & $1,903 \pm 0,026$ & $1,650 \pm 0,026$ & $1,680 \pm 0,024$ & $1,825 \pm 0,033$ & $1,646 \pm 0,025$ & $1,703 \pm 0,036$ & $1,668 \pm 0,025$ \\
\hline 0 & 1,342 & $1,375 \pm 0,016$ & $1,284 \pm 0,018$ & $1,292 \pm 0,016$ & $1,352 \pm 0,021$ & $1,279 \pm 0,017$ & $1,291 \pm 0,024$ & $1,289 \pm 0,017$ \\
\hline 0,5 & 1,000 & $0,991 \pm 0,016$ & $0,996 \pm 0,018$ & $0,990 \pm 0,016$ & $1,001 \pm 0,021$ & $0,990 \pm 0,017$ & $0,975 \pm 0,024$ & $0,992 \pm 0,017$ \\
\hline 1,0 & 0,734 & $0,713 \pm 0,016$ & $0,769 \pm 0,018$ & $0,756 \pm 0,016$ & $0,740 \pm 0,021$ & $0,763 \pm 0,017$ & $0,732 \pm 0,024$ & $0,761 \pm 0,017$ \\
\hline 1,5 & 0,533 & $0,511 \pm 0,016$ & $0,590 \pm 0,018$ & $0,573 \pm 0,016$ & $0,545 \pm 0,021$ & $0,584 \pm 0,017$ & $0,546 \pm 0,024$ & $0,579 \pm 0,017$ \\
\hline 2,0 & 0,272 & $0,258 \pm 0,016$ & $0,338 \pm 0,018$ & $0,321 \pm 0,016$ & $0,293 \pm 0,021$ & $0,332 \pm 0,017$ & $0,293 \pm 0,024$ & $0,327 \pm 0,017$ \\
\hline 3,0 & 0,127 & $0,124 \pm 0,016$ & $0,182 \pm 0,018$ & $0,169 \pm 0,016$ & $0,154 \pm 0,021$ & $0,177 \pm 0,017$ & $0,144 \pm 0,024$ & $0,172 \pm 0,017$ \\
\hline 4,0 & 0,052 & $0,054 \pm 0,016$ & $0,085 \pm 0,018$ & $0,077 \pm 0,016$ & $0,077 \pm 0,021$ & $0,080 \pm 0,017$ & $0,056 \pm 0,024$ & $0,078 \pm 0,017$ \\
\hline 5,0 & 0,018 & $0,017 \pm 0,016$ & $0,025 \pm 0,018$ & $0,021 \pm 0,016$ & $0,035 \pm 0,021$ & $0,021 \pm 0,017$ & $0,005 \pm 0,024$ & $0,020 \pm 0,017$ \\
\hline 6,0 & & & & & & & & \\
\hline
\end{tabular}




\subsection{Utilização da Dosimetria Termoluminescente para a Calibração dos Aplicadores de ${ }^{90} \mathrm{Sr}+{ }^{90} \mathrm{Y}$}

A seguir, serão apresentados os testes e os estudos realizados com os dosímetros termoluminescentes de CaSO4:Dy com e sem 10\% de grafite, referentes a sua caracterização dosimétrica, à calibração dos aplicadores e ao estudo de dose x profundidade. A utilização destas pastilhas na calibração dos aplicadores clínicos consiste no Método 4.

\subsubsection{Caracterização Dosimétrica das Pastilhas Finas de CaSO4:Dy}

Neste item serão apresentados os resultados obtidos para a caracterização dos dosímetros: reprodutibilidade da resposta TL, linearidade da resposta TL $x$ tempo de irradiação e determinação do limite inferior de detecção.

\subsubsection{Reprodutibilidade das Pastilhas de CaSO4:Dy}

Inicialmente, as amostras de $\mathrm{CaSO} 4 \mathrm{Dy}$ com e sem grafite foram estudadas com relação à reprodutibilidade de sua resposta TL. Todos os tratamentos térmicos no início do trabalho foram realizados a $300{ }^{\circ} \mathrm{C}$ durante 1 hora. Porém, devido ao fato das doses aplicadas às pastilhas serem altas, foi necessário aumentar o tempo do tratamento térmico das amostras para 3 horas (CAMPOS e LIMA, 1987).

A reprodutibilidade da resposta TL, que foi estudada utilizando-se 45 pastilhas de CaSO4:Dy e 38 pastilhas de CaSO4:Dy $+10 \%$ de grafite, foi obtida após 5 séries de medições e tratamento térmico entre cada série. Para este estudo, as amostras foram irradiadas com a fonte de ${ }^{90} \mathrm{Sr}+{ }^{90} \mathrm{Y}$ de $1850 \mathrm{MBq}$, a $11 \mathrm{~cm}$ de distância entre fonte e pastilha, e para uma dose de $1 \mathrm{~Gy}$, sem a utilização de filtro uniformizador de campo. A reprodutibilidade obtida foi de 12,3\% para as amostras de CaSO4:Dy e de 13,6\% para as amostras de CaSO4:Dy + 10\% de grafite. 
Todas as medições de TL foram corrigidas para um valor pré-determinado de "lâmpada padrão", medição TL realizada com uma fonte de ${ }^{14} \mathrm{C}$ embutida no equipamento leitor de TL. Foram ainda realizadas as medições de TL das pastilhas não irradiadas, mas tratadas termicamente. $\mathrm{O}$ valor médio destas medições, denominada " $0 \mathrm{R}$ ", foi subtraído de todos os valores TL após irradiação.

O estudo de reprodutibilidade da resposta TL permitiu realizar uma seleção de pastilhas. A partir de um histograma, que pode ser observado na Figura 4.17, foi possível fazer a primeira seleção.

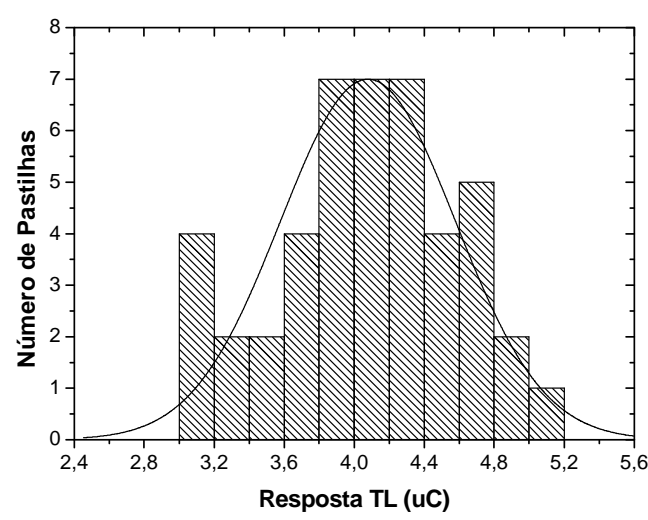

(a)

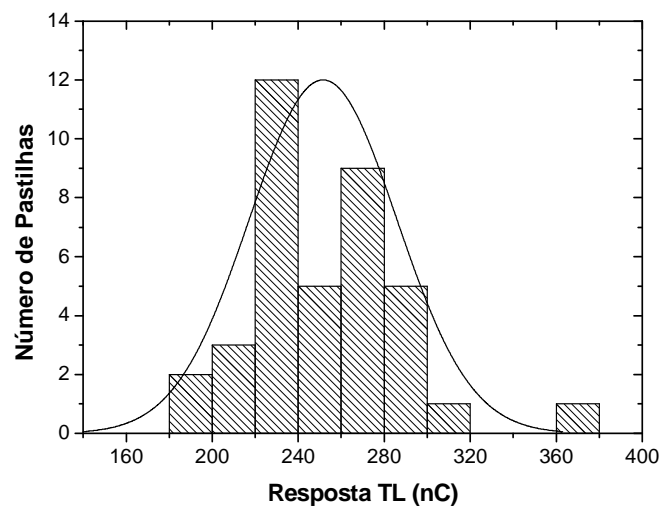

(b)

Figura 4.17: Histogramas elaborados para a primeira seleção de pastilhas de (a) CaSO4:Dy e (b) CaSO4:Dy + 10\% C.

A partir destes histogramas, foram escolhidas 21 pastilhas de CaSO4:Dy, com resposta TL entre 3,8 uC e 4,4 uC, e 31 pastilhas de CaSO4:Dy + 10\% de grafite, com resposta TL entre 220,0 e 300,0 nC. Entretanto, após a seleção, foram utilizadas neste trabalho apenas 16 pastilhas de $\mathrm{CaSO}_{4}$ :Dy e 17 pastilhas de CaSO4:Dy + 10\% de grafite. A reprodutibilidade destas pastilhas foi de 4,1\% para as pastilhas sem grafite, e $9,0 \%$ para as pastilhas com grafite.

Assim, analisando-se os valores finais de reprodutibilidade, foi decidido que apenas as pastilhas de $\mathrm{CaSO} 4: \mathrm{Dy}$ sem grafite seriam utilizadas a partir deste ponto do trabalho (exceto no caso de determinação do limite inferior de detecção). 


\subsubsection{Linearidade da Resposta TL x Tempo de Irradiação (para Aplicadores} A e B)

A resposta TL das amostras foi estudada com relação ao tempo de exposição às fontes. Este estudo foi realizado irradiando-se as pastilhas de CaSO4:Dy sem grafite com os aplicadores dermatológicos A e B. As amostras foram irradiadas durante 5, 10, 15 e 20 minutos, a uma distância nula entre as pastilhas e os aplicadores. Os resultados obtidos neste estudo são mostrados na Figura 4.18.

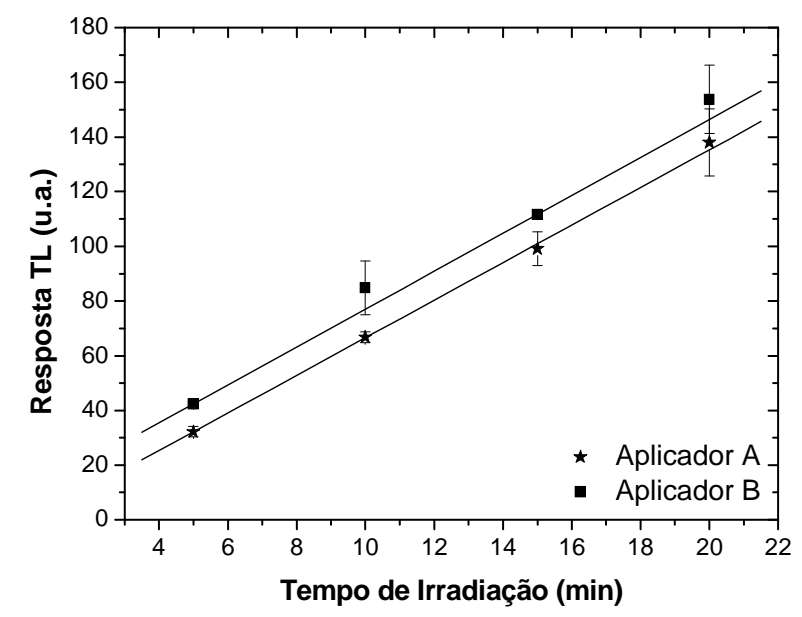

Figura 4.18: Resposta TL das pastilhas finas de CaSO4:Dy, em função do tempo de irradiação, para os aplicadores A e B de ${ }^{90} \mathrm{Sr}+{ }^{90} \mathrm{Y}$.

Pode-se observar que as respostas TL dos dois aplicadores apresentaram comportamentos lineares. As incertezas máximas associadas a estas medições foram de $8,9 \%$ para as pastilhas de $\mathrm{CaSO}_{4}$ :Dy irradiadas com o aplicador A e de 11,6\% para as pastilhas de CaSO4:Dy irradiadas com o aplicador B.

\subsubsection{Limite Inferior de Detecção}

O limite inferior de detecção em dose, para ambos os materiais, foi outra característica dosimétrica determinada, estudando-se a variabilidade de resposta 
TL de pastilhas não irradiadas. Este valor foi obtido da soma da média das leituras $\mathrm{TL}, \bar{x}_{T L}$, das pastilhas não irradiadas e 3 vezes o valor do desvio padrão destas medições, multiplicada pelo fator de calibração, $f_{c}$, referente a cada tipo de amostra, conforme:

$$
L_{\text {inf erior }}=\left[\bar{x}_{T L}(O R)+3 . \sigma\right] f_{c}
$$

O limite inferior de detecção obtido para as pastilhas de $\mathrm{CaSO} 4: \mathrm{Dy}$ foi 77,2 $\mu \mathrm{Gy}$, e para as pastilhas de CaSO4:Dy $+10 \%$ de grafite, foi de $92,0 \mu \mathrm{Gy}$.

Os valores de limite inferior de detecção foram obtidos para ambas as pastilhas e apresentaram-se na mesma ordem de grandeza dos resultados obtidos num estudo anterior por Campos e Lima (1987).

\subsubsection{Calibração dos Aplicadores com Dosímetros Termoluminescentes (Método 4)}

A calibração dos aplicadores clínicos também foi realizada com a utilização de dosímetros termoluminescentes; este é o Método 4. Este item explanará os procedimentos realizados para a calibração e dosimetria dos aplicadores, a começar pela obtenção de uma curva de calibração das pastilhas de CaSO4:Dy com o aplicador NIST.

A resposta TL das amostras foi obtida em função da dose absorvida no ar, utilizando o aplicador NIST a uma distância nula entre as pastilhas e o aplicador, e para o intervalo de dose entre 5 e 20 Gy. Os resultados obtidos são mostrados na Figura 4.19. A incerteza máxima relativa obtida nas medições para a curva de calibração foi de $6,7 \%$.

As amostras TL apresentaram resposta adequada no intervalo de dose estudado: comportamento linear até a dose de 10 Gy, como já demonstrado em estudo anterior (OLIVEIRA e CALDAS, 2007b), indicando a seguir supralinearidade e uma tendência à saturação. 


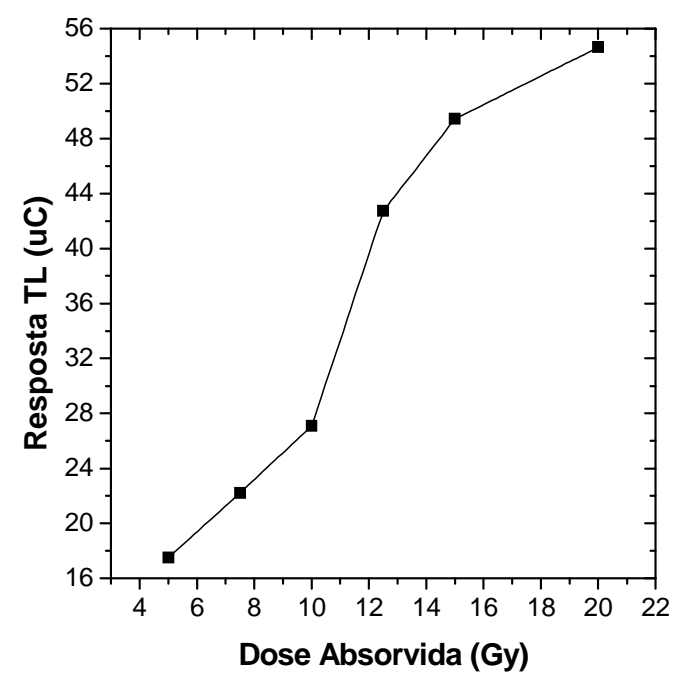

Figura 4.19: Curva de dose-resposta obtida das pastilhas finas de CaSO4:Dy, para o aplicador NIST $\left({ }^{90} \mathrm{Sr}+{ }^{90} \mathrm{Y}\right)$.

Os dosímetros finos de CaSO4:Dy inicialmente selecionados foram irradiados com cada aplicador clínico, A, B, C, D, E e F, pelos intervalos de tempo de irradiação de 330, 330, 25, 300, 240 e 360 s, respectivamente, levando-se em conta a atividade de cada fonte, à distância nula entre as pastilhas e os aplicadores.

Aplicando-se a resposta $\mathrm{TL}$, em $\mu \mathrm{C}$, obtida pelas medições com cada aplicador, à curva de calibração, foi possível obter-se a dose absorvida, em Gy, referente a cada intervalo de tempo de irradiação; este procedimento foi utilizado para cada aplicador.

Os resultados obtidos com o Método 4 estão apresentados na Tabela 4.7. A incerteza máxima relativa à estas medições foi igual a 20,7\% (aplicador A).

As taxas de dose absorvida para cada aplicador clínico, obtidas com a utilização de dosímetros termoluminescentes, serão comparadas com os Métodos 1,2 e 3 no item 4. 
Tabela 4.7: Taxas de dose absorvida (às distâncias nulas), dos aplicadores, utilizando o Método 4.

\begin{tabular}{ccc}
\hline $\begin{array}{c}\text { Distância } \\
(\mathrm{mm})\end{array}$ & Aplicador & $\begin{array}{c}\text { Taxa de dose } \\
\text { absorvida } \\
\text { (Gy/s) } \\
\text { Método } 4\end{array}$ \\
\hline 0 & $\mathrm{~A}$ & $0,0281 \pm 0,0058$ \\
\hline 0 & $\mathrm{~B}$ & $0,0322 \pm 0,0027$ \\
\hline 0 & $\mathrm{C}$ & $0,5364 \pm 0,0646$ \\
\hline
\end{tabular}

\begin{tabular}{ccc}
\hline $\begin{array}{c}\text { Distância } \\
(\mathbf{m m})\end{array}$ & Aplicador & $\begin{array}{c}\text { Taxa de dose } \\
\text { absorvida } \\
\text { (Gy/s) } \\
\text { Método 4 }\end{array}$ \\
\hline 0 & $\mathrm{D}$ & $0,0397 \pm 0,0056$ \\
\hline 0 & $\mathrm{E}$ & $0,0420 \pm 0,0031$ \\
\hline 0 & $\mathrm{~F}$ & $0,0307 \pm 0,0027$ \\
\hline
\end{tabular}

\subsubsection{Curvas de Dose x Profundidade para os Aplicadores Clínicos de ${ }^{90} \mathrm{Sr}+{ }^{90} \mathrm{Y}$}

O estudo de dose $\mathrm{x}$ profundidade também foi realizado usando as pastilhas de CaSO4:Dy, para todos os aplicadores clínicos.

Foram utilizadas as mesmas placas de acrílico do estudo com a mini-câmara de extrapolação, de sete espessuras diferentes $(1,0 \mathrm{~mm}$ a 5,0 $\mathrm{mm})$. As pastilhas foram posicionadas sobre um suporte de acrílico com um orifício para o encaixe da pastilha, especialmente desenvolvido para esta finalidade, e os aplicadores foram posicionados verticalmente sobre a amostra, inicialmente a uma distância nula entre dosímetro e aplicador, e então, posicionando-se as placas de acrílico, sucessivamente. A Figura 4.20 mostra uma pastilha sendo irradiada de acordo com o arranjo utilizado.

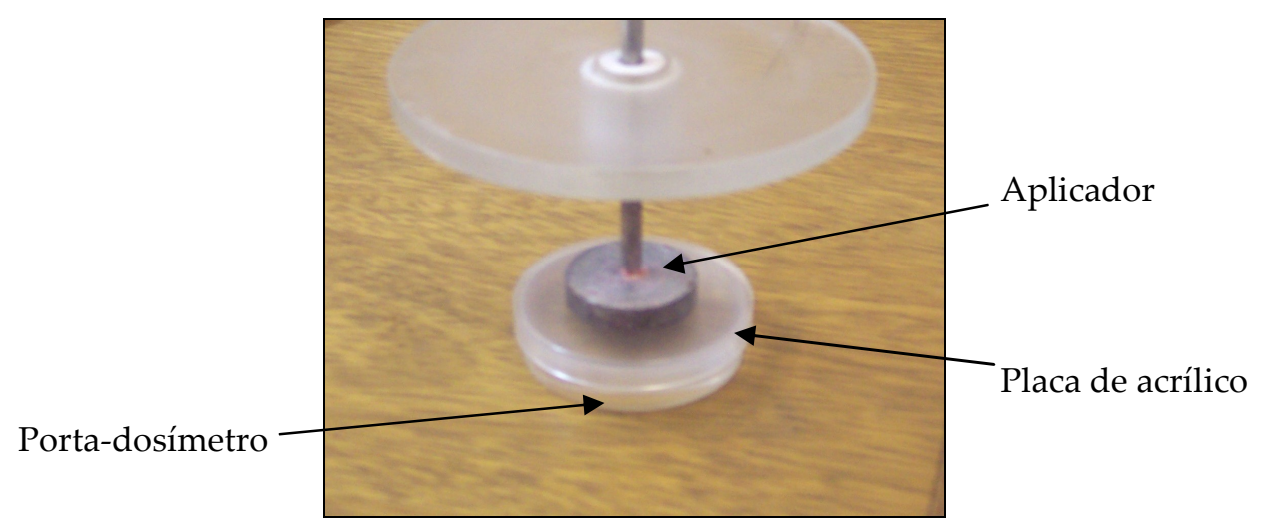

Figura 4.20: Arranjo experimental utilizado durante a irradiação das pastilhas para a determinação da distribuição da dose $x$ profundidade na água. 
Inicialmente, este estudo foi realizado para o aplicador A e, após verificada a viabilidade das pastilhas, o estudo de dose $\mathrm{x}$ profundidade também foi realizado com os outros aplicadores. Os resultados obtidos no estudo de dose $\mathrm{x}$ profundidade utilizando-se o aplicador clínico A podem ser observados na Figura 4.21 .

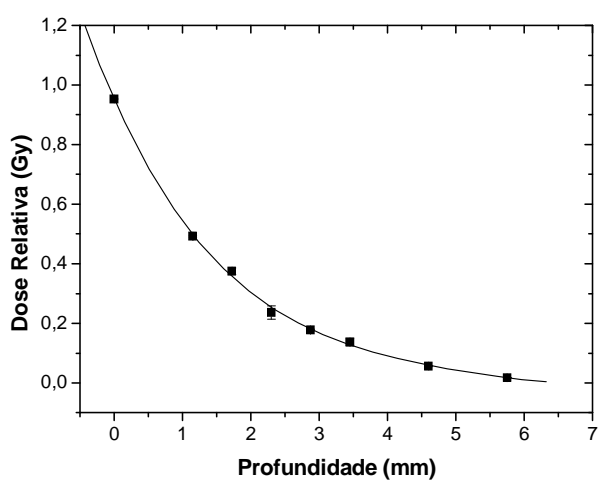

(a)

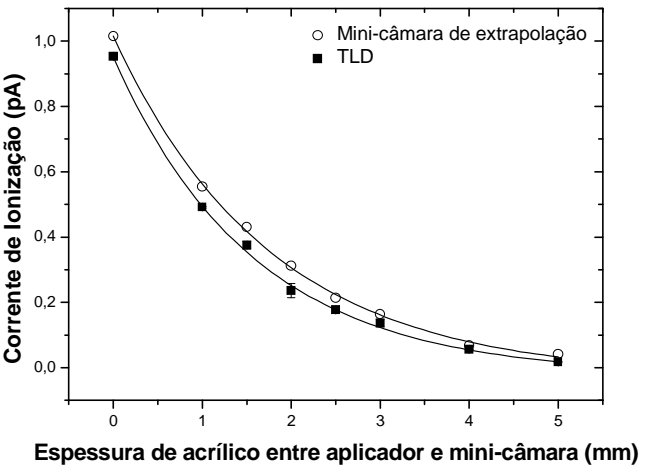

(b)

Figura 4.21: Curvas de dose $x$ profundidade obtidas com (a) dosímetros termoluminescentes, e (b) comparando-se estes resultados com os obtidos com a mini-câmara de extrapolação, para o aplicador A, variando-se a espessura de acrílico entre fonte e dosímetro.

Os resultados obtidos foram comparados com os do estudo de dose $x$ profundidade para o aplicador $A$, utilizando-se a mini-câmara de extrapolação de janela plana. A Figura 4.21-b mostra estes resultados, que foram considerados satisfatórios. A incerteza máxima relativa obtida nas medições para o aplicador A foi de 11,0\%.

Estes resultados foram obtidos para todos os aplicadores e, da mesma forma como foi realizado no caso da mini-câmara de extrapolação, os resultados foram comparados em um mesmo gráfico. Nas Figuras 4.22 e 4.23, as curvas de dose $\mathrm{x}$ profundidade para os outros aplicadores podem ser observadas. As incertezas máximas relativas obtidas foram de 22,3\% (aplicador NIST), 12,3\% (B), $18,4 \%$ (C), 10,3\% (D), 16,1\% (E) e 13,6\% (aplicador F). 


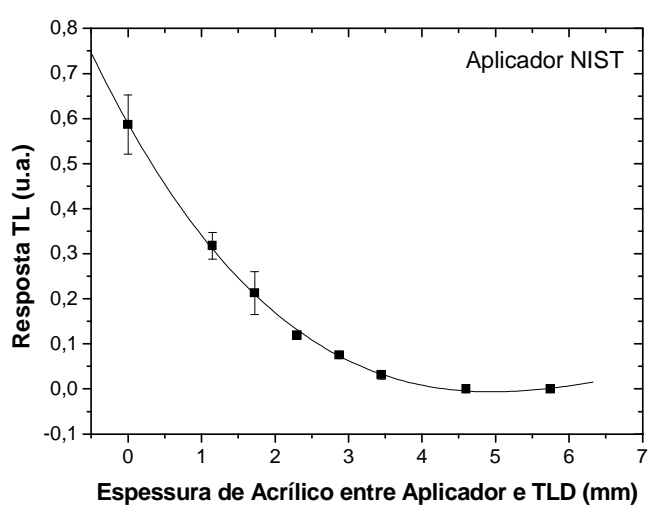

(a)

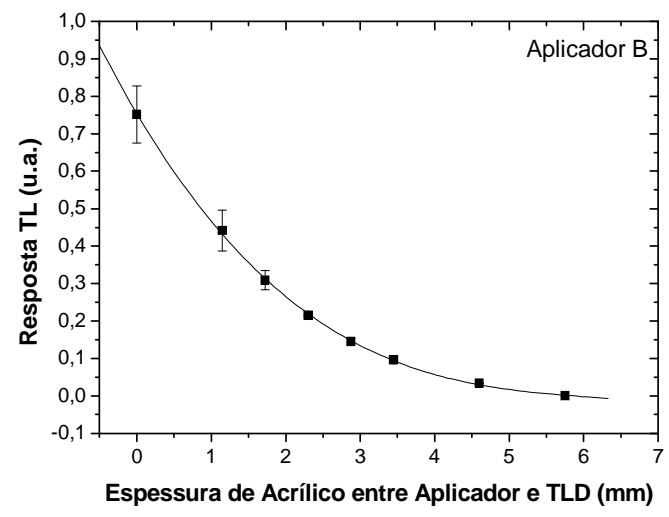

(b)

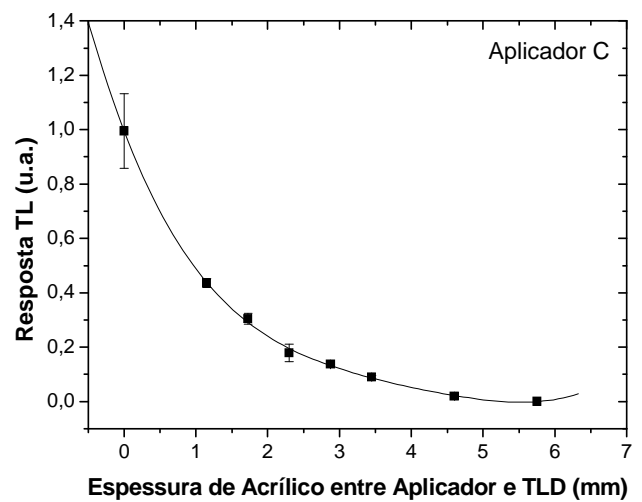

(c)

Figura 4.22: Curvas de dose $\mathrm{x}$ profundidade obtidas utilizando-se dosímetros termoluminescentes de CaSO4:Dy, para: (a) aplicador NIST, (b) aplicador B e (c) aplicador C. 


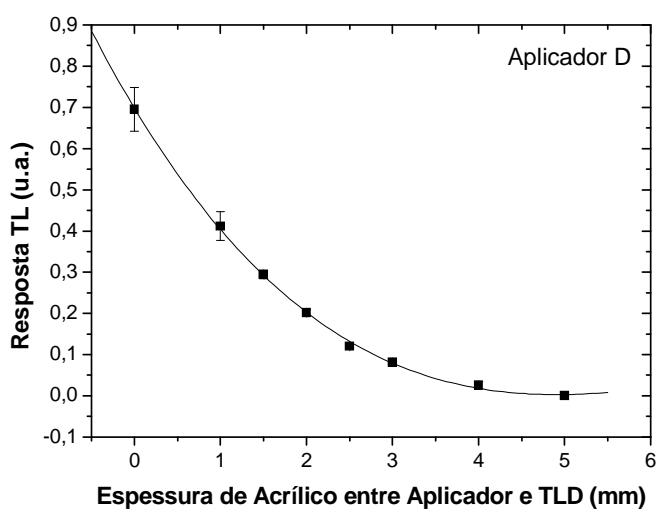

(a)

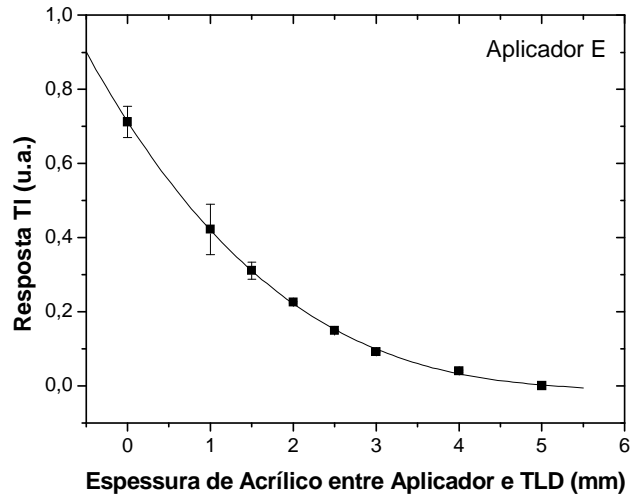

(b)

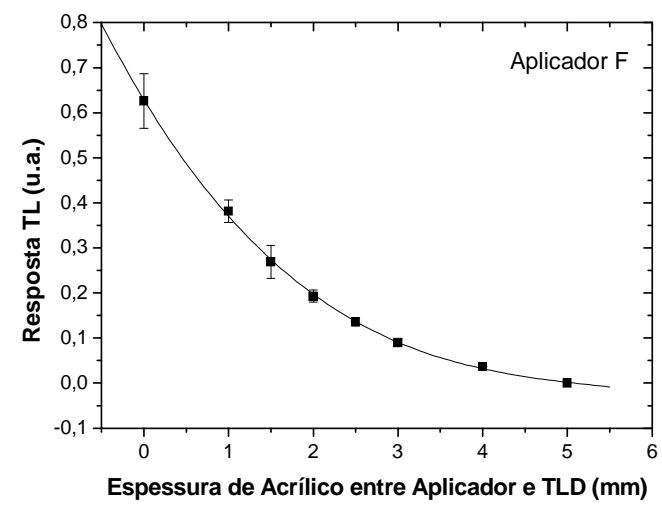

(c)

Figura 4.23: Curvas de dose x profundidade obtidas com amostras de CaSO4:Dy, para: (a) aplicador D, (b) aplicador E e (c) aplicador F.

Os valores obtidos a partir das curvas de dose $x$ profundidade com as pastilhas de CaSO4:Dy foram normalizados para 1,0 mm e a Equação 3.3 foi utilizada para a conversão de acrílico para meio equivalente à água, da mesma maneira que foi realizada para os resultados obtidos utilizando-se a mini-câmara de extrapolação de janela plana. Uma comparação entre todos os aplicadores pode ser vista na Figura 4.24. 


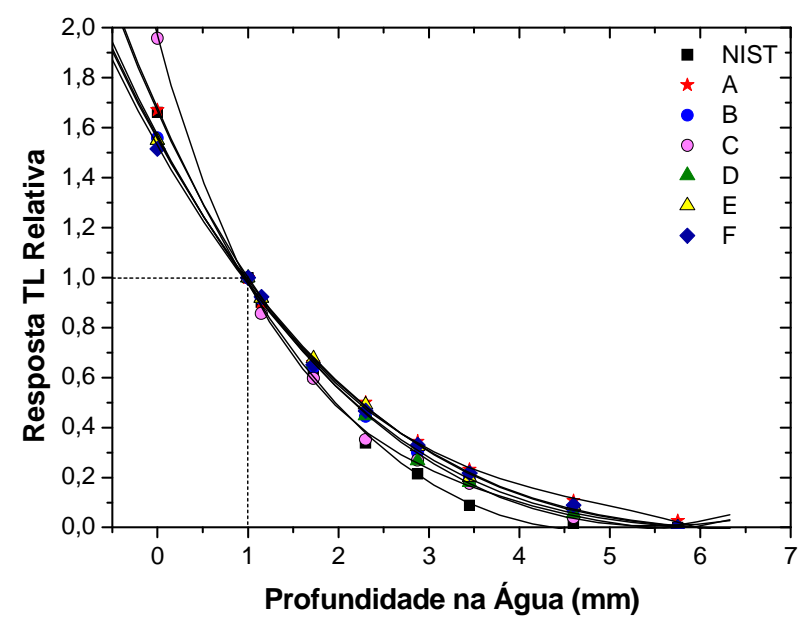

Figura 4.24: Curvas de dose $\mathrm{x}$ profundidade obtidas para os aplicadores clínicos de ${ }^{90} \mathrm{Sr}+{ }^{90} \mathrm{Y}$ NIST, A, B, C, D, E, e F, com dosímetros termoluminescentes finos de $\mathrm{CaSO} 4: \mathrm{Dy}$.

Na Tabela 4.8, pode-se observar que a diferença entre os valores obtidos para cada aplicador e os fornecidos pela norma, à profundidade nula, foram razoavelmente semelhantes (levando-se em conta as incertezas), apresentando uma variação entre $0,1 \%$ (aplicador NIST) e 15,4\% (aplicador F). A partir da profundidade na água de 5,0 $\mathrm{mm}$, os valores foram muito baixos e, por isso, não são confiáveis. 
Tabela 4.8: Dose x profundidade para os aplicadores clínicos de ${ }^{90} \mathrm{Sr}+{ }^{90} \mathrm{Y}$, com dosímetros termoluminescentes e em relação aos valores da norma IAEA (2002), variando-se as profundidades em água e normalizando-se os valores para 1,0 mm de profundidade.

\begin{tabular}{ccccccccc}
\hline \multirow{2}{*}{$\begin{array}{c}\text { Profundidade } \\
\text { na água } \\
(\mathbf{m m})\end{array}$} & $\begin{array}{c}\text { Norma } \\
\text { IAEA }\end{array}$ & \multicolumn{7}{c}{ Corrente de Ionização Relativa } \\
\cline { 5 - 9 } & $\mathbf{( 2 0 0 2 )}$ & NIST & A & B & C & D & E & F \\
\hline 0 & 1,752 & $1,662 \pm 0,483$ & $1,670 \pm 0,183$ & $1,562 \pm 0,192$ & $1,960 \pm 0,360$ & $1,550 \pm 0,159$ & $1,554 \pm 0,250$ & $1,518 \pm 0,207$ \\
\hline 0,5 & 1,342 & $1,334 \pm 0,388$ & $1,287 \pm 0,141$ & $1,260 \pm 0,155$ & $1,383 \pm 0,254$ & $1,264 \pm 0,130$ & $1,250 \pm 0,201$ & $1,243 \pm 0,169$ \\
\hline 1,0 & 1,000 & $0,999 \pm 0,290$ & $0,979 \pm 0,107$ & $0,988 \pm 0,121$ & $0,976 \pm 0,179$ & $0,996 \pm 0,102$ & $0,989 \pm 0,159$ & $0,988 \pm 0,135$ \\
\hline 1,5 & 0,734 & $0,705 \pm 0,205$ & $0,732 \pm 0,080$ & $0,751 \pm 0,092$ & $0,687 \pm 0,126$ & $0,755 \pm 0,078$ & $0,767 \pm 0,123$ & $0,762 \pm 0,104$ \\
\hline 2,0 & 0,533 & $0,469 \pm 0,136$ & $0,532 \pm 0,058$ & $0,552 \pm 0,068$ & $0,481 \pm 0,088$ & $0,549 \pm 0,056$ & $0,581 \pm 0,093$ & $0,570 \pm 0,078$ \\
\hline 3,0 & 0,272 & $0,171 \pm 0,049$ & $0,230 \pm 0,025$ & $0,269 \pm 0,033$ & $0,229 \pm 0,042$ & $0,253 \pm 0,026$ & $0,304 \pm 0,049$ & $0,293 \pm 0,039$ \\
\hline 4,0 & 0,127 & $0,043 \pm 0,012$ & $0,005 \pm 0,000$ & $0,121 \pm 0,015$ & $0,098 \pm 0,018$ & $0,103 \pm 0,010$ & $0,132 \pm 0,021$ & $0,144 \pm 0,020$ \\
\hline 5,0 & 0,052 & $0,016 \pm 0,005$ & $-0,183 \pm 0,000$ & $0,051 \pm 0,006$ & $0,028 \pm 0,005$ & $0,045 \pm 0,005$ & $0,040 \pm 0,006$ & $0,067 \pm 0,009$ \\
\hline 6,0 & 0,018 & $0,001 \pm 0,000$ & $-0,343 \pm 0,000$ & $-0,032 \pm 0,000$ & $-0,010 \pm 0,000$ & $-0,020 \pm 0,000$ & $0,000 \pm 0,000$ & $-0,037 \pm 0,000$ \\
\hline
\end{tabular}




\subsection{Comparação entre os Resultados das Curvas de Dose x Profundidade, obtidos com a Mini-Câmara de Extrapolação e os Dosímetros Termoluminescentes}

Após a obtenção dos resultados de corrente de ionização relativa, das curvas de distribuição de dose em profundidade na água, utilizando-se a mini-câmara de extrapolação e os dosímetros termoluminescentes, foi feita uma comparação entre os resultados.

A Tabela 4.9 mostra a diferença percentual entre os resultados obtidos por meio das duas técnicas.

Tabela 4.9: Diferença percentual entre os valores de dose $\mathrm{x}$ profundidade, obtidos com a mini-câmara de extrapolação e dosímetros termoluminescentes.

\begin{tabular}{ccccccccc}
\hline $\begin{array}{c}\text { Profundidade } \\
\text { na água } \\
(\mathbf{m m})\end{array}$ & NIST & A & B & C & D & E & F \\
\cline { 2 - 8 } & 14,5 & 1,2 & 7,5 & 7,4 & 6,2 & 9,6 & 9,9 \\
\hline 0 & 3,1 & 0,2 & 2,5 & 3,0 & 1,2 & 3,3 & 3,7 \\
\hline 0,5 & 0,8 & 1,7 & 0,2 & 2,6 & 0,6 & 1,4 & 0,4 \\
\hline 1,0 & 1,1 & 5,0 & 0,7 & 7,7 & 1,1 & 4,8 & 0,1 \\
\hline 1,5 & 8,9 & 10,9 & 3,8 & 13,3 & 6,4 & 6,4 & 1,6 \\
\hline 2,0 & 50,9 & 46,9 & 19,3 & 27,9 & 31,2 & 3,7 & 11,6 \\
\hline 3,0 & & & & & & &
\end{tabular}

Analisando-se a tabela pode-se verificar que para as profundidades na água de 0 a 2,0 mm, as incertezas variaram entre 0,1\% (aplicador F) e 14,5\% (aplicador NIST). As diferenças na profundidade igual ou superior a 3,0 $\mathrm{mm}$ apresentaram-se maiores, uma vez que nestas profundidades o valor de corrente de ionização é muito baixo. 


\subsection{Comparação entre os 4 Métodos de Calibração de Aplicadores Clínicos}

Levando-se em conta os resultados obtidos para a calibração de aplicadores clínicos de ${ }^{90} \mathrm{Sr}+{ }^{90} \mathrm{Y}$, por meio dos 4 métodos, foi possível a comparação entre eles. A Tabela 4.9 mostra os valores obtidos na calibração de cada aplicador pelos 4 métodos.

Os aplicadores C, D, E e F foram utilizados na determinação das taxas de dose absorvida mais de uma vez. $\mathrm{O}$ aplicador $\mathrm{C}$ foi medido em diversas condições: sem o uso de capa protetora e a $0 \mathrm{~mm}\left(C_{1}\right)$, sem o uso de capa protetora e a $1,0 \mathrm{~mm}$ de distância entre fonte e mini-câmara $\left(\mathrm{C}_{1 \mathrm{~A}}\right)$, com capa contendo orifício $\left(\mathrm{C}_{2}\right)$ e com capa protetora $\left(C_{3}\right)$. É importante ressaltar que o aplicador $C$ é utilizado como aplicador dermatológico e oftálmico, e o aplicador F é oftálmico. Entretanto, estes aplicadores também foram calibrados e estudados em relação à dose $\mathrm{x}$ profundidade para uma possível comparação com os resultados dos aplicadores dermatológicos, e a verificação do desempenho dos 4 métodos para a calibração deste tipo de aplicador.

Analisando-se os valores de taxas de dose absorvida, pode-se concluir que os Métodos 2 e 3, e os Métodos 1 e 4, apresentam resultados semelhantes. O Método 4 apresenta valores de taxa de dose absorvida próximos aos do Método 1, no qual se usou o aplicador NIST, pelo fato do Método 4 ter sido realizado, utilizando-se uma curva de calibração que foi obtida com o aplicador NIST. A variação destas medições, quando comparadas com o valor do certificado, apresentou-se entre 1,1\% para o aplicador E e 71,2\% para o aplicador D.

De modo geral, o Método 3, ou seja, utilizando a mini-câmara de extrapolação como sistema de referência absoluta, apresentou resultados mais semelhantes se comparados com os valores de taxa de dose absorvida fornecidos pelo certificado. Além disso, as incertezas associadas aos valores de taxa de dose absorvida obtidos neste método foram menores, o que do ponto de vista de garantia de controle de qualidade é muito importante. Por estes motivos, o Método 3 foi escolhido como o sendo o mais adequado para a calibração de aplicdores clínicos. 
Tabela 4.10: Calibração dos aplicadores NIST, A, B, C, D, E e F por meio de 4 métodos diferentes.

\begin{tabular}{|c|c|c|c|c|c|c|}
\hline \multirow{2}{*}{$\begin{array}{c}\text { Distância } \\
(\mathbf{m m})\end{array}$} & \multirow{2}{*}{ Aplicador } & \multicolumn{5}{|c|}{ Taxa de dose absorvida (Gy/s) } \\
\cline { 3 - 7 } & & Certificado & Método 1 & Método 2 & Método 3 & Método 4 \\
\hline 0 & NIST & $0,3473 \pm 0,0417$ & - & $0,2519 \pm 0,0510$ & $0,2417 \pm 0,0037$ & - \\
\hline 0 & A & $0,0213 \pm 0,0043$ & $0,0295 \pm 0,0036$ & - & $0,0203 \pm 0,0004$ & $0,0281 \pm 0,0058$ \\
\hline 0 & B & - & $0,0329 \pm 0,0040$ & $0,0236 \pm 0,0048$ & $0,0227 \pm 0,0002$ & $0,0322 \pm 0,0027$ \\
\hline 0 & $C_{1}$ & $0,3245 \pm 0,0649$ & $0,4953 \pm 0,0587$ & $0,3426 \pm 0,0694$ & $0,3288 \pm 0,0059$ & $0,5364 \pm 0,0646$ \\
\hline 0 & $C_{1}$ & $0,3239 \pm 0,0648$ & $0,4773 \pm 0,0587$ & $0,3433 \pm 0,0695$ & $0,3295 \pm 0,0054$ & - \\
\hline 1 & $C_{1 A}$ & - & $0,3854 \pm 0,0472$ & $0,2772 \pm 0,0560$ & $0,2660 \pm 0,0034$ & - \\
\hline 1 & $C_{1 A}$ & - & $0,3742 \pm 0,0461$ & $0,2691 \pm 0,0545$ & $0,2583 \pm 0,0045$ & - \\
\hline 0 & $C_{2}$ & - & $0,3045 \pm 0,0375$ & $0,2190 \pm 0,0443$ & $0,2102 \pm 0,0036$ & - \\
\hline 0 & $C_{2}$ & - & $0,2431 \pm 0,0298$ & $0,1749 \pm 0,0354$ & $0,1678 \pm 0,0022$ & - \\
\hline 0 & $C_{3}$ & - & $0,0354 \pm 0,0044$ & $0,0254 \pm 0,0052$ & $0,0244 \pm 0,0005$ & - \\
\hline 0 & D & $0,0299 \pm 0,0060$ & $0,0446 \pm 0,0055$ & $0,0321 \pm 0,0065$ & $0,0308 \pm 0,0004$ & $0,0397 \pm 0,0056$ \\
\hline 0 & D & $0,0299 \pm 0,0060$ & $0,0471 \pm 0,0059$ & $0,0339 \pm 0,0069$ & $0,0325 \pm 0,0008$ & - \\
\hline 0 & E & $0,0349 \pm 0,0070$ & $0,0511 \pm 0,0065$ & $0,0368 \pm 0,0076$ & $0,0353 \pm 0,0014$ & $0,0420 \pm 0,0031$ \\
\hline 0 & E & $0,0349 \pm 0,0070$ & $0,0479 \pm 0,0059$ & $0,0345 \pm 0,0070$ & $0,0331 \pm 0,0014$ & - \\
\hline 0 & F & $0,0257 \pm 0,0051$ & $0,0302 \pm 0,0037$ & $0,0217 \pm 0,0044$ & $0,0208 \pm 0,0003$ & $0,0307 \pm 0,0027$ \\
\hline 0 & F & $0,0257 \pm 0,0051$ & $0,0304 \pm 0,0037$ & $0,0219 \pm 0,0044$ & $0,0210 \pm 0,0003$ & - \\
\hline
\end{tabular}


É importante salientar que esta diferença, bem como a diferença existente de modo geral entre os 4 métodos, deve-se ao fato, dentre outros fatores, dos aplicadores da Amersham apresentarem uma incerteza de $20 \%$ em sua calibração. Além disso, os aplicadores apresentam uma falta de uniformidade do material radioativo em sua superfície (SOARES, 2009), o que também pode causar uma diferença nos resultados obtidos. 


\subsection{Elaboração de um Sistema Postal Dosimétrico}

Levando-se em conta a caracterização dosimétrica realizada com as pastilhas de $\mathrm{CaSO}_{4}$ :Dy, utilizadas neste trabalho, e o Método 4 de calibração, foi possível a elaboração de um sistema postal dosimétrico. A partir da análise dos resultados, foi determinado um procedimento de irradiação das amostras deste sistema.

Este sistema postal deverá ser enviado às clínicas e aos hospitais que utilizam aplicadores clínicos de ${ }^{90} \mathrm{Sr}+{ }^{90} \mathrm{Y}$, para a irradiação dos dosímetros com as fontes. Por fim, estas amostras serão devolvidas ao LCI, para avaliação das pastilhas e para posterior emissão de um certificado de calibração da fonte (Apêndice B). Este processo se torna importante, pois evita o transporte dos aplicadores de seus locais de uso para o LCI/IPEN/SP, uma vez que este transporte pode acarretar alguns problemas, como por exemplo a interrupção nos tratamentos de pacientes até o retorno do aplicador.

Juntamente a este sistema postal, foi elaborado um procedimento de sua utilização e irradiação das pastilhas, por parte dos usuários (técnicos ou físicosmédicos). Este procedimento pode ser observado no Apêndice A. Na Figura 4.25 pode-se observar os cinco porta-dosímetros a serem enviados aos usuários.

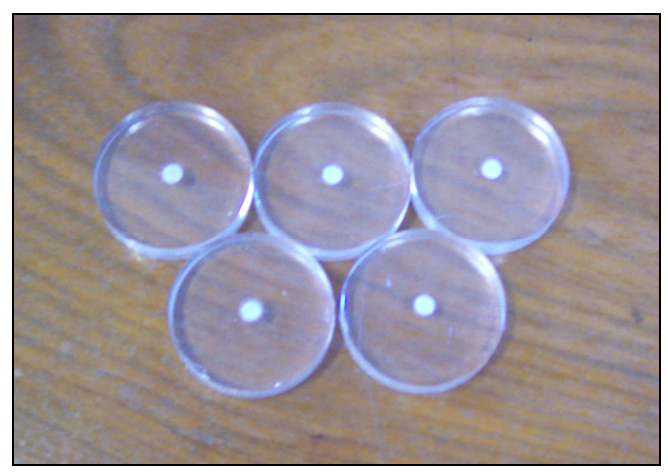

Figura 4.25: Porta-dosímetros de acrílico confeccionados para a irradiação das 5 pastilhas a serem enviados para as clínicas.

No sistema postal deverão ser enviados cinco pastilhas termoluminescentes acondicionadas de forma adequada, suportes e um procedimento de utilização. 
Optou-se pelo envio destas peças de acrílico embaladas por um filme plástico, de densidade superficial igual a 1,095 $\mathrm{mg} / \mathrm{cm}^{2}$. Esta opção foi tomada como medida de precaução e cuidado com os dosímetros, uma vez que se as amostras fossem soltas, poderiam ser perdidas, ou amassadas pelo mau uso com a pinça, quando fossem colocadas nos orifícios do porta-amostras.

Das cinco pastilhas termoluminescentes, duas serão enviadas como amostras de controle, que não deverão ser irradiadas pelos aplicadores. Elas terão o objetivo de medir qualquer radiação durante o transporte, para posterior desconto dos resultados relativos às pastilhas irradiadas pelos aplicadores clínicos. 


\section{CONCLUSÕES}

Neste trabalho, quatro métodos de calibração e de dosimetria de aplicadores clínicos de ${ }^{90} \mathrm{Sr}+{ }^{90} \mathrm{Y}$ foram estudados e comparados, como objetivo principal. Estas técnicas consistiram no uso de uma mini-câmara de extrapolação de janela plana, desenvolvida no LCI/IPEN, e da dosimetria termoluminescente.

O Método 1, no qual se utilizou um aplicador dermatológico padrão do LCI, calibrado pelo laboratório padrão primário do NIST, como referência, apresentou valores de taxa de dose absorvida variando entre 17,5\% (aplicador F) e 57,5\% (aplicador D) dos valores fornecidos pelos certificados.

Com relação ao Método 2, onde se utilizou o aplicador dermatológico da Amersham, também do LCI, como referência, os resultados de taxa de dose absorvida obtidos também diferiram dos valores do certificado entre 1,1\% (aplicador E) e 18,4\% (aplicador F). Esta diferença possui relação com os valores altos de incerteza do aplicador NIST e da Amersham, que são de 12,0\% e 20,0\%, respectivamente, fornecidos em seus certificados de calibração. Além disso, os aplicadores possuem uma falta de uniformidade do material radioativo presente em sua superfície, o que também pode ter causado uma diferença nos resultados.

Dos quatro métodos de calibração, verificou-se que o Método 3, no qual foi utilizada a mini-câmara de extrapolação de janela plana como padrão absoluto, é o mais adequado; neste caso não há necessidade de um aplicador de referência. A escolha deste método como sendo o mais adequado deve-se ao fato dos resultados obtidos de taxa de dose absorvida serem os mais compatíveis com os valores fornecidos pelos certificados de calibração dos aplicadores. Este será o método a ser seguido no LCI sempre que o aplicador do cliente puder ser enviado ao Laboratório de Calibração.

O Método 4, no qual se utilizou a dosimetria termoluminescente, também apresentou resultados diferentes dos fornecidos pelos certificados de calibração, 
embora os valores tenham se apresentado próximos aos do Método 1, uma vez que nos dois métodos foi utilizado o aplicador NIST como referência.

Os objetivos específicos deste trabalho foram alcançados:

1 - A câmara de extrapolação PTW foi submetida aos testes de controle de qualidade, corrente de fuga, repetitividade e reprodutibilidade da resposta da câmara. Os resultados obtidos de corrente de fuga apresentaram-se inferiores ao limite de $0,5 \%$, conforme a norma recomenda. A variação obtida no teste de repetitividade foi de $0,88 \%$, e no teste de reprodutibilidade, a variação máxima foi de 3,2\%; estes resultados demonstram o bom desempenho desta câmara em campos de radiação beta de ${ }^{90} \mathrm{Sr}+{ }^{90} \mathrm{Y}$.

Neste caso, as curvas de extrapolação foram obtidas para três fontes de ${ }^{90} \mathrm{Sr}^{+90} \mathrm{Y}$ de atividades diferentes, de dois sistemas padrões secundários, e para os dois eletrodos coletores de alumínio e grafite da câmara de extrapolação. A câmara PTW foi calibrada utilizando-se estas fontes. Todas as curvas apresentaram comportamento linear, com coeficiente de correlação inferior a 0,9992. Além disso, pôde-se comprovar, com estes resultados, que a câmara com eletrodo coletor de grafite é a mais adequada para detectar radiação beta.

2 - Uma mini-câmara de extrapolação de janela plana, desenvolvida no LCI, foi utilizada neste trabalho. Para esta mini-câmara, os testes de controle de qualidade foram realizados, como determinação da corrente de fuga, repetitividade e reprodutibilidade. Os resultados de corrente de fuga foram adequados, isto é, inferiores a $0,5 \%$. Os resultados dos testes de repetitividade e reprodutibilidade também foram satisfatórios, uma vez que a variação máxima da resposta da câmara se apresentou inferior a $0,3 \%$ e $0,7 \%$, respectivamente.

Com a mini-câmara, foram obtidas curvas de extrapolação para os 7 aplicadores clínicos estudados (5 dermatológicos, 1 oftálmico e 1 dermatológico/oftálmico). Todas estas curvas apresentaram comportamento linear, com coeficiente de correlação inferior a 0,9995. Utilizando-se o coeficiente angular das curvas de extrapolação, os aplicadores puderam ser calibrados pelos Métodos 1, 2 e 3. 
3 - No caso das pastilhas termoluminescentes de $\mathrm{CaSO} 4: \mathrm{Dy}$, as pastilhas finas sem grafite foram selecionadas. Uma caracterização destas pastilhas foi realizada, estudando-se a reprodutibilidade de sua resposta TL. Os resultados confirmaram que as pastilhas de CaSO4:Dy são úteis para a calibração de aplicadores clínicos de ${ }^{90} \mathrm{Sr}+{ }^{90} \mathrm{Y}$.

Estes resultados possibilitaram a elaboração de um sistema postal dosimétrico, que constitui um método alternativo de calibração de aplicadores clínicos e deverá ser enviado às clínicas e hospitais quando os aplicadores não puderem ser enviados ao LCI. Este sistema postal é composto por 5 suportes de pastilhas, com uma pastilha em cada um deles e acondicionadas adequadamente, e um procedimento de sua utilização. Este sistema tem por objetivo o seu envio a clínicas e hospitais que utilizam estas fontes (aplicadores clínicos em braquiterapia). A elaboração e o envio deste sistema postal evita o transporte dos aplicadores ao LCI, causando atrasos nos tratamentos de pacientes. Após avaliação das amostras, um certificado de calibração será emitido para o aplicador em questão.

4 - Além da determinação das taxas de dose absorvida na água, dos aplicadores, ainda é necessária a determinação das curvas de distribuição de dose em profundidade na água, que foram obtidas utilizando-se a mini-câmara de extrapolação, os dosímetros termoluminescentes e as placas de acrílico de diferentes espessuras. Os resultados obtidos para todos os 7 aplicadores foram comparados com os dados fornecidos em uma norma sobre dosimetria de fontes utilizadas em braquiterapia, sob as mesmas condições. Para a mini-câmara de extrapolação, os resultados apresentaram-se próximos aos fornecidos pela norma, com uma variação máxima entre o valor obtido e o fornecido, nas espessuras de 0 a 1,0 mm, de 8,6\%, para o aplicador NIST.

Com relação aos resultados obtidos com os dosímetros termoluminescentes, eles também se apresentaram próximos aos valores fornecidos pela norma, porém, com uma variação maior se comparada com os resultados da mini-câmara. A variação máxima entre o valor obtido e o fornecido, nas espessuras de 0 a 1,0 mm, foi de $15,4 \%$ para o aplicador $F$. 


\section{REFERÊNCIAS BIBLIOGRÁFICAS}

ABNT. Guia para expressão da incerteza da medição. $2^{\circ} \mathrm{Ed}$. Brasileira em Língua Portuguesa. Rio de Janeiro: ABNT, INMETRO, SBM, 1998.

ALBUQUERQUE, M. P. P.; CALDAS, L. V. E. New ionization chambers for beta and X-radiation. Nucl. Instrum. Methods A., v. 280, p. 310-313, 1989.

AMERSHAM RADIOCHEMICAL CENTRE. Certificate of measurement of beta emitting surface applicator. B-1661, Buckinghamshire, England, 1968.

AMERSHAM INTERNATIONAL PLC - AMERSHAM LABORATORIES. Radioactive source report. SIQ 21, G45027, Buckinghamshire, England, 1986.

AMERSHAM INTERNATIONAL PLC. Instructions for unpacking and use of medical brachytherapy sources. SIA20, Buckinghamshire, England, 1996.

ATTIX, F. H. Introduction to radiological physics and radiation dosimetry. New York: John Wiley \& Sons, 1986.

BOAG, J. W. Ionization chambers. In: KASE, K. R.; BJÄRNGARD, B. E.; ATTIX, F. $\mathrm{H}$. The dosimetry of ionizing radiation. Orlando, FL: Academic Press Inc., v.2, 1987.

BÖHM, J.; SCHNEIDER, U. Review of extrapolation chamber measurements of beta-rays and low energy X-rays. Radiat. Prot. Dosim., v. 14, n. 2, p. 193-198, 1986.

CALDAS, L. V. E. Alguns métodos de calibração e de dosimetria da radiação beta. São Paulo: 1980. Tese (Doutoramento) - Instituto de Física, Universidade de São Paulo.

CALDAS, L. V. E. Performance characteristics of an extrapolation chamber for beta radiation detection. Appl. Radiat. Isot., v. 37, n. 9, p. 988-990, 1986.

CAMPOS, L. L.; LIMA, M. F. Thermoluminescent CaSO4:Dy teflon pellets for beta radiation detection. Radiat. Prot. Dosim., v. 18, n. 2, p. 95-97, 1987. 
DE ALMEIDA, C.; DEWERD, L.; JÄRVINEN, H.; SOARES, C. Guidelines for the calibration of low energy photon sources and beta-ray brachytherapy sources. SSDL Newsletter, n. 43, p. 4-25, 2000.

DIAS, S. K. Desenvolvimento de uma câmara de extrapolação como instrumento de referência para dosimetria de radiação beta. São Paulo: 1996. Tese (Doutoramento) - Instituto de Pesquisas Energéticas e Nucleares, Universidade de São Paulo.

DIAS, S. K.; CALDAS, L. V. E. Development of an extrapolation chamber for the calibration of beta-ray applicators. IEEE Trans. Nucl. Scie., v. 45, n. 3, p. 1666$1669,1998$.

DIAS, S. K.; CALDAS, L. V. E. Characteristics of an extrapolation chamber for $\beta$ ray protection level measurements. J. Appl. Phys., v. 86, n. 1, p. 671-673, 1999.

DIAS, S. K.; CALDAS, L. V. E. Extrapolation chamber response in low-energy X radiation standard beams. J. Appl. Phys., v. 89, n. 1, p. 669-671, 2001.

FAILLA, G. Measurement of tissue dose in terms of the same unit for all ionizing radiations. Radiology, v. 29, p. 202-215, 1937.

FRIEDELL, H. L.; THOMAS, C. I.; KROHMER, J. S. Beta-ray application to the eye: with the description of an applicator utilizing ${ }^{90} \mathrm{Sr}$ and its clinical use. Am. J. Ophthalmol., v. 33, n. 4, p. 525-535, 1950.

FURETTA, C.; WENG, P. Operational thermoluminescence dosimetry. Singapore: World Scientific, 1998.

GLECKLER, M.; VALENTINE, J. D.; SILBERSTEIN, E. B. Calculating lens dose and surface dose rates from ${ }^{90} \mathrm{Sr}$ ophthalmic applicators using Monte Carlo modeling. Med. Phys., v. 25, n. 1, p. 29-36, 1998.

HOLMES, S. M.; MICKA, J. A.; DEWERD, L. A. Ophthalmic applicators: an overview of calibrations following the change to SI units. Draft. Accredited Dosimetry Calibration Laboratory (ADCL), University of Wisconsin, 2009.

IAEA, INTERNATIONAL ATOMIC ENERGY AGENCY. Absorbed dose determination in photon and electron beams. An international code of practice. Vienna, 1987 (Technical Reports Series, n. 277). 
IAEA, INTERNATIONAL ATOMIC ENERGY AGENCY. Calibration of dose meters used in radiotherapy. Vienna, 1994 (Technical Reports Series, n. 374).

IAEA, INTERNATIONAL ATOMIC ENERGY AGENCY. Calibration of photon and beta ray sources used in brachytherapy. Vienna, 2002 (IAEA-TECDOC1274).

ICRU, INTERNATIONAL COMMISSION ON RADIATION UNITS AND MEASUREMENTS. Fundamental quantities and units for ionizing radiation. Bethesda, MD, 1998 (ICRU Report no 60).

ICRU, INTERNATIONAL COMMISSION ON RADIATION UNITS AND MEASUREMENTS. Dosimetry of beta rays and low-energy photons for brachytherapy with sealed sources. V. 4, n. 2, England, 2004 (ICRU Report $\mathrm{n}^{\circ}$ 72).

IEC, INTERNATIONAL ELECTROTECHNICAL COMMISSION. Medical electrical equipment dosimeters with ionization chambers as used in radiotherapy. Geneva, Jul. 1997 (IEC 60731).

ISO, INTERNATIONAL ORGANIZATION FOR STANDARDIZATION. Beta reference radiations for calibrating and determining the response as a function of beta energy of dosemeters and dose rate meters. Geneva, 1984 (ISO 6980).

ISO, INTERNATIONAL ORGANIZATION FOR STANDARDIZATION. Nuclear energy - Reference beta-particle radiation - Part 2: Calibration fundamentals related to basic quantities characterizing the radiation field. Geneva, 2004 (ISO/FDIS 6980-2:2004).

KNOLL, G. F. Radiation detection and measurement. $3^{\mathrm{a}}$ ed. New York: John Wiley \& Sons, 2000.

LOEVINGER, R.; TROTT, N. G. Design and operation of an extrapolation chamber with removable electrodes. Int. J. Appl. Radiat. Isot., v. 17, p. 103-111, 1966.

McKEEVER, S. W. S. Thermoluminescence in solids. Cambridge: Cambridge University Press, 1985. 
McKEEVER, S. W. S.; MOSCOVITCH, M.; TOWNSEND, P. D. Thermoluminescence dosimetry materials: properties and uses. Ashford: Nuclear Technology Publishing, 1995.

NATIONAL INSTITUTE OF STANDARDS AND TECHNOLOGY. Report of calibration of ${ }^{90} \mathrm{Sr}^{+{ }^{90} Y}$ beta-particle source. NIST DG11789/03, Gaithersburg, USA, 2003.

OGUNLEYE, O. T.; PALIWAL, B. R. A proposed modification of the cavity theory for electrons. Health Phys., v. 49, n. 5, p. 937-944, 1985.

OLIVEIRA, M. L. Desenvolvimento de um sistema de referência e de uma metodologia para calibração de aplicadores oftálmicos utilizados em braquiterapia. São Paulo: 2005. Tese (Doutoramento) - Instituto de Pesquisas Energéticas e Nucleares, Universidade de São Paulo.

OLIVEIRA, M. L.; CALDAS, L. V. E. Performance of different thermoluminescence dosimeters in ${ }^{90} \mathrm{Sr}+{ }^{90} \mathrm{Y}$ radiation fields. Radiat. Prot. Dosim., v. 111, n. 1, p. 1720, 2004.

OLIVEIRA, M. L.; CALDAS, L. V. E. A special mini-chamber for calibration of ${ }^{90} \mathrm{Sr}+{ }^{90}$ Y sources. Phys. Med. Biol., v. 50, p. 2929-2936, 2005 a.

OLIVEIRA, M. L.; CALDAS, L. V. E. Características pré-operacionais de uma minicâmara de extrapolação para calibração de fontes de ${ }^{90} \mathrm{Sr}+{ }^{90} \mathrm{Y}$. Revista Brasileira de Física Médica., v. 1, n. 1, p. 20-26, 2005b.

OLIVEIRA, M. L.; CALDAS, L. V. E. Performance of a prototype of an extrapolation minichamber in various radiation beams. Appl. Radiat. Isot., v. 65, p. 975-979, 2007a.

OLIVEIRA, M. L.; CALDAS, L. V. E. Performance of thin CaSO4:Dy pellets for calibration of a ${ }^{90} \mathrm{Sr}+{ }^{90} \mathrm{Y}$ source. Nucl. Instr. Meth. Phys. Res. A., v. 580, p. 293295, 2007b.

PAYNE, W. H.; WAGGNER, R. G. An extrapolation chamber for the calibration of beta-ray applicators. Med. Phys., v. 1, n. 3, p. 165-166, 1974.

PHYSIKALISCH-TECHNISCHE BUNDESANSTALT. Calibration certificate of ${ }^{90} \mathrm{~S} r+{ }^{90} Y$ source. PTB-6.61/25, Braunschweig, 1981a. 
PHYSIKALISCH-TECHNISCHE BUNDESANSTALT. Calibration certificate of ${ }^{90} \mathrm{Sr}^{90} \mathrm{Y}$ source. PTB-6.61/37, Braunschweig, 1981b.

PHYSIKALISCH-TECHNISCHE BUNDESANSTALT. Calibration certificate of ${ }^{90} \mathrm{Sr}^{90}{ }^{90}$ source. PTB-6.34-BSS2_04, Braunschweig, 2005.

PODGORSAK, E. B. Radiation oncology physics: a handbook for teachers and students. Vienna: International Atomic Energy Agency (IAEA), 2005.

PRUITT, J. S.; SOARES, C. G.; EHRLICH, M. NBS measurement services: calibration of beta-particle radiation instrumentation and sources. Washington: U.S. Government Printing Office, 1988.

ROSA, L. A. R. Dosimetria termoluminescente aplicada à Física Médica. Departamento de Física Médica, Instituto de Radioproteção e Dosimetria (IRD), Comissão Nacional de Energia Nuclear (CNEN), 2000.

REFT, C. S.; KUCHNIR, F. T.; ROSENBERG, I.; MYRIANTHOPOULOS, L. C. Dosimetry of Sr-90 ophthalmic applicators. Med. Phys., v. 17, n. 4, p. 641-646, 1990.

SCHARMANN, A.; BÖHM, M. Basic concepts of thermoluminescence. In: OBERHOFER, M.; SCHARMANN, A. Health physics and radiation protection. Techniques and management of personnel thermoluminescence dosimetry services. Dordrecht, The Netherlands: Kluwer Academic Publishers, v. 2, 1993.

SHANI, G. Radiation dosimetry: instrumentation and methods. New York: CRC Press, 1991.

SILVA, I. Projeto e construção de uma câmara de ionização de extrapolação para dosimetria beta. Belo Horizonte: 1985. Dissertação (Mestrado) - Universidade Federal de Minas Gerais.

SINCLAIR, W. K.; TROTT, N. G. The construction and measurement of beta-ray applicators for use in ophthalmology. Brit. J. Radiol., v. 29, p. 15-23, 1956.

SOARES, C. G. Calibration of ophthalmic applicators at NIST: A revised approach. Med. Phys., v. 18, n. 4, p. 787-793, 1991. 
SOARES, C. G.; DARLEY, P. J.; CHARLES, M. W.; BAUN, J. W. Hot particle dosimetry using the extrapolation chambers and radiochromic foils. Radiat. Prot. Dosim., v. 39, n. 1-3, p. 55-59, 1991.

SOARES, C. G. A method for the calibration of concave ${ }^{90} \mathrm{Sr}+{ }^{90} \mathrm{Y}$ ophthalmic applicators. Phys. Med. Biol., v. 37, n. 4, p. 1005-1007, 1992.

SOARES, C. G. Comparison of NIST and manufacturer calibrations of ${ }^{90} \mathrm{Sr}+{ }^{90} \mathrm{Y}$ ophthalmic applicators. Med. Phys., v. 22, n. 9, p. 1487-1493, 1995.

SOARES, C. G.; VYNCKIER, S.; JÄRVINEN, H.; CROSS, W. G.; SIPILÄ, P.; FLÜHS, D.; SCHAEKEN, B.; MOURTADA, F. A.; BASS, G. A.; WILLIAMS, T. T. Dosimetry of beta-ray ophthalmic applicators: Comparison of different measurement methods. Med. Phys., v. 28, n. 7, p. 1373-1384, 2001.

SOARES, C. G. Comunicação pessoal, 2009.

SPENCER, L. V.; ATTIX, F. H. A theory of cavity ionization. Radiat. Res., v. 3, p. 239-254, 1955.

TAUHATA, L.; SALATI, I. P. A.; DI PRINZIO, R.; DI PRINZIO, M. A. R. R. Rdioproteção e dosimetria: fundamentos. $5^{\mathrm{a}}$ revisão. Rio de Janeiro: Instituto de Radioproteção e Dosimetria, 2003.

UNIVERSIDADE ESTADUAL PAULISTA - UNESP, FACULDADE DE ODONTOLOGIA DE ARAÇATUBA. Documento com informações sobre a calibração de um aplicador dermatológico de ${ }^{90} \mathrm{Sr}+{ }^{90} \mathrm{Y}$. Aplicador Amersham, modelo Sr 5072 2096. Araçatuba, 2003a.

UNIVERSIDADE ESTADUAL PAULISTA - UNESP, FACULDADE DE ODONTOLOGIA DE ARAÇATUBA. Documento com informações sobre a calibração de um aplicador oftálmico de ${ }^{90} \mathrm{~S} r+{ }^{90} \mathrm{Y}$. Aplicador Amersham, modelo SAI 6/1418. Araçatuba, 2003b.

VIM, Vocabulário internacional de termos fundamentais e gerais de metrologia. Inmetro, Editora SENAI: Rio de Janeiro, 2007. 5ํe edição. 


\section{APÊNDICE A - PROCEDIMENTO PARA A IRRADIAÇÃO DE DOSÍMETROS TERMOLUMINESCENTES COM APLICADORES CLÍNICOS DE ${ }^{90} \mathrm{Sr}+{ }^{90} \mathrm{Y}$.}

\section{A.1 - Objetivo}

O objetivo desta instrução de trabalho é descrever o procedimento de irradiação de amostras termoluminescentes de CaSO4:Dy com fontes emissoras de radiação beta de ${ }^{90} \mathrm{Sr}+{ }^{90} \mathrm{Y}$ utilizadas em procedimentos dermatológicos em braquiterapia. Esta irradiação deverá ser feita por parte dos funcionários que trabalham com aplicadores clínicos, em clínicas e hospitais.

\section{A.2 - Campo de Aplicação}

Estas informações aplicam-se ao uso dos aplicadores clínicos:

- Quem: Técnico ou Físico Médico;

- Quando: Logo após o envio do sistema postal;

- Onde: Nas clínicas e hospitais que realizam braquiterapia.

\section{A.3 - Procedimento}

\section{A.3.1 - Condições e Recursos Necessários}

$\checkmark$ Físico Médico ou Técnico com conhecimentos em Proteção Radiológica;

$\checkmark$ Amostras finas de CaSO4:Dy, anteriormente calibradas no IPEN;

$\checkmark$ Protetor de acrílico para a face ou óculos protetor de acrílico;

$\checkmark$ Luvas cirúrgicas;

$\checkmark$ Suportes em acrílico para as amostras (porta-amostras ou porta-dosímetros) já com as pastilhas corretamente posicionadas (o porta-dosímetro é envolto por filme plástico, para garantir e facilitar a segurança e o manuseio das pastilhas e para facilitar o trabalho do usuário;

$\checkmark$ Instrumentos para medições das condições ambientais: barômetro, termômetro e higrômetro;

$\checkmark$ Cronômetro digital com alarme. 


\section{A.3.2 - Cuidados Especiais}

Por se tratar de fontes radioativas com altas taxas de dose, devem ser tomados cuidados especiais no seu manuseio para diminuir a dose absorvida na pele, especialmente nas mãos do operador. Recomenda-se a utilização de dosímetros de extremidade enquanto a fonte estiver sendo manuseada. Logo após a irradiação das amostras, o sistema postal deverá ser enviado ao IPEN, para a avaliação das amostras termoluminescentes para, em seguida, ocorrer a emissão dos certificados de calibração para as clínicas e os hospitais.

\section{A.3.3 - Descrição das Atividades}

1. Ler com atenção este procedimento;

2. Preencher a planilha de informações referentes à irradiação, como a data e horário, temperatura, pressão e umidade do local de trabalho, tipo de aplicador, fabricante, modelo e número de série, os dados da empresa, e os dados da fonte, como atividade, data de referência e incerteza, além do tempo de irradiação;

3. Retirar os cinco porta-amostras (porta-dosímetro) da embalagem do sistema postal, contendo 1 dosímetro em cada um dele (obs.: não retirar o filme plástico que envolve o porta-dosímetro);

4. Posicionar o aplicador verticalmente sobre a amostra;

5. Calcular o tempo de irradiação das amostras, que depende da taxa de dose absorvida na data de referência fornecida pelo certificado de calibração de cada aplicador.

a) Inicialmente, deve-se calcular a taxa de dose absorvida da fonte para a data da irradiação utilizando-se a expressão:

$$
\dot{D}(t)=\dot{D}_{0} \cdot e^{\frac{\ln 2 . \Delta t}{T_{1 / 2}}}
$$

onde: $\dot{D}_{0}$ é a taxa de dose absorvida fornecida pelo certificado de calibração do aplicador, na sua data de referência; $\dot{D}(t)$ é a nova taxa de dose absorvida a ser 
calculada, na data da medição (data na qual as pastilhas serão irradiadas); $\Delta t$ corresponde ao intervalo de tempo entre a data da taxa de dose absorvida inicial (do certificado) e a data com relação à qual se deseja determinar a nova taxa de dose absorvida; e $T_{1 / 2}$ é a meia-vida do radioaisótopo ${ }^{90} \mathrm{Sr}+{ }^{90} \mathrm{Y}(28,8$ anos).

b) Utilizando-se a taxa de dose absorvida obtida, pode-se calcular o tempo de irradiação para uma determinada dose, que deve ser de 1,0 Gy.

6. Cronometrar o tempo obtido em cada irradiação; este tempo deve ser exatamente o mesmo para cada um dos dosímetros;

7. Guardar os porta-amostras na embalagem do sistema postal, juntamente com a planilha de informaçoes e enviar o mais rápido possível ao Laboratório de Calibração de Instrumentos, do IPEN. 


\section{APÊNDICE B - MODELO DE CERTIFICADO DE CALIBRAÇÃO A SER EMITIDO PELO IPEN.}

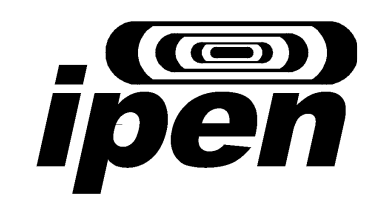

Certificado de Calibração № 0XXX/2009

Data da Calibração:

Proprietário:

Razão Social:

Endereço:

CNPJ:

Responsável:

01. Especificações do Aplicador Clínico:

Tipo:

Fabricante:

Modelo:

Atividade nominal:

Taxa de dose absorvida:

Data de referência:

Calibração original por:

02. Condições Ambientais durante a Calibração do Aplicador pelo Usuário:

Temperatura:

Pressão:

Umidade Relativa do Ar:

03. Dados sobre o Leitor Termoluminescente:

Fabricante: Harshaw Nuclear Systems

Modelo: 2000A/B

Taxa de Aquecimento Linear: $10^{\circ} \mathrm{C} / \mathrm{s}$

Variação da Temperatura: de 180 a $350^{\circ} \mathrm{C}$

Tempo do Ciclo de Leitura: 30 s 


\section{Método de Irradiação e Avaliação TL:}

As pastilhas de $\mathrm{CaSO}_{4}$ :Dy foram irradiadas no local de uso do aplicador clínico de ${ }^{90} \mathrm{Sr}+{ }^{90} \mathrm{Y}$, pelo Técnico ou Físico Médico responsável pelo procedimento de betaterapia. As amostras foram avaliadas após a chegada do sistema postal ao LCI/IPEN.

05. Aplicador Padrão de Referência:

\begin{tabular}{ccccc}
\hline Aplicador & Tipo & $\begin{array}{c}\text { Marca } \\
\mathbf{e} \\
\text { Modelo }\end{array}$ & $\begin{array}{c}\text { Taxa de Dose } \\
\text { Absorvida } \\
\text { Nominal } \\
\text { (Gy/s) }\end{array}$ & $\begin{array}{c}\text { Data de } \\
\text { Calibração } \\
\text { (Certificado) }\end{array}$ \\
\hline \multirow{2}{*}{ NIST } & Dermatológico & $\begin{array}{c}\text { Atlantic Research } \\
\text { Corporation/ } \\
\text { B-1 S/N 233 }\end{array}$ & $0,40 \pm 0,05$ & 28.01 .2003 \\
\hline
\end{tabular}

06. Resultados:

\begin{tabular}{|c|c|c|c|}
\hline Fonte & Tipo & $\begin{array}{c}\text { Taxa de Dose } \\
\text { Absorvida } \\
\text { (Gy/s) }\end{array}$ & $\begin{array}{c}\text { Data de } \\
\text { Calibração }\end{array}$ \\
\hline${ }^{90} \mathrm{Sr}+{ }^{90} \mathrm{Y}$ & & & \\
\hline
\end{tabular}

\section{Recalibração:}

Devido às características do instrumento, recomenda-se que ele seja calibrado periodicamente. Além disso, a recalibração é necessária no caso de ocorrência de quaisquer danos ou alterações que possam modificar a resposta do aplicador clínico.

São Paulo, xx de $x x x x x x x x$ de $x x x x$.

Nome do Técnico

Responsável pela Calibração
Nome do Responsável

pelo Laboratório de Calibração

de Instrumentos/IPEN 